Portland State University

PDXScholar

Fall 12-6-2016

\title{
A Meta-Analysis of the Nomological Network of Work Ability
}

Grant Brady

Portland State University

Follow this and additional works at: https://pdxscholar.library.pdx.edu/open_access_etds

Part of the Psychology Commons

Let us know how access to this document benefits you.

\section{Recommended Citation}

Brady, Grant, "A Meta-Analysis of the Nomological Network of Work Ability" (2016). Dissertations and Theses. Paper 3341.

https://doi.org/10.15760/etd.5238

This Thesis is brought to you for free and open access. It has been accepted for inclusion in Dissertations and Theses by an authorized administrator of PDXScholar. Please contact us if we can make this document more accessible: pdxscholar@pdx.edu. 
A Meta-Analysis of the Nomological Network of Work Ability

by

Grant Brady

A thesis submitted in partial fulfillment of the requirements for the degree of

\author{
Master of Science \\ in \\ Psychology
}

Thesis Committee:

Donald Truxillo, Chair

Todd Bodner

David Cadiz

\title{
Portland State University \\ 2016
}




\begin{abstract}
As the workforces of industrialized countries around the world continue to age, research is needed to better understand how policies regarding retirement, and exit from the workforce, impact older workers. In particular, it is important to identify mechanisms that can be used to understand and promote the retention of older workers. Work ability (WA), a construct that has been predominately studied in Scandinavian and European countries, has been studied in this context, and identified as a predictor of exit from the workforce. Using the Job Demands-Resources model (JDR; Demerouti, Bakker, Nachreiner, \& Schaufeli, 2001) as the theoretical basis, the goal of the present study was to compile and synthesize the existing literature on WA, quantitatively analyze its antecedents and outcomes (via meta-analysis), and assess potential moderators to these relationships. To my knowledge, this is the first quantitative synthesis of the WA literature. In total $k=158$ studies including $n=149,758$ workers were included in this this meta-analysis. Results showed that WA was related to a number of antecedents including job demands $\bar{r}=[-.15,-.30]$, job resources $\bar{r}=[.19, .25]$, and personal resources $\bar{r}=$ $[.14, .45]$; as well as to several outcomes including job satisfaction $\bar{r}=.23$, job performance (self-rated) $\bar{r}=.23$, and exit behaviors $\bar{r}=[-.19,-.36]$. Moderator analyses showed that when assessing the relationship between WA and some correlates (e.g., disability, retirement), studies that used the Work Ability Index (WAI) found stronger relationships with WA than studies that used measures of perceived WA. Additionally, studies that included workers from certain occupations (e.g., blue collar jobs) found weaker relationships between WA and some of its correlates (e.g., physical job demands, job control) compared to studies of workers in other occupation groups (e.g., white collar
\end{abstract}


jobs). The mean age of the sample also moderated the relationships between WA and some of its correlates. Specifically, studies that consisted of older workers found stronger relationships between WA and certain correlates (e.g., job control, physical job demands), whereas for other correlates (e.g., musculoskeletal disease, disability) studies consisting of younger workers found stronger relationships with WA. This study contributes to the existing literature by synthesizing findings from existing work, identifying gaps in the existing literature, and determining how various measures of WA impact the relationships between WA and its correlates. In addition, this study helps to identify factors that can be considered in interventions aimed at retaining older workers and extending working careers. 


\section{Acknowledgements}

I would like to thank my committee, Dr. Donald Truxillo, Dr. Todd Bodner, and Dr.

David Cadiz for supporting me in the pursuit of my Master's degree. I would also like to thank Dr. Jenn Rineer, Dr. David Caughlin, Cosimo Gonnelli, and Aaron Greenfield for their assistance with launching this study and coding the articles for this meta-analysis. Finally, I would like to express gratitude to my wife Jacquelyn for her support during this process as well as my family, friends, and colleagues that have supported me throughout my academic pursuits. The support of each of these individuals has been invaluable to my academic and professional progress, and I greatly appreciate each of them for their continued guidance and support. 


\section{Table of Contents}

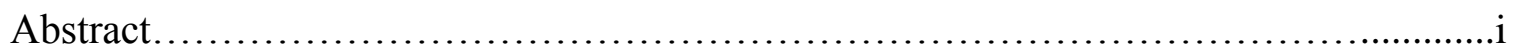

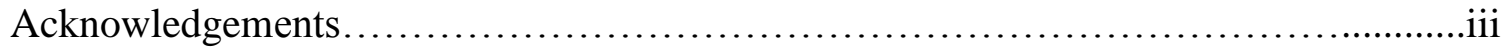

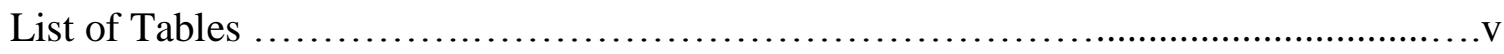

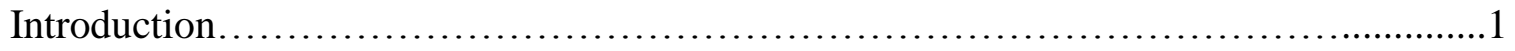

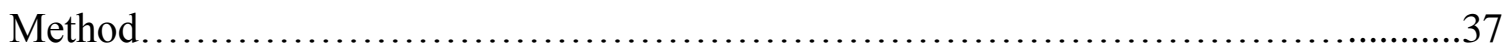

Results......................................................................45

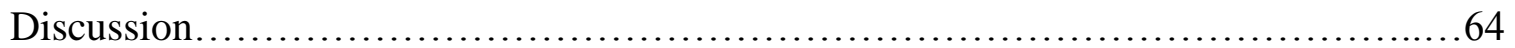

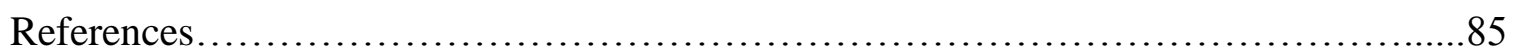

Appendices

A. Full Work Ability Index..................................................................116

B. Work Ability Index Short Form...............................................................121

C. Theoretical Model of the Antecedents and Outcomes of Work Ability........ 123

D. Meta-Regression of Physical Demands on Age......................... 124

E. Meta-Regression of Job Control on Age.............................. 125 


\section{List of Tables}

Table 1. Meta-Analytic Estimates - Direct Effects...............................76

Table 2. Meta-Analytic Estimates - Moderated by WA Measure.......................77

Table 3. Meta-Analytic Estimates - Moderated by Occupation........................79

Table 4. Meta-Regression Estimates - Moderated by Age.............................83 


\section{Introduction}

As the workforce continues to age, an estimated $38.2 \%$ of the workforce in the United States will be at least 55 years old by 2024 (Toossi, 2015). This trend suggests that a relatively large number of workers will soon be entering retirement-eligible ages, and they will be exiting the workforce in larger numbers than previous generations. Given the significant personal and organizational costs associated with exit from the workforce (e.g., lost income and job knowledge), understanding how to keep individuals working effectively later in life is important for individuals and organizations. Working later in life can provide individuals with financial (Butrica, 2011), psychological (Kulik, Ryan, Harper, \& George, 2014; Rohwedder \& Willis, 2010; Zhan, Wang, Liu, \& Shultz, 2009), and health benefits, particularly for those that desire to continue working (Herzog, House, \& Morgan, 1991). By the same token, organizations can benefit from older workers' positive job attitudes (Ng \& Feldman, 2008), depth of job knowledge, and higher rates of organizational citizenship behaviors (Ng \& Feldman, 2008). Given that the trend of an aging workforce is expected to continue (National Institutes of Health, 2011; Toossi, 2005), individuals and organizations will need to develop strategies for accommodating these shifts.

\section{The Work Ability Construct}

One strategy for dealing with this demographic shift may be in the promotion of work ability among workers. Work ability (WA) can be viewed as one's physical and mental ability to perform job functions relative to the demands of their job (Ilmarinen, et al., 1991a, Ilmarinen, 2009). WA was originally developed in the 1980s in the field of 
occupational health and medicine by researchers at the Finnish Institute of Occupational Health where they developed a measure of WA, the Work Ability Index (WAI) (Ilmarinen, 2007, 2009; Tuomi et al., 1997). The WAI was originally developed with the specific intention of measuring WA to help meet the challenges associated with an aging workforce (Ilmarinen, et al., 1991b). Since this initial introduction, the study of WA and the use of the WAI specifically, have proliferated globally, with a particular focus in Scandinavian and European countries (e.g., Ilmarinen, 2009) and more recent use in the industrial/organizational psychology (IO) and organizational behavior (OB) literatures (McGonagle, Fisher, Barnes-Farrell, \& Grosch, 2015; Palermo, Fuller-Tyszkiewicz, Walker, \& Appannah, 2013).

Research has shown that WA is related to a range of outcomes including mental and physical health, burnout, and job attitudes such as organizational commitment (Bethge, Radoschewski, \& Gutenbrunner, 2012b; Feldt, Hyvönen, Mäkikangas, Kinnunen, \& Kokko, 2009). Furthermore, researchers at the Finnish Institute of Occupational Health conducted several longitudinal studies which demonstrated that WA is related to workforce exit behaviors such as increased rates of sick leave, early retirement, and increased rates of disability (Tuomi, Vanhala, Nykyri \& Janhonen, 2004; Feldt et al., 2009). Additional research across many countries has focused directly or indirectly on the relationship between WA and turnover or other exit attitudes and behaviors (Camerino et al., 2006; McGonagle et al., 2014; McGonagle et al., 2015). Recent research in the IO field has led to several key contributions including the identification of potential antecedents of WA, including job resources such as supervisor 
and coworker support, and job demands such as role overload, physical demands, and time pressure (McGonagle, et al., 2015). Additional research has identified personal resources such as self-efficacy, health, and coping as being associated with higher WA (Palermo et al., 2013).

Given the links between WA and a range of important work and nonwork factors, particularly those related to health and exit from the workforce, the construct of WA can serve as an important tool for investigating factors that impact the aging workforce. In particular, the study of WA may help to further identify potential avenues for interventions aimed at keeping employees working effectively, supporting them, and meeting their job demands later in life, an increasingly prevalent issue as the workforce ages. Although this potential for the WA construct certainly exists, several questions remain in the existing WA literature around the nature of the WA construct and its measurement, and until these questions are answered, the full utility of WA for retaining workers and designing interventions will remain limited.

\section{Goals of the Present Study}

Although the construct of WA has been primarily researched in the field of occupational medicine (Ilmarinen, 2007, 2009), it has been also been studied across a range of other fields (e.g., medical literature; Bethge, Radoschewski, \& Gutenbrunner, 2012b). However, it has only recently been used in IO and OB research, and to a far lesser extent (e.g., McGonagle, et al., 2015; Weigl, Müller, Hornung, Zacher, \& Angerer, 2013). The diverse range of fields investigating WA is beneficial to understanding the broader nomological network of WA. However, due in part to a lack of consensus 
regarding the definition of the WA construct and inconsistencies in how WA is operationalized, these literatures have remained fragmented.

Specifically, there are now numerous measures of WA, each with slightly different conceptualizations of the construct, and thus both the definition and measurement of WA need to be clarified as researchers continue to investigate WA (Ahlstrom, Grimby-Ekman, Hagberg, \& Dellve, 2010; McGonagle et al., 2015; Palermo et al., 2013). As an example, one of the key tensions has been between how WA was originally measured (i.e., the WAI) and the more recent measures of WA that have been developed. The WAI contains items assessing both objective (e.g., number of diagnosed diseases) and perceived (e.g., current WA compared to their lifetime best) aspects of WA. On the other hand, many of the more recent measures of WA focus exclusively on perceived WA, yet the majority do not address this discrepancy.

Using the Job Demands-Resources (JD-R) model (Demerouti, Bakker, Nachreiner, \& Schaufeli, 2001) as a theoretical lens, where WA is an outcome of resources and demands from both the job and personal domains, this study addresses several gaps in the existing literature. In order to accomplish this, studies investigating WA across disciplines were compiled and subsequently meta-analyzed to better understand the nomological network of the WA construct. Using the JD-R framework and meta-analysis, this study addresses the following research questions: 1) what are the antecedents and outcomes of WA and how strong are these relationships, 2) how do various WA measures impact the nomological network of WA, and 3) what variables moderate the relationship between WA and the antecedents and outcomes of WA. 


\section{Review of the Work Ability Literature}

As stated previously, the construct of WA has been studied across a variety of disciplines with a variety of measures, and this lack of a uniform definition, compounded by a number of measurement tools that contain a range of content, has led to a lack of clarity in the existing literature. Despite lacking a uniform definition of WA, there are specific points on which there appears to be some consensus. WA is generally seen as a balance between an individual's physical and mental abilities and the demands of their job (Ilmarinen et al., 1991b, Ilmarinen, 2009). In this regard, researchers suggest that characteristics of the individual as well as the workplace must be considered simultaneously when studying WA (Mäkitalo \& Palonen, 1994). In the following section I provide a brief historical background of the WA construct, identify several specific WA measures currently being used, and discuss the content variation among these measures.

\section{Background}

As noted earlier, WA as a construct was formally developed in the 1980s in Finland for use in the study of aging, work, and retirement among Finnish workers (Ilmarinen et al., 1991b). Finland was unique in that the country began experiencing this demographic shift to an aging workforce earlier than the United States and some other European countries (Ilmarinen et al., 1991b). Due to this shift, researchers were tasked with answering the questions of how long employees can continue to work effectively and whether various occupations warrant different retirement eligibility ages (Ilmarinen et al., 1991b, Ilmarinen, 2009). 
The basic premise for understanding WA was that negative strain outcomes experienced by workers resulted from work stressors and that individuals draw on personal characteristics such as their physical, mental, and social abilities in order to meet these work demands (Ilmarinen et al., 1991b). Thus, in a sense, an individual's WA was viewed as the workers' ability to meet their occupational demands. Finnish researchers found, on average, that over an 11-year period workers' WA declined, and that declines were particularly prevalent among those older than 51 and those working in physically demanding jobs (Ilmarinen, Tuomi, \& Klockars, 1997). Interestingly, similar to research on other age-related differences (e.g., cognitive changes), there was a high level of variability in WA trajectories among workers over this time period, with $30 \%$ of workers experiencing a significant decline in WA, $60 \%$ experiencing minimal changes in WA, and $10 \%$ that actually experienced an improved level of WA over the 11 years (Ilmarinen, Tuomi, \& Klockars, 1997). These findings suggested that there is considerable between-individual variability in WA trajectories, that WA trajectories may be malleable, and that contextual/workplace factors (i.e., and not just individual factors) may play an important role in the trajectory of one's WA.

One existing review of the WA literature was published by van den Berg and colleagues (2009). This review included 20 empirical studies, and pointed to a variety of demographic, personal, and organizational factors that were related to WA. Although this review established some baseline understanding of the literature on WA, the literature searches were conducted in 2006, and they were limited to medical journals and studies that used the WAI. Since the time that this review was conducted, a great deal of research 
on WA has been published, and there has been a proliferation of WA measures. Thus, the present study greatly extends the review by van den Berg and colleagues (2009) in terms of the scope of correlates assessed and the number of studies included.

In addition to the review article, a study by Feldt and colleagues (2009) found that psychosocial workplace factors such as organizational climate and job control at baseline predicted WA trajectory over a 10-year period (Feldt et al., 2009). Drawing on these findings, Feldt and colleagues (2009) as well as Ilmarinen (2009) began calling for additional research to investigate the impact of psychosocial workplace factors on WA (Feldt, et al., 2009; Ilmarinen, 2009). In recent years, researchers have seemingly begun to answer this call. However, this increase in the number of WA studies has also led to further proliferation of the WA measures being used. The following section outlines the original measure of WA and the development of additional WA measures that have been recently utilized as well as conceptual concerns regarding this proliferation.

\section{The Work Ability Index}

The first measure developed to assess WA was the WAI. The WAI contains seven dimensions, with higher scores indicating higher levels of WA (Ilmarinen et al., 1997; Morschhäuser \& Sochert, 2006). The complete WAI, and scoring instructions are provided in Appendices A \& B. The first dimension is "current WA compared to lifetime best." This dimension is assessed with a single item, "Assume that your work ability at its best has a value of 10 points. How many points would you give your current WA?" and is scored on a scale of 1 (completely unable to work) - 10 (lifetime best). The second dimension is "WA in relation to the demands of the job" and is measured with two items. 
The first item assesses "WA in relation to the physical demands of one's job" and the other item assesses "WA in relation to the mental demands of one's job." Each item is scored on a 1 (very poor) - 5 (very good) scale and weighted depending on the individual's type of work. In physically demanding occupations, the physical demands item is multiplied by 1.5 , and the mental demands item is multiplied by .5 , whereas in mentally demanding occupations the physical demands item is multiplied by .5 and the mental demands item is multiplied by 1.5. The two scores are then summed and results in scores ranging from $2-10$.

The third dimension is the "number of diseases, disorders or injuries that an individual has been diagnosed with." Participants are presented a list of 51 ailments and select all that they have been diagnosed with (self-diagnosed or physician diagnosed). The number of ailments an individual has are summed and assigned scores from 1 (5 or more ailments) - 7 (no ailments). The fourth dimension is "impairment due to current illness or injury." This dimension is assessed with a single item "is your illness or injury a hindrance to your current job?" and scored on a scale of 1 (I am entirely unable to work) - 6 (no hindrance/I have no diseases).

The fifth dimension is "sick leave during the past 12 months." This dimension is scored on a 1 ( $\geq 100$ days of work missed due to health problems) - 5 (zero days of work missed due to health problems) scale. The sixth dimension is an individual's own prognosis of their WA in two years, and asks participants "Do you believe that from a health standpoint you will be able to do your current job two years from now?" Participants indicate 1 of 3 possible response options: 1 (unlikely), 4 (not certain), and 7 
(relatively certain). Finally, the seventh dimension is termed "mental resources" which is assessed with three items each scored on a 0 (never) - 4 (often) scale. An example item is "in general have you been active and alert?" with the timeframe reference of over the past three months. These items are summed to produce a score ranging from $0-12$, then grouped into 4 categories. Scores from 0-3 are assigned a value of 1, scores from 4-6 are assigned to value of 2 , scores from 7-9 are assigned a value of 3 , and scores between 10 12 are assigned a value of 4.

Scoring of the WAI results in scores ranging from 7-49 in which the following guidelines were developed for occupational health researchers. Individuals with WA scores from 7-27 are considered to have "poor WA", scores ranging from 28-36 indicate "medium WA", scores between 37 and 43 suggest "good WA", and scores between 44 and 49 indicate "very good WA" (Morschhäuser \& Sochert, 2006). These categories are based on the early Finnish studies which included over 4,000 participants. The lower and upper $15^{\text {th }}$ percentile of the sample used in the initial studies were used as cutoff points for the poor and excellent WA categories (Ilmarinen et al., 1997; Tuomi et al., 1991). In support of this categorization system, recent research found that an ideal WAI cutoff score for predicting an individual's need for rehabilitation was a score below 37, which corresponds with the upper limit of the "moderate WA" category (Bethge et al., 2012b). Although these categories have been consistently used in the research on WA, it is worth noting that WA may differ across countries, work environments, and demographic characteristics. 
In order to facilitate a quicker assessment of WA and reduce the amount of personal information participants need to provide, researchers modified the original WAI to a shorter, seven-item WAI. In the updated, seven-item WAI the number of diagnosed diseases is simply quantified by how many diagnosed diseases or disorders an individual has, and the remaining dimensions are assessed with single-item measures (Ilmarinen, 2007). One drawback to this approach is that WA in relation to mental and physical demands of the job are assessed by a composite item "WA in relation to the demands of the job." This change may result in the loss of some valuable information with regard to monitoring the types of tasks assigned to workers and in designing interventions to promote and maintain WA. The seven-item WAI retains the same7-49 score ranges, and the same possible scores per dimension which ultimately leads to a measurement tool that is simpler to administer and score and contains less personal information.

\section{Other WA Measures}

Beyond the shortened WAI, many researchers have simply used the first item from the WAI by itself, that is, "current work ability compared to your lifetime best" (Ahlstrom et al., 2010; von Bonsdorff, Seitsamo, Ilmarinen, von Bonsdorff, \& Taina, 2012). Interestingly, this measure clearly does not include the more objective health components of the original WAI, such as diagnosed diseases or previous sick leave. Rather, this single item may be best described as one's perceived WA, but it has retained the "WA" label. Despite this difference, Ahlstrom and colleagues found the single-item indicator of WA resulted in a similar pattern of results compared to the full WAI in terms of the relationships between WA and future sick leave use, self-reported health ratings, 
and current level of stress (Ahlstrom et al., 2010). Although this study is frequently cited as justification for using the single-item measure, it is important to note that this study included an exclusively female sample of workers on long-term (>60 days) sick leave, which leaves questions regarding how these findings generalize to more representative samples. A second study by El Fassi and colleagues (2013) included a larger more diverse sample, and also supported the relative utility between the full WAI and the single item WA measure. However, both of these studies focused on measures of stress, pain, heath indicators (e.g., BMI), and follow-up sick leave status, which represents a limited range of antecedents and outcomes of WA and does not take into account differences in WA by occupation or age. Further, these researchers did not consider many occupational factors (e.g., job demands and resources) or established longer term outcomes such as disability status and retirement age which were some of the core constructs of interests in the development of the original WAI.

On the other hand, the single-item measure of WA has also been used in more representative samples and shown to be related to a variety of factors including age, diagnosed medical diseases, disability, physical activity, and even mortality at a 28-year follow up assessment (von Bonsdorff et al., 2012). While these findings suggest WA when measured as a "current WA compared to lifetime best" is related to a range of outcomes, it remains unclear how this single-item measure compares to the original WAI or to the seven-item WAI measure in terms of its relationships with the longer term outcomes associated with WA. 
Seemingly in response to calls from Ilmarinen (2009) and Feldt and colleagues (2009), researchers have conducted several studies on the psychosocial factors that impact WA (McGonagle et al., 2015; Palermo et al., 2013; Weigl et al., 2013). These studies have also tended to develop new measures of WA or modified existing measures of WA in some manner. Weigl and colleagues (2013) assessed WA with two items from the original WAI, specifically, "WA in relation to the physical demands of the job" and "WA in relation to the mental demands of the job," However, these ratings were provided by supervisors that were asked to rate employee WA, rather than an individual's selfperceptions of WA or objective health indicators. In this study, Weigl and colleagues did find that supervisor-rated WA was related to both job control and occupation (Weigl et al., 2013).

Palermo and colleagues (2013) assessed WA using a four-item measure that included two items from the WAI, the first dimension "current WA compared to lifetime best" and the sixth dimension, one's expectation of their WA two years from now with regard to their health and ability to work in their current job (Palermo et al., 2013). Palermo and colleagues then added two items, asking individuals to rate their prognosis of their WA at both five, and 10 years from now with regard to one's health and ability to work in their current job. Palermo and colleagues found that WA, as measured in their study, was related to work strain, health, and leadership effectiveness (Palermo et al., 2013). Although this measure was termed WA, it seems that "perceived WA" may be a more fitting label in this case due to the nature of the items, particularly when compared to the items from the WAI. 
A third WA measure that has been recently developed by McGonagle and colleagues $(2014,2015)$ is a four-item measure that includes the first three items from the original WAI; "current WA compared to lifetime best, current WA relative to the physical demands of one's job, and current WA relative to the mental demands of one's job." McGonagle and colleagues then added an item assessing "current WA in relation to the social skill demands of one's job" (McGonagle et al., 2014). McGonagle and colleagues termed this measure "perceived WA" and found that their perceived WA measure was related to sense of control, self-rated health status, lack of a chronic illness, disability leave, absence, and retirement (McGonagle et al., 2015). Similar to the singleitem measure itself, as well as to the subjective ratings others have used to assess WA, it seems that the content of this WA measure is different from, and more subjective than, the content covered in the original WAI. Thus, the term used by McGonagle and colleagues, perceived WA, seems to be more appropriate for this measure as well as other measures which include exclusively subjective WA items.

Finally, another new measure of WA, termed WA - personal radar (WA-PR), has recently been developed by Finnish researchers to help address some of the practical issues associated with using the WAI in workplace and occupational settings (Ilmarinen, Ilmarinen, Huuhtanen, Louhevaara, \& Näsman, 2015). This measure contains 18 items and is based on a house model of WA where WA is derived from five domains; health and functional capacity, competence, attitudes and motivation, work (including organizational, management, and peer aspects of the job), and non-work activities (e.g., family or spare time activities). This measure is a more traditional self-report measure 
and seemingly easier to administer and score compared to the WAI. Interestingly, this measure subsumes many of the predictors of WA into dimensions of the WA measure itself. However, it is not based in a specific theory of work, nor does it include a number of psychosocial and health factors that may be related to WA (e.g., McGonagle et al., 2015).

Taken together, it is clear that the construct of WA has been operationalized in a variety of ways. Specifically, these measures vary in terms of objective versus subjective components as well as the degree to which they incorporate health as part of the measure. Despite these inconsistencies, it is also apparent that WA as it has been measured is related to a host of important individual and organizational factors. The inconsistencies in measurement of WA serve as one of the primary research questions that this study addresses, that is, does the WAI, which includes objective health items, relate to antecedents and outcomes differently compared to WA measures that include only individual perceptions of WA?

\section{Job Demands-Resources Model and Work Ability}

As noted earlier, WA has only recently been introduced to the IO and OB

literature. As such, researchers have only recently begun applying psychological theoretical models to the study of WA in order to better understand its antecedents and outcomes. One theoretical model that fits particularly well with the study of WA is the Job Demands-Resources (JD-R) model (Bakker \& Demerouti, 2007: Demerouti et al., 2001). The JD-R was developed out of the Job Demands-Control (JDC; Karasek, 1979), and later Job Demand-Control-Support (JDCS; Johnson \& Hall, 1988) models. Research 
on the JDC and JDCS models indicates that jobs high in demands (e.g., workload) and low in control (e.g., autonomy) are related to high strain and low job satisfaction (Johnson \& Hall, 1988; Karasek, 1979; Van der Doef, \& Maes, 1999). While these models viewed job demands primarily in terms of workload and time pressure, and control and support as the primary methods for attenuating the negative effects of these demands, the JD-R extended beyond these models by suggesting that all work factors could be categorized as either a job demand or job resource (Bakker \& Demerouti, 2007; Demerouti et al., 2001).

According to the JD-R, job demands are characteristics of the job or work environment (e.g., work overload and role conflict) that require sustained effort or skill and result in physiological or psychological costs (Bakker \& Demerouti, 2007; Demerouti et al., 2001). In contrast, job resources (e.g., supervisor support and autonomy) are aspects of the job or work environment that are useful in accomplishing work goals, reduce job demands, or encourage personal growth. It is important to note that job demands are not necessarily negative; for example, low-level challenges may promote the development of skills. However, when demands are constant and employees have not recouped a sufficient amount of resources prior to engaging in their work, demands can lead to increased strain and decreased motivation (Bakker \& Demerouti, 2007). In contrast, job resources can increase motivation and personal growth while buffering against the negative effects of job demands (Bakker \& Demerouti, 2007). Although the JD-R was initially developed using burnout as the outcome of various job demands and resources, this model has been extended to include other health 
and motivation outcomes as well (e.g., health impairment and engagement; Bakker \& Demerouti, 2007; Demerouti \& Bakker, 2011). Additionally, the JD-R has been extended to include personal resources (e.g. health and self-efficacy) as resources an individual can draw upon to meet the demands of their job (Bakker \& Demerouti, 2007; Palermo et al., 2013; Xanthopoulou, Bakker, Demerouti, \& Schaufeli, 2007). Taken together, the JD-R and these recent extensions offer a framework in which researchers can incorporate work and personal factors in a more holistic approach to examining how personal and environmental factors influence strain and motivation outcomes.

Given that WA is seen as a balance between one's job demands and their mental and physical ability to meet those demands, the JD-R is a natural fit when investigating the construct of WA. Indeed, IO and OB researchers have utilized the JD-R when studying WA and have shown this approach to be useful in answering the call to include more psychosocial research on factors that impact WA (Airila et al., 2014; McGonagle et al., 2014; McGonagle et al., 2015). However, there are still some questions among researchers as to where WA best fits into a nomological network and theoretical framework. For example, Airila and colleagues (2014) included WA as a personal resource in the JD-R framework, whereas McGongale and colleagues $(2014,2015)$ included WA as a strain-related outcome. Based on the definition of WA and studies pointing to health as an antecedent of WA, in this thesis I view WA as best fitting into the JD-R as a strain-related outcome Although the above research has differed in the specific application of the JD-R, they have laid a foundation for applying the JD-R to research on WA and identified a host of specific factors that may relate to WA. 


\section{Antecedents of WA}

Within the JD-R framework, job demands and job and personal resources are seen as the primary antecedents to strain-related outcomes, and in the present study to WA. Identifying factors that impact WA is critically important for developing useful interventions and best practices that promote and maintain WA and thus the ability of older workers to continue effective participation in the workforce later in life. In the following sections I will outline which constructs have been studied in relation to WA, and develop hypotheses for their expected relationship to WA. A complete diagram of the conceptual model is provided in Appendix A.

\section{Job demands.}

Physical demands. Physical demands are aspects of the job in which some physical task or awkward body position is required on a regular basis (e.g., bending or lifting heavy objects; Abma, Amick III, Brouwer, van der Klink, \& Bültmann, 2012). One's ability to perform these job duties is likely to be heavily dependent on physical health, strength, and physical functioning. While there is a great deal of variation in the rate at which individuals age and experience age-related physical declines, at some point older individuals will begin to experience declines in physical strength and functioning (Gallagher et al., 1997; Goodpaster et al., 2006; Millanvoye, 1998). As an individual ages, these reductions in physical strength and functioning are likely to result in perceiving physically demanding tasks as more difficult to perform and thus leading to a reduction in one's perception of their ability to perform these job duties. Although some research has found mixed results regarding the relationship between physical demands 
and WA (e.g., McGonagle et al., 2015), others have consistently found that physical demands and jobs requiring awkward body positions are negatively related to WA (Airila, Hakanen, Punakallio, Lusa, \& Luukkonen, 2012; Bethge et al., 2012b). Given the clear theoretical link between the physical demands of a job and WA, as well as a number of empirical results supporting this link, I hypothesize that physical job demands will be negatively related to WA.

H1: Physical demands will be negatively associated with WA.

Perceptions of injustice. Another job demand that has been studied in relation to WA is the perception of injustice, which can be measured by effort-reward imbalance (ERI) as well as other measures of perceived fairness (e.g., Bethge, Radoschewski, \& Gutenbrunner, 2012a). ERI, is a specific perception of injustice which develops when the effort expended in a given job exceeds the perceived rewards provided in that role (Bethge et al., 2012a). Over time this feeling of imbalance may create negative affective feelings or a sense of undue burden and ultimately lead to a reduction in one's WA. Although only a limited number of studies have investigated WA in relation to ERI, there is initial support for ERI leading to lower levels of WA (Bethge et al., 2012a). In addition to ERI, other measures of perceived justice (e.g., distributive justice) and fairness will also be included in this job demand category as they are conceptually similar and all measure some aspect of perceptions of injustice. Given the initial support found between the ERI and WA, I hypothesize that perceptions of injustice will be negatively related to WA.

H2: Perceptions of injustice will be negatively related to WA. 
Quantitative Job Demands. Quantitative job demands are aspects of a job that require working at a fast pace or having a high workload. Two specific examples of a quantitative job demand are work overload and time pressure. Work overload develops when an individual is assigned too many tasks or perceives that the sheer amount of work being asked of them is so great that the work cannot be completed while maintaining a sufficient level of quality (Bakker \& Demerouti, 2007; Karasek, 1979). Similarly, time pressure occurs when an individual does not have enough time to complete assigned tasks and is required to work at a fast pace (Karasek et al., 1998). Although these constructs are distinct, they both assess a perception of having too much work to do in a given amount of time and these constructs have been combined in measures of "work overload" (Bakker, Demerouti, \& Euwema, 2005) or “job demands” (e.g., HSE stress tool; Edwards, Webster, Van Laar, \& Easton, 2008) by other researchers. Work overload and time pressure were included in Karasek's original JDC model and are among the most frequently studied and supported job demands that lead to strain related outcomes (Bakker \& Demerouti, 2007). The limited research on work overload and time pressure with WA has generally supported the link between these job demands and WA (McGonagle et al., 2015). Due to some studies using combined measures of workload and time pressure as well as the limited number of studies assessing each individually, these constructs will be combined for the purpose of this meta-analysis. Based on the extant literature and the theoretical basis for these job demands negatively impacting WA, I believe that quantitative job demands will be negatively related to WA. H3: Quantitative job demands will be negatively related to WA. 
Emotional and mental job demands. In addition to quantitative job demands (e.g., time pressure), other job demands such as emotional and mental demands may have a negative impact on WA. These emotional and mental job demands do not necessarily require working at a fast pace or having a high workload, but do hinder one's ability to perform their job duties. For example, role ambiguity is the perception of not knowing one's role, or what is expected of them, whereas role conflict occurs when an individual is assigned competing job duties or tasks that conflict with one another (Bakker \& Demerouti, 2007; Edwards et al., 2008; McGonagle et al., 2015). These demands indicate some level of uncertainty in one's role, and thus are likely to place an additional emotional and mental burden on employees. In additional to role conflict and ambiguity, other emotional demands such as emotional labor or conflict with customers/patients that are often required in service oriented jobs can be emotionally and mentally draining without necessarily containing a component of high workload or working at a fast pace (Kenworthy, Fay, Frame, \& Petree, 2014). Given the non-quantitative nature of these demands and their emotional and mental laden nature, these constructs were assessed as a broader emotional and mental demands category. Research that has investigated the link between some of these demands (e.g., role ambiguity and conflict) and WA has shown both initial support and some null findings (Guidi, Bagnara, \& Fichera, 2012; McGonagle et al. 2015). Although there have been some null findings regarding this relationship, none have reported a positive relationship between these emotional and mental demands and WA. Furthermore, the majority of studies have found support for a negative link 
between these emotional and mental demands and WA, thus I anticipate that emotional and mental demands will be negatively related to WA.

H4: Emotional and mental job demands will be negatively related to WA.

\section{Job resources.}

Support. Social support is a known resource that can help to a) buffer against the negative impact of stress on other health outcomes or b) provide a direct positive influence on stress and health outcomes (Cohen and Wills, 1985; Van der Doef \& Maes, 1999). In the workplace, two primary types of support, coworker and supervisor support, have been studied and shown to influence strain related outcomes such as burnout (Bakker et al., 2005; Bakker and Demerouti, 2007). Guidi and colleagues (2012) also found that supervisor and coworker support were related to WA in a sample of Italian bank employees. Support from these two sources may influence one's perceptions of their own ability to perform their job duties through positive feedback, higher levels of LMX, and through increasing self-efficacy. Supervisor support and coworker support have even been shown to influence WA, even when accounting for other health factors (Alavinia, van Duivenbooden, \& Burdorf, 2007). Given these findings, I hypothesize that both supervisor and coworker support will be positively related to WA.

H5: a) Supervisor and b) coworker support will be positively related to WA.

Job control. Job control and aspects of job control (e.g., autonomy and schedule control) can allow individuals to adjust specifically how or when a task is completed to better fit their own work style. The affordance of autonomy and job control to employees is linked to a range of positive outcomes such as higher job satisfaction and performance 
as well as lower levels of distress and physical symptoms (Spector, 1986). Job control has been consistently identified as a key resource and was identified in Karasek's (1979) original Job Demands-Control model as important for employee performance and health outcomes. Similarly, in the JD-R framework autonomy is one of the more commonly studied resources and is a key job resources that leads to lower levels of burnout (Bakker et al., 2005; Demerouti et al., 2001). Given that control over one's work has consistently been shown to have positive impacts on work and health outcomes, I anticipate that job control will be positively related to WA.

H6: Job control will be positively related to WA.

\section{Personal resources.}

Core self-evaluations. Core self-evaluations, such as self-esteem and generalized self-efficacy, are one's beliefs about their overall worth and perception of their ability to cope and be successful (Judge \& Bono, 2001). These core self-evaluations, such as selfefficacy and organizational based self-esteem, have been linked to both work exhaustion and engagement (Xanthopoulou et al., 2007). Additionally, self-efficacy has been shown to be an important resource for coping with work related stressors (Palermo et al., 2013) and may serve as an important resource for coping with age-related physical and mental changes as well. Given that core self-evaluations are related to strain outcomes and work engagement, I hypothesize that core self-evaluations will be positively related to WA. H7: Core self-evaluations will be positively related to WA.

Health. An individual's health is perhaps their most important personal resource as it may impact everyday functioning as well as their ability to perform more complex 
tasks. Furthermore, health problems are among the most commonly reasons cited for exiting the workforce, an outcome of particular interest to those studying WA (Shultz, Morton, \& Weckerle, 1998; Shultz \& Wang, 2007). Due to the roots of WA in occupational medicine, many health indicators are actually imbedded in the original WAI and have been commonly studied as antecedents to perceived WA (Abdolalizadeh et al., 2012; Bethge et al., 2012b; Morschhäuser \& Sochert, 2006; von Bonsdorff, Huuhtanen, Tuomi, \& Seitsamo, 2009). Health factors likely influence an individual's perception of their ability to perform job duties because they often directly impact their actual ability. Furthermore, dealing with health issues can be time-consuming and can drain resources that could be otherwise spent on resource replenishing activities. General measures of health often combine mental and physical components or ask participant to rate their global or overall health. While these measures are less specific, they have been identified as antecedents to WA (Bethge et al., 2012b) and are still informative in establishing a broader link between health and WA.

Physical health is often a manifestation of both health destructive (Rimm, Klatsky, Grobbee, \& Stampfer, 1996; Schane, Ling, \& Glantz, 2010) and health promoting behaviors, which alter an individual's risk for a variety of chronic health conditions (Warburton, Nicol, \& Bredin, 2006). Physical health is likely to be important for those in physically demanding positions, however because it is often associated with a host of other health conditions, physical health may also become increasingly important in less physically demanding positions as an individual ages. In support of the link between 
physical health and WA, Sörensen and colleagues (2008) found that physical health was related to WA (Sörensen et al., 2008).

Mental health is often assessed with items regarding depression or anxiety related symptoms and may also include items regarding an individual's level of fatigue (McHorney, Ware, \& Raczek, 1993). As jobs continue to become more cognitively demanding, mental health may continue to play an increasingly important role in employee WA. As an example, in cognitively demanding positions mental health may be critically important for performing job duties effectively, in the same manner physical health is critical for performing physical job tasks. Thus individuals with poor mental health are likely to perceive that their ability to perform these cognitive duties is lower compared to those with fewer mental health symptoms. Based on the literature reviewed, I anticipate that general, physical, and mental health will be positively related to WA. H8: a) General, b) physical, and c) mental health will be positively related to WA.

Other health indicators. In addition to the broader measures of health, specific physical aspects of one's health such as body mass index (BMI), perceived pain, and chronic health conditions such as musculoskeletal disorders (MSDs) have also been studied in relation to WA (Sormunen, Remes, Hassi, Pienimaki, \& Rintamaki, 2009; von Bonsdorff et al., 2012). Greater BMI is used to indicate an individual's level of obesity and at higher levels may make both job demands and everyday activities more difficult. As a more objective measure of physical health, BMI is likely to impact WA in a similar manner. That is, those with a high BMI may actually have more difficulty completing job tasks and thus perceive their ability to complete these tasks as lower compared to those in 
a lower and healthier BMI range. Supporting this notion, BMI is associated with increased risk for going on disability leave (Neovius, Kark, \& Rasmussen, 2008), lower health related quality of life (Jia \& Lubetkin, 2005) and to a wide range of chronic health conditions (Must et al., 1999). Furthermore, those with a high BMI may experience weight based stigma in both work and home domains, which can lead to lower motivation to exercise, body dissatisfaction (Vartanian \& Shaprow, 2008), binge eating, and higher rates of depression (Wott \& Carels, 2010).

Pain is another specific health related challenge that can be a particularly difficult to manage because it can be exacerbated even in jobs that are low in physical demands (e.g., office work) by requiring sitting in a given position for an extended period of time. Furthermore, pain may develop directly from working in a given position for an extended period of time and being required to make repetitive motions to complete job tasks (e.g., wrist pain; Sormunen et al., 2009). This presents a great challenge given that in some cases the individual is presented with two options, a) leaving that job and potentially occupation to alleviate their pain or b) dealing with the pain on a regular basis and being uncomfortable when working on a regular basis.

A third health indicator identified as an antecedent to WA is the presence of chronic health conditions such as Musculoskeletal Disorders MSDs (von Bonsdorff et al., 2012). Recall, chronic health conditions are one of the dimensions measured in the WAI, however research including only perceived WA items has shown chronic health conditions as related to perceived WA. These conditions often stay with a person for life and need to be treated and managed, which requires significant time and effort. 
Furthermore, these conditions can impact one's level of comfort on the job and are often associated with increases in exiting the workforce (Shultz \& Wang, 2007). For the present study, I assessed specifically MSDs in relation to WA as that was the most commonly reported chronic illness, whereas other chronic illnesses (e.g., coronary heart disease) were not included in the present study. Given the strong links between these specific health factors and WA, I believe that each of these specific health indicators will be negatively associated with WA.

H9: a) BMI, b) pain, and c) musculoskeletal disorders (MSDs) will be negatively related to WA.

Individual health behaviors. In addition to health measured directly, behaviors that impact one's health are also likely related to WA. Behaviors such as smoking and excessive alcohol consumption can negatively impact health (Rimm et al., 1996; Schane et al., 2010). These negative impacts on health are likely to also negatively impact one's physical and mental abilities, leading to a reduction in WA. While the negative impact of even light smoking on health is clear (e.g., cardiovascular disease and mortality; Schane et al., 2010), alcohol consumption can have health benefits in moderate amounts (e.g., reduced risk of coronary heart disease; Rimm et al., 1996), but grave health consequences when consumed at high levels (e.g., breast cancer and cirrhosis of the liver; Room, Babor, \& Rehm, 2005).Based on the links between these behaviors and other negative health related outcomes as well as physical and mental abilities, I hypothesize that smoking and alcohol consumption will be negatively related to WA. H10: a) Smoking and b) alcohol consumption will be negatively related to WA. 
Although some behaviors negatively impact health, there are also behaviors that have been shown to provide many health benefits. Physical activity is linked to higher levels of physical and mental health (Penedo \& Dahn, 2005) and has been shown to be an effective form of therapy for a range of health conditions (Pedersen \& Saltin, 2006). Thus, the health benefits that physical activity provides may directly impact one's ability to perform their job duties by improving their physical and mental functioning. In support of this link, researchers have found modest support for physical activity being positively related to WA (Kaleta, Makowiec-Dabrowska, \& Jegier, 2006; von Bonsdorff et al., 2012). Given the benefits of physical activity, I anticipate that physical activity will serve as a protective factor that is positively associated with WA.

H11: Physical activity will be positively related to WA.

\section{Demographic factors.}

Age. Given that the aging workforce was the initial reason for the development of the WAI, and study of WA more generally, I expect that age will be negatively related to WA. While there are certainly great differences in how individuals age, age is associated with declines in both physical abilities (Millanvoye, 1998) and some cognitive abilities (e.g., fluid intelligence; Schaie \& Willis, 1993). In addition to these declines, older individuals become at greater risk for chronic health conditions (e.g., chronic back pain; Manchikanti, Singh, Datta, Cohen, \& Hirsch, 2008) and as noted earlier, these chronic conditions are also associated with lower levels of WA. Thus, despite the variation in timing, I still anticipate that on average age will be negatively related to WA, such that older individuals will report lower levels of WA. 
H12: Age will be negatively related to WA.

\section{Outcomes}

Job satisfaction. Job satisfaction is a pleasurable emotional state that forms when one's job provides an individual with the benefits they are seeking from their job (Locke, 1969). Researchers have found that positive job attitudes and job satisfaction in particular generally develop when an individual has greater levels of resources (e.g., health and well-being; Faragher, Cass, \& Cooper, 2005). Although early research on WA did not investigate job satisfaction as an outcome of WA, recent studies have found initial support for the link between WA and job satisfaction (McGonagle et al, 2015; Palermo et al., 2013). Individuals that perceive they are able to meet the demands of their job are likely to also enjoy their job and thus have higher job satisfaction compared to those that view their ability to perform their job duties as insufficient. Based on the initial support for the link between WA and job satisfaction, I anticipate that WA will be positively related to job satisfaction.

H13: WA will be positively related to job satisfaction.

Job performance. Job performance is perhaps the most important organizational outcome from a bottom line standpoint. Performance is based at least in part on one's ability to perform job duties, thus those with higher levels of ability are capable of performing at higher levels. WA includes one's ability to perform their job duties (objective or subjective) and thus WA is likely tied to actual performance as well. If an individual has low WA, and particularly if that assessment is accurate, then it is likely that their actual job performance is low as well. Surprisingly, few studies have 
investigated the relationship between job performance and WA. Furthermore, of those that have investigated the relationship between WA and job performance many have used self-report measures of job performance (Tuomi, Huuhtanen, Nykyri, \& Ilmarinen, 2001; Wagenaar, Kompier, Houtman, van den Bossche, \& Taris, 2015). Although existing literature on the link between WA and job performance is limited, the initial support combined with a strong theoretical rationale lead me to believe that WA will be positively related to job performance.

H14: WA will be positively related to job performance.

\section{Strain indicators.}

Burnout. According to the JD-R, strain (e.g., burnout) results from an imbalance of demands and resources, where an individual experiences high demands and insufficient resources to meet those demands (Bakker \& Demerouti, 2007). Given that strain results from a pattern of imbalance between demands and resources, strain outcomes predicted in this framework (e.g., burnout and as I am proposing WA) are likely to be related to one another. The link between strain and WA is supported by researchers finding consistent negative relationships between WA and burnout in samples of teachers (Hakanen, Bakker, \& Schaufeli, 2006) and nurses (Radkiewicz \& Widerszal-Bazyl, 2005). Although the direction of this relationship has been consistent, the magnitude of the relationship across contexts has not been assessed. Based on the consistent findings in support of the negative association between WA and burnout, I anticipate that WA will be negatively related to burnout.

H15: WA will be negatively related to burnout. 


\section{Exit behaviors.}

Absenteeism. Absenteeism is generally defined as the number of days an individual has missed work (aside from vacation or planned absences) over a given period of time (Collins et al., 2005; Sormunen et al., 2009). Individuals miss work for a variety of reasons, for example, chronic health conditions (Collins et al., 2005), acute illness, and management of other personal challenges. As noted above, WA is also influenced by an individual's health. Thus, I anticipate that those with lower levels of health and subsequently lower levels of WA will have higher rates of absenteeism compared to those with higher levels of WA. In addition, other strain related outcomes (e.g., exhaustion, work stress, and burnout) have been linked directly to absenteeism (Darr \& Johns, 2008; Schaufeli, Bakker, \& Van Rhenen, 2009), and I anticipate that WA will also be related to absenteeism in a similar fashion. Given the well-established link between other measures of strain and absenteeism, as well as evidence that poor health leads to absenteeism, I hypothesize that WA will be negatively related to absenteeism. H16: WA will be negatively related to absenteeism.

Disability. Disability status is generally established when some medical condition or injury renders an individual unable to continue working (Social Security Administration, 2016). Exit from the workforce via disability has become an increasingly common occurrence (World Health Organization, 2015). As the workforce continues to age, disability will continue to be a pressing issue and one that naturally aligns with the study of WA. Early research on the concept of WA included questions regarding exit from the workforce which resulted in researchers finding that WA is related to being 
placed on disability in the future (Ilmarinen et al., 1997). Similar to the link between sick leave and WA, those that no longer perceive they are able to perform their job duties effectively (low WA) and are not yet at retirement age may seek out disability as a way to exit the workforce. Given the longitudinal evidence supporting the link between WA and disability status, I anticipate that WA will be negatively related to disability status. H17: WA will be negatively related to disability status.

Retirement. Similar to the study of disability, retirement was one of the key outcomes researchers were interested in assessing when the concept of WA was initially developed (Ilmarinen et al., 1991b). Although retirement is influenced by a wide range of factors, these factors can often be described as those that either push or pull an individual to retire (Schultz et al., 1998). Push factors are negative factors (e.g., poor health and low job satisfaction) that encourage an individual to retire, whereas pull factors are factors are typically positive retirement considerations (e.g., pursuing a hobby and more time with family) that encourage an individual to retire (Schultz et al., 1998). In line with this research, I conceptualize low levels of WA as a push factor that encourages individuals to retire because they no longer feel they can adequately perform their job duties. In support of this, researchers have found that WA is related to both intentions to retire (Camerino et al., 2006) and actual retirement (Feldt et al., 2009). Based on this evidence, I hypothesize that WA will be negatively related to retirement intentions and actual retirement. WA will be negatively related to a) retirement intentions and b) retirement.

\section{Untested Hypotheses.}


Gender. Although my initial intent was to assess the research question of whether or not men and women differ in their level of WA, I ultimately was unable to assess this relationship. Further, after looking at the proportion of men and women in specific occupations, it became apparent that any comparison between men and women would be confounded by occupation in samples of gendered occupation groups (e.g., manual labor, nursing). However, in addition to this point the primary reason I was unable to assess the relationship between gender and WA was the general lack of clarity in reporting which gender was higher on the measure of WA. In many studies, the comparison was made using odds ratios, and included a heading such as (male/female), but frequently did not indicate which gender was the referent. Additionally, many studies reported the mean WA score for each gender, but did not report the standard deviation. Based on these two issues that were discovered during the coding process, the decision was made to not pursue assessing this relationship.

Occupation. The second untested hypothesis my hypothesis that workers in physically demands or high stress occupations (e.g., nurses) would have lower levels of WA compared to other occupation groups. In the majority of studies, effect size estimates and the necessary information to compute those estimates between occupations was not provided. For example, most studies stated the number of individuals within a given occupation, and the overall WA for the sample, but did not delineate between the occupational groups. Additionally, studies reported a wide range of occupations and comparisons among occupations (e.g., nursing aides compared to nurses) which would have made these comparisons particularly difficult to aggregate. Although occupation 
was not assessed per se, I was able to assess the impact of physical job demands - the key component of manual labor jobs that differentiates these jobs from other occupations, as well as assess occupation (including nursing/healthcare) as a moderating variable.

Sick leave. The third hypothesis I was unable to assess in the present metaanalysis was the hypothesized negative relationship between WA and sick leave. Some of the studies that assessed sick leave investigated populations already on sick leave, and compared whether or not they returned to work based on their WA score, rather than using WA as a predictor of sick leave. Thus, relatively few studies assessed WA at Time 1 and predicted future sick leave. Additionally, the studies that did predict future sick leave could typically be categorized into the absenteeism category. Studies that did predict future sick leave, generally looked at relatively short term (e.g., two weeks) sick leave. However, this overlaps significantly with studies of absenteeism which included having missed up to 60 days of work in the past year. Based on these factors, sick leave was not assessed in the present study, however the more consequential outcome of disability and more proximal outcome of absenteeism were assessed.

\section{Moderators}

\section{Measure of WA}

As discussed earlier, one of the lingering concerns regarding the utility of WA in research is how to actually operationalize and measure it. While some initial research has compared the utility of the WAI and measures of perceived WA, these studies have been limited to specific samples and only a handful of correlates (e.g., Ahlstom et al., 2010; El Fassi et al., 2013). Given the breadth of the construct domain presented in the WAI, it 
may be that some constructs that correlate with the WAI do not correlate with perceived WA or that the magnitude of these relationships are markedly different. The present study will assess how the WAI compares to measures of perceived WA in terms of the relationships between WA and its correlates. This investigation will be largely exploratory, however I do anticipate that indicators of health will be more closely related to WA in studies using the WAI due to the inclusion of more objective health indicators in the WAI, whereas perceptual correlates (e.g., core self-evaluations) may be more closely linked to WA in studies that use perceived WA measures.

Research question 1: Are the WAI and perceived measures of WA comparable in terms of how they are related to the antecedents and outcomes of WA?

\section{Occupation}

The second moderator I propose in this study is the occupation of the employees from which an effect size is drawn. For example, I anticipate that age will be related to WA, however I also anticipate that occupation will moderate this relationship such that in occupations that are more demanding, the relationship between age and WA will be stronger. This assertion is in some ways supported by the scoring of the WAI which weights the importance of physical and mental job demands according to how physically or mentally demanding a position is. It is inherent in this scoring system that specific occupations will be more or less demanding in terms of physical or mental demands, and that the relative importance of these demands will differ based upon which demands are most prevalent. Furthermore the actual demands of the job and thus one's occupation must be considered in the study of WA because moving to another position may alone be 
sufficient to increase or decrease an individual's WA (Ilmarinen et al., 1997;

Morschhäuser \& Sochert, 2006). As noted in the WAI manual, an individual with poor WA in a construction job may have good WA in a different role (e.g., a leadership role) where the physical demands are removed (Ilmarinen et al., 1997; Morschhäuser \& Sochert, 2006).

H19: Occupation will moderate the relationships between WA and its correlates such that the relationships will be stronger for studies conducted in occupations that are considered highly stressful or physically demanding (e.g., nursing and construction).

\section{Sample Age}

In addition to age being related to WA directly, age may also serve as a moderator to the relationships between WA and its correlates, such that these relationships will be stronger in studies drawn from older samples of employees. For example, I anticipate that WA will be related to rates of disability and retirement, but that this relationship will be stronger when the sample is older and thus closer to retirement age. On the other hand, due to the general trend of muscle mass and physical ability being greater in younger individuals, physical job demands may be less strongly related to WA in samples of younger workers compared to samples of older workers. Given the initial intent of the researchers that introduced the concept of WA was to investigate age related challenges in the workforce and that some of the items consider previous or anticipated working ability (factors directly influenced by age and experience), it is likely that when studying WA age is an important factor to consider even if it is not one of the focal constructs of interest. 
H20: The mean age of the sample will serve as a moderator between WA and its correlates, such that the relationships between WA and its correlates will be stronger in studies that consisted of older employees. 


\section{Method}

In order to collect articles that included measures of WA, Boolean searches were conducted in PyscINFO and PubMed using the following terms: "Work Ability", "Work Ability Index”, "Work Ability Assessment”, “WAI”, “Work Capacity”, “Work Capability", or "Capacity to Work". The search criteria were limited to studies published after 1980 and prior to June, 2015. The year 1980 was chosen as the start date because that is when the concept of WA was introduced into the literature. These searches yielded 1410 unique articles after cross-checking for duplicate search results, 599 from the PsycINFO database and 811 from the Pubmed database.

Due to the large number of studies that included "work ability" in the common use of the term, but not as conceptualized in this study or the existing literature on WA, my first step was to screen the articles for those that included a valid measure of WA. Constructs that were considered a valid measure of WA included the original long version of the WAI, the shorter version of the WAI (including the single item indicators), as well as other perceived WA measures (e.g., McGonagle et al., 2015; Weigl et al., 2013). On the other hand, constructs derived from a physician's determination of "ability to work" were not included in this study. This initial screening for a valid WA measure reduced the number of available articles to 585 .

Following this initial screening, articles were reviewed for the inclusion of a usable effect size, that is, an effect size that could be converted to a Pearson's correlation. One of the biggest challenges within the WA literature is that much of the research has been published without correlation matrices (often because the studies were not published 
in psychology journals) and instead with effect sizes such as betas from multiple regression equations or adjusted odds ratios where demographic factors (e.g., age, gender, and occupation) are being statistically controlled for. Thus, these effect sizes are not raw associations between WA and its correlates and cannot be included in the meta-analysis. This step yielded a total of 361 studies for complete coding and inclusion in the present meta-analysis.

Any study that contained sufficient information to calculate an effect size for the relationship between WA and another variable was coded in the initial coding procedures. Antecedent and outcome variables were coded at the most detailed level possible and then grouped into categories after reviewing the number of available effect size estimates for each construct. For example, in the initial coding, the related constructs of self-esteem, self-efficacy, and other core self-evaluations (Judge \& Bono, 2001) were coded with as much precision as possible into their narrowest construct category (e.g., self-esteem). After the initial coding was complete, these constructs were then grouped into a broader categories (e.g., core self-evaluations) for the purpose of analysis based on the number of available studies and the theoretical similarity among the constructs.

Each article was individually coded by two members of the research team, and disagreements between coders were resolved by a group discussion while reviewing the article in question. The process for this comparison was for one team member to compare the coding sheets of the two coders and determine if there were any discrepancies. If any differences were found, they were added to a list of questions to be addressed at the following meeting or via an email chain of discussion. The one exception to this practice 
was in the final grouping of the antecedent and outcome variables where the constructs were grouped into broader categories. In this step, the final decisions regarding how broadly or narrowly to group the antecedent/outcome variables were made by the author. For example, depression and anxiety were initially coded separately in order to potentially examine each construct independently. However, this led to a limited number of studies in each category and would have made moderator analyses more difficult, if not impossible. Based on the conceptual similarity between anxiety and depression, these measures as well as measures that incorporated both of these aspects of mental health were then coded into a broader "mental health" category, and the decision to analyze the data using this broader category was made by the author.

Regarding the coding of the moderator constructs, the following coding decisions were made on theoretical grounds. The WA measure was separated into studies that used the full WAI, which includes objective health indicators (e.g., number of current chronic health conditions) and those that used measures of perceived WA exclusively (i.e., did not include questions about chronic health conditions). The occupation moderator variable was coded according to white collar (e.g., office, IT, administrative), blue collar (manual labor, front-line manufacturing), nurses/healthcare workers (e.g., nurses, nursing assistants, doctors), and studies that included mixed occupations or other unique samples of employees (e.g., nationally representative samples of employees, dentists). One important note is that within this group of "mixed" workers are a subset of workers identified as having a chronic health condition, or having recently returned from sick leave (e.g., rheumatoid arthritis, recovered from a back injury). Although there are 
certainly workers with chronic health conditions in the other occupation groups, the mixed occupation group contains 10 studies where the sample was explicitly made up of individuals that were either currently working with a chronic health condition, or individuals that recently returned from sick leave. Based on this decision, follow-up analyses were conducted to test for differences between the regular sample of mixed occupation employees and the mixed occupation employees that had some sort of chronic health condition or previous sick leave. Across the hypothesized relationships, there were minimal differences between these two groups, and thus the two groups were analyzed together, according to the mixed occupation designation.

\section{Meta-Analytic Approach}

The meta-analysis was conducted in line with the Hedges and Olkin (1985) approach using Comprehensive Meta-Analysis 3.0 software (CMA; Borenstein, Hedges, Higgins, \& Rothstein, 2014) to convert the coded effect sizes into Pearson's correlation coefficients. The Hedges and Olkin approach was chosen to calculate weighted average correlations in part because of limitations in the information provided by researchers publishing articles on WA. Researchers using the WAI generally use the categories mentioned in the literature review section to split WA into four categories and do not report estimates of reliability. Additionally, many of the antecedents and outcomes are measured with single-item indicators (e.g., age, BMI, and diagnosis of a disease or disorder), limiting the ability and theoretical need to correct for measurement error. In other cases, the authors created dichotomous low and high groups on various constructs using a median split and did not report the reliability of the measure being used. Because 
of these limitations, correction for attenuation in the predictor or outcome is either a) not theoretically relevant or b) not possible due to a lack of information provided in the empirical articles. The Hedges and Olkin approach will thus provide a relatively conservative estimate of the effect sizes identified in the present study.

After converting all of the effect sizes into the common metric of a Pearson's correlation coefficient, the meta-analytic estimates were conducted in line with the proposed hypotheses. Consistent with current meta-analytic practices, random-effects models were used for all analyses (Kepes, McDaniel, Brannick, \& Banks, 2013). In the initial meta-analytic estimates, all WA measures (both WAI and perceived WA) were included. However, moderation analyses were also conducted to determine if the perceived and objective measures of WA are related to antecedents and outcomes in a similar manner.

As noted earlier, in some studies, there were multiple measures of a single construct which were ultimately coded into a broader antecedent or outcome category (e.g., depression, anxiety). As suggested by Bornstein and colleagues (2009), the effect size estimates from these relationships were averaged to create a single effect size estimate, which was then included in the meta-analysis. For example, McGonagle and colleagues (2015) assessed WA in relation to role overload and time pressure, which were both ultimately coded as "quantitative job demands". These effect sizes were averaged, and the average effect size was input as the effect size for the meta-analysis. In six of the studies included in this meta-analysis we were able to code the relationships between WA and its correlates using both the WAI and a perceived measure of WA. In 
these cases the relationships between WA and its correlates were entered as independent effect sizes for each WA measure. This step was taken in order to compare the utility of the two WA measures. As an example, in a different sample within the article by McGonagle and colleagues (2015), the researchers measured job satisfaction and reported its relationship with both the WAI and a measure of perceived WA. In this case, the effect size for the relationship between the WAI and job satisfaction, as well as the effect size for the relationship between perceived WA and job satisfaction were each entered as an independent effect size in the current meta-analysis. Although it is not ideal to input dependent effect sizes as independent in meta-analytic studies, research by Scammacca and colleagues (2013) showed that there were minimal difference in the overall estimated effect sizes when the effect sizes were input as independent. Given that one of the research questions of interest was how the WA measure moderated the relationships between WA and its correlates, it was necessary to input studies that reported effect size estimates with both the WAI and perceived WA as independent. Furthermore, there were only a total of seven out of the 158 studies in which this process was utilized.

\section{Moderator Analyses}

Prior to conducting the moderator analyses, the first step was to assess the homogeneity of effect sizes included in each meta-analytic estimate using the $Q$ statistic. The $Q$ statistic indicates the presence or absence of heterogeneity among the effect size estimates and thus, when significant suggests when there may be moderators of the relationship being tested (Huedo-Medina, Sánchez- Meca, Marín-Martínez, \& Botella, 2006; Kepes et al., 2013). The $I^{2}$ index indicates the magnitude of the variance among 
effect sizes estimates and was also be computed (Huedo-Medina, et al., 2006; Kepes et al., 2013). Although these tests serve as indicators of the potential presence of moderators, the specific moderator analyses were conducted in line with the hypotheses stated in the preceding sections. In the bivariate analyses between WA and a single correlate (without any moderator), the $Q$ statistic suggests the potential presence of a moderator due to the heterogeneity in the effect size estimates among studies. In the subsequent moderator analyses, the $Q$ statistic indicates heterogeneity of the effect size estimates between the specific subgroups. Thus, for the moderator analyses the $Q$ statistic indicates that the effect size estimates between two individual subgroups (e.g., studies that used the full WAI compared to those using perceived WA measures) differs.

Given that the moderator of occupation consisted of four groups (blue collar, white collar, nursing/healthcare, and mixed occupations), follow-up post-hoc orthogonal contrasts were conducted when the initial $Q$ statistic indicated that there was heterogeneity among the effect sizes estimates between the groups. These contrasts were conducted in order to identify specifically how the occupation in which the study was conducted influenced the relationships between WA and its correlates. In cases where there were not at least two occupation groups with three or more effect size estimates included in the study, the moderator analyses for that relationship were not conducted. Although the moderation analyses were not conducted in these cases, the average correlation coefficients by occupation (regardless of the number of available studies), and $Q$ statistic estimates are provided in Table 3 . 
In order to assess the mean sample age as a moderator, meta-regression analyses were conducted. Meta-regression was required because the moderator variable is continuous rather than categorical. In these analyses the mean age of the sample is entered as a level-two predictor, with the outcomes of interest being the effect size estimates for the relationship between WA and the correlate of interest. In order to interpret these results, the beta-coefficients, $Z$ value, and corresponding $p$ value are used to determine whether or not the mean age of the sample was a predictor of the relationship between WA and the correlate of interest. For a visual representation of the meta-regression analyses see Appendices D and E, to which I will refer in interpreting specific results. 


\section{Results}

Meta-analytic estimates of the relationship between WA and its correlates were calculated, and the results of these analyses are provided in Table 1. Also included in Table 1 are the indicators of the heterogeneity among the effect size estimates, the $Q$ statistic and $I^{2}$ value, the interpretation of which were discussed in detail in the methods section. The results of the moderator analyses for the type of WA measure (Table 2), occupation (Table 3), and the mean age of the sample (Table 4) are also included in their corresponding tables.

The following sections provide an overview of the results according to the hypothesized antecedent and outcome categories: Job Demands (H1-4), Job Resources (H5-6), Personal Resources (H7-9), Health Behaviors (H10-11), Age (H12), Job Outcomes (H13-14), Strain Indicators (H15), and Exit Behaviors (H16-18). These results will first be discussed in terms of the direct relationships with WA (see Table 1), and then according to how these relationships were moderated by the proposed moderators, the WA measure (Research Question 1; see Table 2), the sample occupation (H19; see Table 1), and the sample age (H20; see Table 4).

\section{Job Demands (Hypotheses 1-4)}

Physical job demands (Hypothesis 1). Twenty-four studies were identified that investigated physical job demands in relation to WA. In support of hypothesis 1, physical job demands were negatively related to WA, $\bar{r}=-.16,95 \% \mathrm{CI}[-.20,-.12]$, and the test of the heterogeneity of the effect size estimates suggested that there were moderators to this relationship, $Q=317.81 p<.01, I^{2}=92.76$ (see Table 1). There was no difference found 
in the strength of this relationship between studies that used the Full WAI compared to those that used a perceived measure of WA, $Q=.10, p=.75$ (RQ1; see Table 2). Occupation did moderate this relationship, such that the relationship between physical demands and WA was weaker in studies consisting of blue collar $\bar{r}=-.06$ and white collar workers, $\bar{r}=-.06$ compared to studies consisting of nursing/healthcare or mixed samples of workers $(\bar{r}=-.17,-.20), Q=13.49, p<.01$ (H19; see Table 3). Post-hoc contrast comparisons showed that among studies consisting of blue collar workers, the relationship between physical demands and WA was weaker $\bar{r}=-.06$ compared to the relationship between physical demands and WA for all other occupation groups (white collar, nursing/healthcare, and mixed occupations), $\bar{r}=-.18, Q=8.60, p<.01$. The comparison between white collar workers, $\bar{r}=-.06$ and the combined nursing/health and mixed occupation samples showed there were was not a significant difference between the two groups, $Q=1.14, p=.29$. Similarly, there was no difference in the effect size estimate when comparing the nursing/healthcare group and the mixed occupation studies, $Q=.4, p=.85$. The relationship between physical job demands and WA was also moderated by the age of the sample. In studies consisting of older workers the relationship between physical demands and WA was stronger, and more negative, compared to the relationship between physical demands and work ability in studies consisting of younger workers, $b=-.01, Z=-2.02, p=.04(\mathrm{H} 20$; see Table $4 \&$ Appendix D).

Perceptions of injustice (Hypothesis 2). A total of 14 studies were identified measuring perceptions of injustice (e.g., effort reward imbalance) and WA. In support of 
hypothesis 2 , the relationship between perceptions of injustice and WA was negative, $\bar{r}=$ $-.29,95 \%$ CI $[-.38,-.20]$. The test for heterogeneity among the effect size estimates suggested that there may be moderators to this relationship, $Q=378.15, p<.01, I^{2}=$ 95.20 (see Table 1). Based on the moderator analyses, there were no differences in the strength of this relationship when comparing studies that used the WAI to those that used a perceived measure of WA, $Q=.80, p=.37$ (RQ1; see Table 2). Although the differences were not statistically significant, there was a marginal effect suggesting that there could be differences in the strength of this relationship based on occupation of the sample, $Q=4.66, p=.097$ (H19; see Table 3). In samples that consisted of nurses and healthcare workers the estimated relationship between perceptions of injustice and WA was $\bar{r}=-.19$, whereas in samples of white collar and mixed occupation workers perceptions of injustice were more strongly related to WA $(\bar{r}=-.34,-.37)$. Follow-up post-hoc orthogonal contrast analyses indicated that compared to white collar and mixed occupation groups, $\bar{r}=-.35$, studies conducted with nursing/healthcare workers showed a weaker relationship between perceptions of injustice and WA, $\bar{r}=-.19, Q=5.84, p=.02$. No differences were found between samples of mixed occupation studies and those with white collar workers, $Q=1.71, p=.19$. The relationship between perceptions of injustice and WA was not moderated by the age of the sample, $b=.02, Z=1.03, p=.30(\mathrm{H} 20$; see Table 4).

Quantitative job demands (Hypothesis 3). Twenty-six studies were identified that assessed quantitative job demands in relation to WA. In support of hypothesis 3 , job demands and WA were negatively related, $\bar{r}=-.15,95 \%$ CI $[-.20,-.10]$ (see Table 1 ). 
Tests for heterogeneity of the effect size estimates suggested that there could be moderators to this relationship, $Q=378.15, p<.01, I^{2}=93.39$ (see Table 1 ). However, after testing the specific moderators hypothesized in the present study, the WA measure, $Q=.23, p=.63$ (RQ1; see Table 2), the sample occupation, $Q=4.43, p=.22$ (H19; see Table 3), or the age of the sample, $b=-.001, Z=-.10, p=.92(\mathrm{H} 20$; see Table 4$)$, there was no evidence that these specific moderators influenced this relationship.

Emotional/mental job demands (Hypothesis 4). In total, eight studies investigated emotional/mental job demands in relation to WA. Overall, the relationship between emotional/mental demands and WA positive, which supports hypothesis $4, \bar{r}=-.17,95 \%$ CI [-.26, -.08] (see Table 1). Additional tests of the heterogeneity of the effect size estimates suggested there could be moderators to this relationship, $Q=114.28, p<.01, I^{2}$ $=93.88$ (see Table 1$)$. There was not a significant difference in the effect size estimates between studies that used the WAI and those that used a perceived measure of WA, $Q=$ $1.59, p=.21$ (RQ1; see Table 2). Given the limited number of studies assessing mental/emotional job demands and WA, I was unable to assess occupation as a moderator to this relationship (H19). The age of the sample participants did have a marginal moderating effect on the relationship between Emotional/Mental Demands and WA. In samples that were comprised of older workers, the relationship between emotional/mental job demands was stronger than when the sample was comprised of younger workers, $b=$ $-.003, Z=-.44, p=.66$ (H20; see Table 4$)$.

\section{Job Resources (Hypotheses 5-6)}


Supervisor support/relations (Hypothesis 5a). Twenty studies assessed supervisor support/relations and WA. In support of hypothesis 5a, the relationship between supervisor support/relations and WA was positive, $\bar{r}=.21,95 \% \mathrm{CI}[.17, .25]$, and tests of heterogeneity among the effect size estimates suggested that there may be moderators to this relationship, $Q=129.06, p<.01, I^{2}=85.28$ (see Table 1 ). The relationship between supervisor support/relations and WA was not moderated by the WA measure, $Q$ $=.33, p=.57$ (RQ1; see Table 2$)$. The occupation in which a study was conducted, $Q=$ $5.16, p=.16(\mathrm{H} 19$; see Table 3$)$ and the mean age of the sample, $b=-.002, Z=-.41, p=$ .68 (H20; see Table 4), did not moderate the relationship between supervisor support/relations and WA.

Coworker support (Hypothesis 5b). Twelve studies assessed coworker support in relation to WA. In support of hypothesis $5 b$, the relationship between coworkers support and WA was positivie, $\bar{r}=.25,95 \%$ CI $[.20, .30]$, and tests of heterogeneity of the effect size estimates suggested that there may be moderators to this relationship, $Q=59.23, p$ $<.01, I^{2}=81.43$ (see Table 1). The moderator analysis on the relationship between coworker support and WA showed there was a marginally significant difference in the effect size estimate when comparing studies that used the WAI to studies that used a perceived measure of WA, $Q=2.14, p=.14$ (RQ1; see Table 2). In studies that used the WAI, the relationship between coworker support and WA was $\bar{r}=.32$, however in studies that used a perceived measure of WA, the relationship was weaker, $\bar{r}=.23$. The majority of studies that assessed coworker support were of mixed occupation groups (10 of the 12 studies), and thus I was unable to conduct a moderator analysis for occupation 
on the relationship between coworker support and WA (H19). The relationship between coworker support and WA was not moderated by the mean age of the sample, $b=-.004$, $Z=-.98, p=.33(\mathrm{H} 20 ;$ see Table 4$)$.

Job control (Hypothesis 6). Twenty-nine studies were identified that assessed job control and WA. The estimated effect size of the relationship between job control and WA was positive and supported hypothesis $6, \bar{r}=.19,95 \%$ CI $[.15, .23]$. The test for heterogeneity of the effect size estimates suggested that there may be moderators to this relationship, $Q=426.11, p<.01, I^{2}=93.43$ (see Table 1). The relationship between job control and WA was not moderated by the WA measure being used, $Q=.01, p=.97$ (RQ1; see Table 2), however it was moderated by the occupation of the sample. Among samples of blue collar workers, the relationship between job control and WA was very weak, $\bar{r}=.04,95 \%$ CI $[-.04, .11]$, however among all other occupation groups (e.g., nurses, white collar workers) the relationship between job control and WA was stronger, ranging from $\bar{r}=.19-.28, \mathrm{Q}=22.27, p<.01(\mathrm{H} 19$; see Table 3). Post-hoc orthogonal contrasts indicated that the relationship between job control and WA was weakest in studies consisting of blue collar workers $\bar{r}=.04$ compared to studies consisting of white collar, nursing/healthcare, and mixed occupation samples, $\bar{r}=.21, Q=17.04, p<.01$. There was no difference in the strength of the relationship between job control and WA when comparing studies of nursing/healthcare workers, $\bar{r}=.19$, to studies of white collar workers and mixed occupation groups, $\bar{r}=.22, Q=.36, p=.55$. Similarly, there was no difference between studies of white collar workers and studies of mixed occupation studies, $Q=2.28, p=.13$. The relationship between job control and WA was also 
moderated by the mean age of the sample, such that for studies that consisted of older workers the relationship between job control and WA was stronger than the relationship between job control and WA in studies that contained samples of younger workers, $b$ $=.01, Z=2.22, p=.03, \mathrm{R}^{2}=.42(\mathrm{H} 20$; see Table $4 \&$ Appendix $\mathrm{E})$.

\section{Personal Resources (Hypotheses 7-9)}

Core self-evaluations (Hypothesis 7). Twelve studies investigated the relationship between CSE and WA. In support of hypothesis 7, there was a positive relationship between CSE and WA, $\bar{r}=.34,95 \%$ CI $[.27, .41]$. The test of hetereogeneity showed that there may be moderators of this relationship, $Q=52.97, p<.01, I^{2}=79.23$ (see Table 1). Although the heterogeneity test indicates there may be moderators to this relationship, the moderators assessed in this meta-analysis were not found to moderate the relationship between CSE and WA. The relationship between CSE and WA was not moderated by the WA measure being used, $Q=.97, p=.33$, (RQ1; see Table 2$)$, the occupation of the sample, $Q=4.39, p=.11$, (H19; see Table 3$)$, or the mean age of the sample, $b=-.001, Z=-.01, p=.98$ (H20; see Table 4).

General health (Hypothesis 8a). Thirty-two studies investigated the relationship between general health and WA. General health was positively related to WA, which supports hypothesis $8 \mathrm{a}, \bar{r}=.44,95 \% \mathrm{CI}[.37, .50]$. The test of heterogeneity of the effect size estimates suggested that there were moderators to this relationship, $Q=6,715.36, p<$ $.01, I^{2}=99.54$ (see Table 1). Although the difference was not significant at $p<.05$, the strength of the relationship between general health and WA did trend in the direction of being stronger among studies where the WAI was used $(\bar{r}=.49)$ compared to studies 
where perceived measures of WA were used, $\bar{r}=.38, Q=1.27, p=.26$ (RQ1; see Table 2). Similarly, there was a marginal moderating effect for occupation on the relationship between general health and WA. Among those in white collar and mixed occupation categories, the relationship between general health and WA was weaker $(\bar{r}=.37-.40)$, compared to the relationship between general health and WA in studies where the sample consisted primarily of nursing and healthcare staff or blue collar workers $(\bar{r}=.58, .58)$, $Q=6.28, p=.10(\mathrm{H} 19 ;$ see Table 3$)$. Orthogonal post-hoc contrasts were conducted to further investigate the effect of occupation on this relationship. Among studies consisting of blue collar and nursing/healthcare workers the relationship between general health and WA was stronger, $\bar{r}=.58$ compared to studies of white collar and mixed occupation workers, $\bar{r}=.41, Q=6.14, p=.01$. No differences were found in the effect size estimate between studies of blue collar, $\bar{r}=.58$, and nursing/healthcare samples, $\bar{r}=.58, Q=.00$, $p=.99$. Similarly, there was no difference when comparing the effect sizes from studies of white collar, $\bar{r}=.37$ and mixed occupation samples, $\bar{r}=.41, Q=.09, p=.77$. The mean age of the sample was also found to be a marginally significant moderator of the relationship between general health and WA. In studies that consisted of younger workers the relationship between general health and WA was stronger than in studies where the sample consisted of older workers, $b=-.01, Z=1.74, p=.08$ (H20; see Table 4).

Physical health (Hypothesis 8b). A total of 15 studies investigated physical health in relation to WA. There was a positive relationship between physical health and WA, which supports hypothesis $8 \mathrm{~b}, \bar{r}=.45,95 \% \mathrm{CI}[.28, .59]$. The test of heterogeneity indicated that there may be moderators to this relationship, $Q=1,857.57, p<.01, I^{2}=$ 
99.25. The relationship between physical health and WA was not moderated by the WA measure, $Q=.04, p=.85$ (RQ1; see Table 2), the occupation of the participants, $Q=.14$, $p=.99(\mathrm{H} 19 ;$ see Table 3$)$, or the mean age of the sample, $b=.00, Z=.03, p=.98(\mathrm{H} 20$; see Table 4).

Mental health (Hypothesis 8c). Thirty-five studies assessed mental health in relation to WA. The estimated relationship between mental health and WA was positive, and supported hypothesis $8 \mathrm{c}, \bar{r}=.42,95 \%$ CI $[.34, .49]$. The test for heterogeneity of the effect sizes suggested that there may be moderators to this relationship, $Q=4,308.30, p<$ $.01, I^{2}=99.21$. Despite the heterogeneity test suggesting there may be moderators to this relationship, the relationship between mental health and WA was not moderated by the WA measure being used, $Q=.04, p=.84$ (RQ1; see Table 2), the occupation of the sample, $Q=2.44, p=.49(\mathrm{H} 19$; see Table 3$)$, or the mean age of the sample, $b=.01, Z=$ $.72, p=.47,(\mathrm{H} 20 ;$ see Table 20$)$.

BMI (Hypothesis 9a). A total of 26 studies were analyzed that assessed BMI and WA. Hypothesis 9a was supported, and BMI was negatively related to WA, $\bar{r}=-.14$, 95\% CI [-.17, -.10]. The test for heterogeneity among the effect size estimates indicated that there may be moderators to this relationship, $Q=105.96, p<.01, I^{2}=76.41$, (see Table 1). There was a marginally significant difference in the strength of the relationship between BMI and WA when comparing studies that use the WAI to those that used a perceived measure of WA. When using the WAI, the relationship between WA and BMI was stronger $(\bar{r}=-.16)$ than the strength of the relationship when using perceived measures of WA $(\bar{r}=-.10), Q=2.31, p=.13$ (RQ1; see Table 2). The relationship 
between BMI and WA was not moderated by the occupation of the sample, $Q=.46, p=$ .93 (H19; see Table 3), or the mean age of the sample, $b=.002, Z=.77, p=.44(\mathrm{H} 20$; see Table 4).

Pain (Hypothesis 9b). Twenty-six studies assessed individuals' perception of pain and WA. In support of hypothesis 9b, individuals' perception of pain was negatively related to WA, $\bar{r}=-.40,95 \% \mathrm{CI}[-.45,-.34]$. The tests for heterogeneity among the effect size estimates indicated that there could be moderators to this relationship, $Q=258.00, p$ $<.01, I^{2}=90.31$ (see Table 1). The relationship between pain and WA differed based on the WA measure used, such that in studies that used the WAI the relationship between WA and pain was stronger, $\bar{r}=-.43$ compared to studies where perceived measures of WA were used, $\bar{r}=-.32, Q=4.62, p=.03$ (RQ1; see Table 2). The relationship between pain and WA was not moderated by the occupation of the sample, $Q=.98, p=.81(\mathrm{H} 19$; see Table 3), or the mean age of the sample, $b=.003, Z=.48, p=.63$ (H20; see Table 4).

Musculoskeletal disease (Hypothesis 9c). Nine studies assessed MSD and WA. The relationship between MSD and WA was negative, which supports hypothesis 9c, $\bar{r}=$ $-.23,95 \%$ CI $[-.30,-.16]$. Tests of the heterogeneity among effect size estimates indicated that there may be moderators to this relationship, $Q=135.16, p<.01, I^{2}=94.08$ (see Table 1). There was a significant difference in the strength of association between MSD and WA based on the WA measure used, such that in studies that used the WAI the relationship between MSD and WA was stronger, $\bar{r}=-.34$, than in studies that used perceived measures of WA, $\bar{r}=-.19, Q=3.95, p=.047$ (RQ1; see Table 2). Occupation was a moderator of the relationship between MSD and WA. Among blue collar workers, 
the relationship between MSD and WA was weaker, $\bar{r}=-.09$ compared to studies that consisted of workers in white collar, nursing/healthcare, or mixed occupation $(\bar{r}=-.23$ to -.31), $Q=16.27, p=.01$. Orthogonal post-hoc contrasts were conducted to better understand this effect. Among studies that sampled blue collar workers, the relationship between MSD and WA was weaker, $\bar{r}=-.09$ compared to studies that samples from nursing/healthcare, white collar, and mixed occupation groups, $\bar{r}=-.28, Q=13.60, p<$ .01. No differences were found when comparing studies of nursing/healthcare workers $\bar{r}$ $=-.29$ to studies of white collar and mixed occupation groups, $\bar{r}=-.28, Q=.02, p=.89$. Similarly, no differences were found when comparing studies of white collar workers to mixed occupation studies, $\bar{r}=-.31, Q=1.70, p=.19$. The strength of the relationship between MSD and WA also differed based on the mean age of the sample. Among studies that consisted of younger workers, the relationship between MSD and WA was stronger, compared to the relationship between MSD and WA in studies consisting of older workers, $b=.02, Z=2.14, p=.03, R^{2}=.35$ (H20; see Table 4).

\section{Health Behaviors (Hypotheses 10-11)}

Smoking (Hypothesis 10a). A total of 22 studies were analyzed that assessed smoking and WA. Smoking was negatively related to WA, which supported hypothesis $10 \mathrm{a}, \bar{r}=-.09,95 \% \mathrm{CI}[-.12,-.05]$. Tests of the heterogeneity of the effect size estimates suggested that there could be moderators to this relationship. $Q=58.43, p<.01, I^{2}=$ 58.43 (see Table 1). Although the heterogeneity estimate suggested there could be moderators to this relationship, there was no evidence that the WA measure, $Q=.94, p=$ 
.33 (RQ1; see Table 2), the occupation of the sample, $Q=2.69, p=.44$ (H19; see Table 3 ), or the mean age of the sample, $b=.002, Z=.93, p=.35$ (H20; see Table 4).

Alcohol consumption (Hypothesis 10b). Thirteen studies assessed the relationship between alcohol consumption and WA. Contrary to hypothesis $10 \mathrm{~b}$, alcohol consumption was not related to WA $(\bar{r}=-.01,95 \% \mathrm{CI}=-.05, .03)$. Tests of the heterogeneity of the effect sizes did suggest this relationship may be moderated by other factors, $Q=40.88, p$ $<.01, I^{2}=70.65$ (see Table 1$)$. The relationship between alcohol consumption and WA was not moderated by the WA measure, $Q=.35, p=.55$ (RQ1; see Table 2), by the occupation of the sample, $Q=.63, p=.89$ (H19; see Table 3$)$, or by the age of the sample, $b=-.004, Z=-1.09, p=.28$ (H20; see Table 4).

Physical activity (Hypothesis 11). A total of 25 studies were included in the metaanalysis that assessed physical activity and WA. In support of hypothesis 11, physical activity was positively linked to WA, $\bar{r}=.15,95 \%$ CI $[.11, .18]$. The test for heterogeneity suggested there could be moderators to this relationship, $Q=64.15, p<$ $.01, I^{2}=62.59$ (see Table 1 ). Despite the heterogeneity of the effect sizes, the moderators assessed in this study, the WA measure, $Q=1.21, p=.27$ (RQ1; see Table2), the occupation of the sample, $Q=3.59, p=.31$ (H19; see Table 3), and the age of the sample, $b=.001, Z=.33, p=.74$ (H20; see Table 4), did not moderate this relationship.

\section{Age (Hypothesis 12)}

Age (Hypothesis 12). A total of 94 studies investigated the relationship between age and WA. The findings supported hypothesis 12, and showed that age and WA were negatively related $\bar{r}=-13,95 \%$ CI [-.15, -.11] (see Table 1). The test for heterogeneity 
in these effect size estimates suggested that there were moderators to this relationship, $Q$ $=1,533.45, p<.01, I^{2}=93.94$ (see Table 1$)$. The WA measure showed a marginal moderating effect on this relationship, such that in studies where the full WAI was used the relationship between age and WA was $\bar{r}=-.14$, whereas in studies that used perceived measures of WA, the relationship between age and WA was $\bar{r}=.11, Q=1.82$, $p=.18$ (RQ1; see Table 2). The relationship between age and WA did not differ based on the sample's occupation, $Q=2.42, p=.49$, or the mean age of the sample, $b=.00, Z=-$ $.03, p=.98$.

\section{Job Outcomes (Hypotheses 13-14)}

Job satisfaction (Hypothesis 13). In total, ten studies investigated the link between WA and job satisfaction. In support of hypotheses 13 , WA was positively related to job satisfaction, $\bar{r}=.23,95 \% \mathrm{CI}[.20, .26]$ (see Table 1 ). The test of heterogeneity suggested there unlikely to be moderators to this relationship, $Q=13.09, p=.16 I^{2}=31.22$ (see Table 1). Despite the homogeneity among the effect size estimates, the planned moderator analyses were conducted to answer the research question, and test the proposed hypotheses. There was a marginally significant moderating effect of the WA measure on the relationship between WA and job satisfaction, such that for studies that used the WAI the relationship between WA and job satisfaction was weaker $\bar{r}=.21$ compared to studies that used perceived measures of WA, $\bar{r}=.24 Q=3.01, p=.08$ (RQ1; see Table 2). The majority of studies (8 of the 10) that assessed the relationship between WA and job satisfaction included mixed samples of workers, thus comparisons across occupation types were not able to be estimated. The relationship between job 
satisfaction and WA was not moderated by the age of the sample, $b=-.001, Z=-.23, p=$ .81 (H20; see Table 4).

Self-rated job performance (Hypothesis 14). Four studies assessed WA and selfrated job performance. In support of hypothesis 14 , the relationship between WA and self-rated job performance was positive $\bar{r}=.19,95 \%$ CI $[.13, .25]$. Test of heterogeneity suggested that it was unlikely that there were moderators to this relationship, $Q=3.23, p$ $=.36, I^{2}=7.21$ (see Table 1$)$. The type of WA measure used showed a slight (nonsignificant) moderating effect on the relationship between WA and self-rated job performance, such that studies that used perceived measures of WA showed a slightly stronger relationship between WA and self-rated job performance $\bar{r}=.23$ compared to studies that used the WAI, $\bar{r}=.19, Q=1.99, p=.16$ There were not enough studies within a given occupation to assess occupation as a moderator of the WA and job performance relationship. The link between job performance and WA was not moderated by the mean age of the sample $b=-.003, Z=-1.02, p=.31$ (H20; see Table 4$)$.

\section{Strain Outcomes (Hypothesis 15)}

Burnout (Hypothesis 15). Seven studies assessed burnout and WA. In support of hypothesis 15 , burnout was negatively related to WA, $\bar{r}=-.47,95 \%$ CI $[-.55,-.40]$. The test of heterogeneity suggested that there may be moderators to this relationship, $Q=$ 74.31, $p<.01, I^{2}=91.93$ (see Table 1). Although not significant, there did appear to be a general trend of differences in the strength of the relationship between burnout and WA depending on the WA measure being used. In studies that used the WAI, the relationship between burnout and WA was $\bar{r}=-.53$ whereas in studies that used perceived measures 
of WA, the relationship between burnout and WA was $\bar{r}=-.43, Q=2.33 p=.13$ (RQ1; see Table 2). The occupation of the sample did not moderate the relationship between burnout and WA, $Q=.01, p=.94$ (H19; see Table 3 ). There was a marginally significant moderating effect of the sample age on the relationship between burnout and WA. In studies consisting of younger workers, the relationship between WA and burnout was stronger compared to studies consisting of older workers, $b=.06, Z=1.46, p=.15, R^{2}=$ .65 (H20; see Table 4).

\section{Exit Behaviors (Hypotheses 16-18)}

Absenteeism (Hypothesis 16). Nine studies assessed absenteeism and WA. In support of hypothesis 16 , the relationship between absenteeism and WA was negative $\bar{r}$ $=-.17,95 \% \mathrm{CI}[-.25,-.14]$. The test for heterogeneity suggested there could be moderators to this relationship, $Q=656.25, p<.01, I^{2}=85.78$ (see Table 1 ). There was a marginally significant moderating effect for the type of WA measure on the relationship between absenteeism and WA, such that in studies that used the WAI the relationship between WA and absenteeism was stronger, $\bar{r}=-.53$, than in studies where perceived measures of WA were used, $\bar{r}=-.43, Q=2.33, p=.13$ (RQ1; see Table 2). The majority of studies that assessed WA and absenteeism consisted of mixed occupational groups (7 of the 9 studies) and thus, the moderating effect of occupation on the relationship between absenteeism and WA was not assessed. There was a marginally significant moderating effect of the mean sample age on the relationship between WA and absenteeism, such that in studies consisting of younger workers the relationship between 
absenteeism and WA as stronger compared to studies that consisted of older workers, $b=$ $.01, Z=1.38, p=.17, R^{2}=.00(\mathrm{H} 20$; see Table 4$)$.

Disability (Hypothesis 17). In total, seven studies investigated the relationship between WA and future disability status. In support of hypothesis 17, WA was negatively related to disability status, such that higher levels of WA predict lower levels of disability in the future, $\bar{r}=-.28,95 \% \mathrm{CI}[-.37,-.18]$ (see Table 1). The test of heterogeneity suggested that there may be moderators to this relationship, $Q=40.75, p<.01, I^{2}=85.28$ (see Table 1). The strength of the relationship between disability and WA depended on the type of WA measure being used. In studies that used the WAI, the relationship between WA and disability was stronger $(\bar{r}=-.42)$, whereas in studies that used measures of perceived WA the relationship between WA and disability was $(\bar{r}=-.23), Q$ $=5.67, p=.02$ (RQ1; see Table 3$)$. The occupation of the sample did not moderate the relationship between WA and future disability status, $Q=1.10, p=.58$ (H19; see Table 3). The strength of the relationship between WA and disability was moderated by the age of the sample. In studies that consisted of older workers, WA was less predictive of disability status than it was in studies that consisted of younger samples of workers, $b=$ $.02, Z=3.10, p<.01, R^{2}=.81(\mathrm{H} 20 ;$ see Table 4$)$.

Retirement intentions (Hypothesis 18a). Five studies were included that estimated the strength of the relationship between WA and retirement intentions. WA was negatively related to retirement intentions, which supports hypothesis $18 \mathrm{a}, \bar{r}=-.36,95 \%$ CI $[-.55,-.12]$, and tests of the heterogeneity of the effect size estimates suggested that there may be moderators to this relationship, $Q=431.20, p<.01, I^{2}=99.07$ (see Table 
1). The WA measure as a moderator of the WA to retirement intentions relationship, such that, when measured using the WAI retirement intentions were strongly related to WA $\bar{r}=-.56$, however when perceived measures of WA were used WA was weakly related to retirement intentions, $\bar{r}=-.20, Q=9.48, p<.01$ (RQ1; see Table 2). There were not enough studies from specific occupational groups to test occupation as a moderator to this relationship. The age of the sample was not a statistically significant moderator of the relationship between retirement intentions and WA, however there was a slight general trend suggesting that WA might be more strongly related to retirement intentions in studies consisting of younger workers rather than older samples of workers, $b=.15, Z=1.39, p=.16(\mathrm{H} 20 ;$ see Table 4$)$.

Retirement (Hypothesis 18b). Four studies were identified that investigated the strength of association between WA and retirement. In support of hypothesis 18b, WA was negatively related to retirement, $\bar{r}=-.19,95 \%$ CI [-.25, -.11]. The test for heterogeneity among the effect sizes suggested that there might be moderators to this relationship, $Q=16.10, p<.01, I^{2}=81.37$ (see Table 1 ). The type of WA measure did moderate the relationship between WA and retirement. In studies that used the WAI the relationship between WA and retirement was stronger, $\bar{r}=-.32$ compared to studies used perceived measures of WA, $\bar{r}=-.14, Q=5.27, p=.02$. Given the limited number of studies, occupation was not able to be tested as a moderator to the relationship between WA and retirement, however ostensibly the effect sizes did vary among occupations from $\bar{r}=-.16$ to $\bar{r}=-.37$ between studies of white collar, blue collar, and mixed occupation 
groups (H19; see Table 3). Age did not moderate the relationship between WA and retirement, $b=-.01, Z=-.48, p=.63(\mathrm{H} 20$; see Table 4$)$.

\section{Moderators}

WA Measure (Research question 1). The results indicate that the measure used to assess WA does influence the relationships between WA and some, but not all of its correlates (see Table 2). The type of WA measure moderated the relationships between WA and pain, MSD status, future disability status, retirement intentions, and actual retirement. Additionally, there was a marginal moderating effect of the type of WA measure on the relationships between WA and coworker support, BMI, age, job satisfaction, and burnout. However in all other cases, there was insufficient evidence to suggest that the relationship between WA and its correlates was moderated by the WA measure being used. In each of these moderations except job satisfaction and job performance, the WAI was more strongly associated with the correlate of interest compared to perceived measures of WA. Based on these findings, I found partial support for the type of WA measure moderating the relationships between WA and its correlates.

Occupation (Hypothesis 19). The occupation that a study sampled from moderated the relationship between WA and the following constructs: physical job demands, job control, and MSD status, Additionally, there was a marginal moderating effect on the relationships between WA and perceptions of injustice, core self-evaluations, and general health. In the majority of cases, the relationships between WA and its correlates was weaker for studies of blue collar workers compared to studies of other occupation groups. Unfortunately, in several instances there were an insufficient number of available studies 
to fully examine occupation as a moderator in this study. Based on these findings, partial support was found for Hypothesis 19, that occupation moderates the relationships between WA and its correlates. Age (Hypothesis 20). Hypothesis 20, that age would moderate the relationships between WA and its correlates, such that the relationships would be stronger for older workers was generally not supported. However, there was support for age as a moderator. The key difference being that in many cases WA was most strongly related to its correlates in younger samples rather than older samples. Age moderated the relationships between WA and physical demands, job control, and future disability status. Additionally, there was a marginal moderating effect of the study sample age on general health, burnout, absenteeism, and retirement intentions. In the majority cases, WA was more predictive of the correlate of interest among younger rather than older samples of workers. However, in other cases (e.g., job control) the relationship between the correlate and WA was stronger for older workers. Based on these findings, my hypothesis was generally unsupported, however age was still found to be a moderator of some relationships between WA and its correlates. 


\section{Discussion}

In support of the proposed hypotheses and theoretical arguments, the results of this study indicate that WA is related to a variety of occupational and individual antecedents and outcomes. In line with the hypotheses made based on the JD-R framework, WA was negatively related to job demands and positively related to both job and personal resources across each demand and resource type assessed in this meta-analysis. These findings imply that occupational factors, which may be under the control of the employer and perhaps even the employee (e.g., increasing job resources), may play a crucial role in maintaining high levels of WA.

Interestingly, the relationships between health-oriented behaviors and WA were weaker than the relationships between WA and occupational factors (e.g., job demands and resources). This suggests that occupational factors are at least equally important to the development of WA as personal behaviors, and perhaps more important. This finding supports the use of future workplace interventions aimed at promoting WA. Given the identified relationship between WA and exit from the workforce (e.g., disability, retirement), results also suggest that WA may be a key mechanism in extending working careers and retaining older workers. Although statistical tests used in this meta-analysis do not allow for causal inference, many studies were longitudinal in nature and suggest a temporal development of WA through job resources (e.g., job control, supervisor support) and personal resources (e.g., self-efficacy, individual health).

Although the conceptual model (see Appendix A) suggests a temporal component in the relationships between WA, its antecedents, and its outcomes, the relationships 
tested in this study consist of both cross-sectional and longitudinal data. However, the majority of studies conceptualized the correlates of WA in a similar manner as I have presented them in this study. For example, when studied in a longitudinal manner, the existing research generally views job demands and resources as antecedents to WA, and thus these demands and resources are measured at Time 1, whereas WA is measured at Time 1 and Time 2 in order to assess changes in WA (e.g., Airila et al., 2014; McGonagle et al., 2015). Accordingly, when assessing disability and retirement, WA was always assessed prior to disability or retirement status. Thus, although I am unable to infer causality based on the results of the present study, there is both theoretical and empirical evidence suggesting that these relationships are associated in the temporal manner I have discussed here.

Although most of the hypotheses were supported, there were some additional unsupported or partially support hypotheses. In terms of the direct hypothesized relationships, the only estimated effect size that was not significant was alcohol consumption. Alcohol use is complex in that it is associated with both positive and negative health and wellbeing outcomes. It may be that binge drinking and excessive alcohol consumption lead to lower levels of WA, whereas a moderate amount of alcohol does not have the same negative effects - or may even be beneficial. Unfortunately this level of detail regarding the alcohol consumption was not available in the present analysis. Future studies should test for these more nuanced relationships, or perhaps even curvilinear relationships. 
In general, the health-related correlates were most strongly associated with WA. This is not surprising in that the WAI includes objective indicators of health. However, it is important to also note that these health measures explain at most $25 \%$ of the variance in WA. Thus, WA should not be viewed simply as a proxy for health, but rather as a more complete picture of a worker's functional capacities (mental and physical ability), health, and the environmental factors associated with workers' ability to meet the demands of their job. This also points to the potential for employer-based programs that support the health and well-being of employees as being critical for the maintenance and promotion of WA.

Some initial efforts to promote well-being, and specifically WA, have been made using workplace based interventions, and this study can help to inform future intervention efforts. Müller and colleagues (2016) introduced an intervention based on selection, optimization, and compensation theory and found significant improvements in mental health and well-being, but did not find increases in WA from baseline to follow-up (Müller, Heiden, Herbig, Poppe, \& Angerer, 2016). In a similar vein, findings from Ahlstrom and colleagues (2013) parallel some of the findings in the present study. They found that when a workplace rehabilitation program had supportive social structures (e.g., job control, social support, high-quality leadership) WA increased over time more than when individuals were provided with a rehabilitation program but did not receive the same supportive social structures. These findings in conjunction with the findings of the present study support the use of organization-based interventions and demonstrate the importance of the social context in organizations. 


\section{Moderators}

In line with the proposed research question and hypotheses, the influence of the moderators (type of WA measure, occupation, and sample age) were assessed for each relationship between WA and its correlates. The Q-statistic suggested the presence of moderators for many of these main effects, although the hypothesized moderators were not fully supported. This suggests there may be additional moderating variables which were untested in the present study.

WA measure. The type of WA measure moderated the relationship between WA and some of its correlates (e.g., disability, retirement). Specifically, the WAI was more strongly related to long-term outcomes (e.g., disability, retirement) and specific health indicators (e.g., pain, MSD) compared to perceived measures of WA. Thus, when studied in a health context, where the focus of the research is influencing health, or long-term job outcomes (e.g., retirement and disability), the WAI seems to offer the benefit of being more strongly correlated with other constructs of interest. However, in the majority of cases (14 of the 25 correlates assessed) there was no statistical difference (or marginally significant difference) in the strength of the relationship between WA and its correlates based on the WA measure. The WA measure did not moderate the relationship between WA and any of the job demand or health behavior constructs. Furthermore, the WA measure only moderated the relationship between WA and one of the job resources (coworker support) and did not moderate the relationship between WA and absenteeism. Thus, in the context of the workplace and a focus on job resources and demands, as well as more immediate outcomes (e.g., job performance, absenteeism) there appears to be no 
benefit to using the full WAI, and instead perceived WA appears to be an adequate alternative.

Occupation. Occupation moderated the relationships between WA and some of its correlates (e.g., physical job demands). However, in the majority of cases, there were either no differences in the relationship between WA and the correlate of interest based on occupation, or there was an insufficient number of studies conducted with specific occupation groups to test this moderation. Interestingly, it seemed that in some cases the findings were counterintuitive. For example, for blue collar workers the relationship between physical job demands and WA was weaker compared to the relationship between physical demands and WA for other occupations. This may be due in part to range restriction in physically demanding, blue collar occupations, or that blue collar workers unable to meet the physical demands of the job transition out of the field more quickly. Another important note is that these analyses were more tenuous than the other moderator analyses due to the large proportion of samples that included mixed groups of workers as opposed to workers from a specific occupation.

Sample age. Interestingly, for many constructs, WA was more strongly associated with the antecedent or outcome for younger rather than older workers. Although this was counter to my initial hypothesis, there appears to be a reasonable explanation to these findings. For younger workers dealing with significant health problems, the effects of these health problem may seem more atypical and be a greater detriment to their perceived ability to meet the job demands. On the other hand, older workers may have either already exited the workforce due to those health conditions, or developed better 
methods for dealing with their health conditions. Additionally, for older workers they may view these health problems as a more natural part of life and not feel the same stigmatization that a younger worker with a chronic health problem may feel.

\section{Future Research Paths}

Although WA has been studied in a diverse range of contexts, this study helped to identify areas where little research on WA has been conducted. The two primary areas in which there was a substantial lack of research was in the interplay between work and family (e.g., work family conflict) and psychosocial job resources. While supervisor support and to some extent supervisor relations has been studied, and shown to positively influence WA, other job resources such as task significance and task variety have only been studied in a limited capacity.

Another area not discussed in the extant WA literature is how age-related stereotyping, age diversity climate, and perceptions of age-related discrimination may influence WA. As the population continues to age, these stereotypes and the general treatment of older workers may play a large role in shaping individuals' perceptions of their ability to continue meeting the demands of their job. These underexplored areas are promising future research directions given the utility of WA in predicting a variety of job outcomes, and the finding that WA is negatively related to age itself.

\section{Contributions}

The results of this study help to inform the WA literature in a number of ways. First, this study compiles and synthesizes the existing literature on WA in a quantitative manner and embedded this synthesis in a robust theoretical framework. This is an 
important step for increasing the understanding and utility of WA given that the literature is currently fragmented among several disciplines. As evidence of the current fragmentation, slightly over half of the included studies were from medical journals (PubMed), whereas fewer than half of the studies were from non-medical journals (PsycINFO), after eliminating overlapping studies. Thus, the integration of these two literatures was needed in order to better understand the nomological network of WA, and work towards integrating the extant literature. Drawing on literature across a broad range of disciplines improves our understanding of how WA is related to a variety of antecedents and outcomes, but this only aides in our understanding of a construct if the literatures are integrated and summarized, which they had not been to this point.

Second, this study identifies the average effect sizes found between WA and a number of antecedents and outcomes. Several studies that investigated WA have included relatively large sample sizes, however this has also led to many relationships being identified as statistically significant even though the magnitude of these effects may be quiet small. Identifying the strength of these associations is critically important because it will inform researchers and practitioners about which factors most strongly influence WA and what outcomes are most strongly influenced by WA. This may be particularly useful for developing interventions aimed at promoting WA and retaining older workers.

Third, this study has identified gaps in the existing literature and constructs that future studies should investigate in relation to WA. Although recent calls for more studies investigating psychosocial factors and WA have been made (e.g., Feldt et al., 2009; Ilmarinen, 2009) this study helps to identify specifically which factors have and have not 
been sufficiently studied in relation to WA. As mentioned earlier, the domains of workfamily balance, a broader array of job resources, discrimination (including age-related discrimination), and a broader range of supervisor behaviors and leadership styles all represent potentially fruitful areas of future research and gaps in the existing literature.

Fourth, this study examined potential moderators of the relationships between WA and its correlates. This helps to determine for whom each of the antecedents to WA are most influential and for whom WA is most predictive of the outcomes included in this study. This study found that for many of long term outcomes (e.g., retirement, disability), it may be useful to prioritize using the full WAI because studies using the WAI found a stronger relationship between WA and those outcomes. In addition, this study found that for the majority of the relationships assessed in this meta-analysis, the relationship with WA was relatively stable (e.g., health, job resources). As more primary studies are conducted, additional moderators such as country of origin can be assessed in this same framework to provide a more accurate picture of the development and maintenance of WA.

Fifth, although the United States is facing a demographic shift to an older workforce, IO/OB researchers in the United States have been slower than those in other countries to adopt research efforts to better understand effective methods and policies for meeting the challenges of an aging workforce. Although that trend has begun to shift with some recent large scale studies (e.g., McGonagle et al., 2015) on these topics, these topics have been given more attention by researchers outside of North America. Given that WA has been linked to important health and workplace outcomes, future studies investigating 
the challenges of an aging workforce or exit from the workforce should consider including WA in their study design. The increased use of WA in recent publications from the United States (e.g., McGonagle et al., 2015) suggest that researchers in the United States are beginning to consider WA in research on the challenges of an aging workforce. However, the integration of WA into the IO and OB literatures and the study of WA in the United States is still relatively new and can clearly be more thoroughly developed. Due to the extensive use of the WA construct internationally, I believe that future research endeavors, particularly those focused on exit from the workforce and the challenges of an aging workforce, should consider incorporating WA in some manner.

Finally, this study helps to identify potential mechanisms for the target of interventions aimed at retaining older workers and extending working careers (e.g., increased job control, reduction in perceptions of injustice). Given the identified relationship between WA and exit from the workforce, it is important for researchers developing interventions to know which factors influence WA and thus which factors may directly or indirectly influence exit from the workforce. This aligns with the original intent of the construct of WA, meeting the challenges of an aging workforce, and does so in a holistic manner that includes constructs across a variety of disciplines. One of the key advantages to this approach is that it also provides information about which antecedents and outcomes are most strongly related to WA in specific occupation and age groups. Furthermore, the findings of this study can help inform researchers developing WA interventions as to which WA measure is most appropriate given their study design, and antecedents/outcomes of interest. 


\section{Limitations}

Although this study has many strengths, there are also some limitations. The most important limitation is the relatively small number of available studies that assessed certain correlates of WA. Although there were several constructs with at least 10 studies available, there were only a few available studies that investigated some of the most important outcomes for organizations (e.g., actual retirement and job performance). This issue should be addressed by both additional primary studies, and more comprehensive reporting in journal articles to help facilitate meta-analytic efforts. Due to these limiting factors, assessing moderators of the estimated effect sizes was not possible for certain correlates of WA. Although there were some limitations due to the number of available studies, I was able to assess the relationships between WA and 25 of its correlates, thus establishing a solid starting point and foundation for the nomological network of WA.

A second limitation of this study is that the moderator of occupation in many cases had a large number of mixed employee groups, that is, samples where employees were in many occupations. This is due in part to the nature of how WA has been studied, and that there have been several longitudinal and nationally representative samples drawn by researchers. These studies yield more heterogeneous samples which allow the primary study to be more generalizable but diminish the ability our ability to compare the nomological network of WA across specific occupations. This may be particularly useful in safety-sensitive occupations and occupations where individuals are tasked with high levels of job demands. Although this did not allow for some moderator analyses by occupation, the mixed samples were heterogeneous and thus, the overall effect sizes 
between WA and the correlate of interest likely carry over to some degree in the vast majority of occupations. Additionally, the moderator of occupation was assessed and found to be important for several of the direct effects (e.g., job control). Thus, although it could have been a more fruitful set of analyses, there were important findings from these analyses that contribute to the existing literature.

A third limitation of the present study is the potential for the "file drawer" problem. That is, there were no checks for publication bias in the present study. Future research should address this through two methods. First, future research should solicit unpublished work from researchers to better assess the potential for publication bias directly. Second, publication bias could be assessed using a funnel plot with the Egger's test (Egger, Smith, Schneider, \& Minder, 1997) or the "trim and fill" method (Duval \& Tweedie, 2000). Although the potential issue of publication bias will be addressed directly in future research, there are also reasons to be confident in the results presented in this study. In many of the studies, the relationship between WA and an individual correlate included in this meta-analysis was not the focal interest in the research paper. Thus, the premise behind the "file drawer" problem, that only studies finding a significant effect would be included, may not be as prominent of an issue relative to other meta-analyses. For example almost no studies were designed explicitly to assess the relationship between age and WA, however we were able to collect enough information from 94 studies to meta-analyze the relationship between age and WA.

Finally, one of the primary challenges with the existing WA literature is the number of studies that seemingly assessed WA and antecedents or outcomes of interest, 
but only published adjusted or multivariate analyses of the relationship between those constructs and WA. Without more uniform reporting standards across the various disciplines that study WA, this will likely remain an issue for future meta-analytic efforts in regard to WA. In order to overcome some of these issues, we used actual counts, and group means when available, to supplement articles that provided effect sizes estimates. This effort included a detailed and thorough check in each article, and in many cases did allow us to obtain some usable effect sizes estimate even when the focal point of the article was a multivariate model.

\section{Conclusion}

In sum, the present study has synthesized an existing body of literature which had yet to be quantitatively synthesized. Through the use of meta-analysis, this study provides estimates of the strength of the relationships between WA and its correlates and has identified moderators to these relationships. This study informs the current literature and provide a starting point for researchers to develop interventions aimed at promoting and maintaining WA and retaining older workers. Furthermore this study provides a clear rationale for researchers across disciplines to consider a broader array of factors when investigating WA. This study should also serve as a call for researchers in the United States and other nations where WA has been less frequently studied to incorporate WA into their future studies. Specifically, IO and OB researchers, who as a group have incorporated WA in only a handful of studies should make a pointed effort to include this construct in future studies related to disability, retirement, and aging. Given the links to important health and workplace outcomes and the continually aging workforce, WA 
appears to be a construct worth considering in future research endeavors, particularly those focused on the challenges of an aging workforce and extending working careers.

Table 1 Meta-Analytic Estimates-Direct Effects

Random Effects Meta-Analytic Estimates of the Relationships between Work Ability and its Antecedents and Outcomes

\begin{tabular}{|c|c|c|c|c|c|c|c|}
\hline \multirow[b]{2}{*}{ Antecedent/Outcome } & \multicolumn{7}{|c|}{$95 \% \mathrm{CI}$} \\
\hline & $n$ & $k$ & $\bar{r}$ & Lower & Upper & $Q$ & $I^{2}$ \\
\hline \multicolumn{8}{|l|}{ Job Demands } \\
\hline Physical Job Demands & 15,353 & 24 & -.16 & -.20 & -.12 & $317.81^{*}$ & 92.76 \\
\hline Justice Perceptions & 11,963 & 14 & -.29 & -.38 & -.20 & $271.08 *$ & 95.20 \\
\hline Quantitative Job & 18,639 & 26 & -.15 & -.20 & -.10 & $378.15^{*}$ & 93.39 \\
\hline \multicolumn{8}{|l|}{ Demands } \\
\hline $\begin{array}{l}\text { Emotional/Mental } \\
\text { Demands }\end{array}$ & 5,060 & 8 & -.17 & -.26 & -.08 & $114.28 *$ & 93.88 \\
\hline \multicolumn{8}{|l|}{$\begin{array}{l}\text { Demands } \\
\text { Job Resources }\end{array}$} \\
\hline Supervisor Support & 17,244 & 20 & .21 & .17 & .25 & $129.06^{*}$ & 85.28 \\
\hline Coworker Support & 9,432 & 12 & .25 & .20 & .30 & $59.23 *$ & 81.43 \\
\hline Job Control & 25,592 & 29 & .19 & .15 & .23 & $426.11 *$ & 93.43 \\
\hline \multicolumn{8}{|l|}{ Personal Resources } \\
\hline Core Self-Evaluations & 4,682 & 12 & .34 & .27 & .41 & $52.97 *$ & 79.23 \\
\hline \multicolumn{8}{|l|}{ Health } \\
\hline General Health & 33,456 & 32 & .44 & .37 & .50 & $6,715.36^{*}$ & 99.54 \\
\hline Physical Health & 10,187 & 15 & .45 & .29 & .59 & $1,857.57 *$ & 99.25 \\
\hline Mental Health & 29,360 & 35 & .42 & .34 & .49 & $4,308.30 *$ & 99.21 \\
\hline BMI & 16,595 & 26 & -.14 & -.17 & -.10 & $105.96 *$ & 76.41 \\
\hline Pain & 12,906 & 26 & -.40 & -.45 & -.34 & $258.00^{*}$ & 90.31 \\
\hline Musculoskeletal & 7,487 & 9 & -.23 & -.30 & -.16 & $135.16^{*}$ & 94.08 \\
\hline \multicolumn{8}{|l|}{ Disease (MSD) } \\
\hline \multicolumn{8}{|l|}{ Health Behaviors } \\
\hline Smoking (Tobacco) & 16,890 & 22 & -.09 & -.12 & -.05 & $58.43 *$ & 64.06 \\
\hline Alcohol Consumption & 13,268 & 13 & -.01 & -.05 & .03 & $40.88 *$ & 70.65 \\
\hline Exercise & 9,630 & 25 & .15 & .11 & .18 & $64.15^{*}$ & 62.59 \\
\hline \multicolumn{8}{|l|}{ Demographics } \\
\hline Age & 81,201 & 94 & -.13 & -.15 & -.11 & $1,533.45^{*}$ & 93.94 \\
\hline \multicolumn{8}{|l|}{ Job Outcomes } \\
\hline Job Satisfaction & 14,155 & 10 & .23 & .20 & .26 & 13.09 & 31.22 \\
\hline Self-Rated Job & 11,291 & 4 & .23 & .21 & .25 & 3.23 & 7.21 \\
\hline \multicolumn{8}{|l|}{ Performance } \\
\hline \multicolumn{8}{|l|}{ Strain Indicator } \\
\hline Burnout & 6,864 & 7 & .47 & .55 & .40 & $74.31 *$ & 91.93 \\
\hline \multicolumn{8}{|l|}{ Exit Behaviors } \\
\hline Absenteeism & 11,682 & 9 & -.19 & -.25 & -.14 & $56.25 *$ & 85.78 \\
\hline
\end{tabular}


Table 1 (continued)

\begin{tabular}{lrrrrrrc}
\hline & & \multicolumn{7}{c}{$95 \%$ CI } \\
Antecedent/Outcome & $n$ & $k$ & $\bar{r}$ & Lower & Upper & $Q$ & $I^{2}$ \\
\hline Disability & 4,006 & 7 & -.28 & -.37 & -.18 & $40.75^{*}$ & 85.28 \\
Retirement Intentions & 7,082 & 5 & -.36 & -.55 & -.12 & $431.30^{*}$ & 99.07 \\
Retirement & 5,598 & 4 & -.19 & -.25 & -.11 & $16.10^{*}$ & 81.37 \\
\hline
\end{tabular}

Note. All analyses were conducted using random effects models to compute the weighted average correlation coefficient $(\bar{r}), k=$ the number of samples included (individual studies may have multiple samples). $Q=$ Indicates the presence of heterogeneity in effect size estimates which suggests moderators may be able to explain some of the variability among effect size estimates. $I^{2}$ indicates the percentage of variance in the effect size estimates that is unaccounted for. *Indicates a significant $Q$ statistic at $p<.01$.

Table 2 Meta-Analytic Estimates-Moderated by WA Measure Mixed Effects Meta-Analytic Estimates of the Relationships Between WA and its Antecedents and Outcomes (by WA Measure)

\begin{tabular}{lccccccc}
\hline $\begin{array}{l}\text { Antecedent/ } \\
\text { Outcome }\end{array}$ & WA & & & \multicolumn{4}{c}{$95 \%$ CI } \\
\hline Job Demands & & $k$ & $n$ & $\bar{r}$ & Lower & Upper & $Q$ \\
$\begin{array}{l}\text { Physical Job } \\
\text { Demands }\end{array}$ & WAI & 11 & 6,670 & -.17 & -.24 & -.10 & \\
& Perc. WA & 13 & 8,683 & -.16 & -.22 & -.09 & .10 \\
Justice Perceptions & WAI & 13 & 6,117 & -.32 & -.42 & -.20 & \\
& Perc. WA & 2 & 5,846 & -.19 & -.43 & .08 & .80 \\
& & & & & & & \\
Quantitative Job & WAI & 12 & 4,970 & -.14 & -.22 & -.06 & \\
Demands & Perc. WA & 14 & 13,669 & -.16 & -.24 & -.09 & .23 \\
& & & & & & & \\
Emotional/Mental & WAI & 4 & 1,658 & -.25 & -.39 & -.10 & \\
Demands & Perc. WA & 4 & 3,402 & -.11 & -.26 & .04 & 1.59 \\
& & & & & & & \\
Job Resources & & & & & & & \\
Supervisor Support & WAI & 5 & 3,822 & .23 & .15 & .31 & \\
& Perc. WA & 15 & 13,422 & .20 & .15 & .25 & .33 \\
Coworker Support & WAI & 3 & 979 & .32 & .22 & .42 & \\
& Perc. WA & 9 & 8,453 & .23 & .17 & .29 & $2.14 \dagger$ \\
Job Control & WAI & 11 & 6,064 & .19 & .12 & .26 & \\
& Perc. WA & 19 & 19,528 & .19 & .13 & .24 & .01
\end{tabular}

Personal

Resources 
Table 2 (continued)

\begin{tabular}{lccccccc}
\hline Antecedent/ & WA & & & \multicolumn{5}{c}{$95 \%$ CI } \\
Outcome & Measure & $k$ & $n$ & $\bar{r}$ & Lower & Upper & $Q$ \\
\hline Core Self- & WAI & 4 & 809 & .38 & .27 & .48 & \\
Evaluations & Perc. WA & 8 & 3,873 & .31 & .23 & .39 & .97 \\
Health & & & & & & & \\
General Health & WAI & 17 & 13,375 & .49 & .36 & .60 & \\
& Perc. WA & 15 & 20,081 & .38 & .23 & .52 & 1.27 \\
Physical Health & WAI & 13 & 8,548 & .44 & .28 & .58 & \\
& Perc. WA & 2 & 1,639 & .48 & .04 & .77 & .04 \\
Mental Health & WAI & 26 & 18,071 & .42 & .33 & .51 & \\
& Perc. WA & 9 & 11,289 & .40 & .24 & .54 & .04 \\
BMI & WAI & 17 & 11,288 & -.16 & -.21 & -.11 & \\
& Perc. WA & 9 & 5,307 & -.10 & -.16 & -.05 & $2.31 \dagger$ \\
Pain & WAI & 18 & 6,820 & -.43 & -.49 & -.37 & \\
& Perc. WA & 8 & 6,086 & -.32 & -.41 & -.23 & $4.62^{*}$ \\
Musculoskeletal & WAI & 3 & 2,099 & -.34 & -.46 & -.21 & \\
Disease & Perc. WA & 6 & 5,388 & -.19 & -.27 & -.10 & $3.95 *$ \\
& & & & & & & \\
Health Behaviors & & & & & & & \\
Smoking & WAI & 13 & 11,258 & -.10 & -.14 & -.06 & \\
(Tobacco) & & & & & & & \\
& Perc. WA & 9 & 5,632 & -.07 & -.11 & -.02 & .94 \\
Alcohol & WAI & 7 & 9,098 & .003 & -.06 & .06 & \\
Consumption & Perc. WA & 6 & 4,170 & -.02 & -.09 & .04 & .35 \\
Physical activity & WAI & 16 & 6,024 & .13 & .08 & .18 & \\
& Perc. WA & 9 & 3,606 & .17 & .11 & .23 & 1.21
\end{tabular}

Demographics

Age

$\begin{array}{ccccccc}\text { WAI } & 62 & 59,132 & -.14 & -.17 & -.11 & \\ \text { Perc. WA } & 32 & 22,069 & -.11 & -.15 & -.07 & 1.82 \dagger\end{array}$

Job Outcomes

Job Satisfaction

$\begin{array}{ccccccc}\text { WAI } & 6 & 8,701 & .21 & .18 & .23 & \\ \text { Perc. WA } & 4 & 5,454 & .24 & .21 & .27 & 3.01 \dagger\end{array}$


Table 2 (continued)

\begin{tabular}{|c|c|c|c|c|c|c|c|}
\hline \multirow{2}{*}{$\begin{array}{l}\text { Antecedent/ } \\
\text { Outcome }\end{array}$} & \multicolumn{3}{|l|}{ WA } & \multicolumn{4}{|c|}{$95 \% \mathrm{CI}$} \\
\hline & Measure & $k$ & $n$ & $\bar{r}$ & Lower & Upper & $Q$ \\
\hline Self-Rated Job & WAI & 2 & 1,325 & .19 & .13 & .24 & \\
\hline Performance & Perc. WA & 2 & 9,966 & .23 & .21 & .25 & $1.99 \dagger$ \\
\hline \multicolumn{8}{|c|}{ Strain Indicator } \\
\hline \multirow[t]{2}{*}{ Burnout } & WAI & 3 & 1,797 & -.53 & -.61 & -.43 & \\
\hline & Perc. WA & 4 & 5,067 & -.43 & -.51 & -.34 & $2.33 \dagger$ \\
\hline \multicolumn{8}{|l|}{ Exit Behaviors } \\
\hline \multirow[t]{2}{*}{ Absenteeism } & WAI & 2 & 2,899 & -.21 & -.32 & -.10 & \\
\hline & Perc. WA & 7 & 8,783 & -.19 & -.25 & -.12 & .15 \\
\hline \multirow[t]{2}{*}{ Disability } & WAI & 2 & 934 & -.42 & -.55 & -.28 & \\
\hline & Perc. WA & 5 & 3,072 & -.23 & -.31 & -.14 & $5.67 *$ \\
\hline \multirow{2}{*}{$\begin{array}{l}\text { Retirement } \\
\text { Intentions }\end{array}$} & WAI & 2 & 1,493 & -.56 & -.69 & -.40 & \\
\hline & Perc. WA & 3 & 5,589 & -.20 & -.36 & -.02 & $9.48 *$ \\
\hline \multirow[t]{2}{*}{ Retirement } & WAI & 2 & 246 & -.32 & -.44 & -.18 & \\
\hline & Perc. WA & 2 & 5,352 & -.14 & -.21 & -.06 & $5.27 *$ \\
\hline
\end{tabular}

Note. All analyses were conducted using mixed effects models to compute the weighted average correlation $(\bar{r}) \cdot Q=$ represents the significance test for heterogeneity in the effect size estimates between the two subgroups (the full WAI compared to perceived WA). $k=$ the number of samples included (individual studies may have multiple samples). $\uparrow$ indicates a marginally significant effect $(p=.05-.20)$. *indicates a significant effect, $p<.05$.

Table 3 Meta-Analytic Estimates-Moderated by Occupation Mixed Effects Meta-Analytic Estimates of the Relationships Between WA and its Antecedents and Outcomes (by Occupation)

\begin{tabular}{lccccccc}
\hline & \multicolumn{8}{c}{$95 \%$ CI } \\
Antecedent/Outcome & $k$ & $n$ & $\bar{r}$ & Lower & Upper & $Q$ & $p$ \\
\hline Job Demands & & & & & & & \\
Physical Job Demands & 24 & 15,353 & -.16 & -.20 & -.12 & 13.49 & $<.01$ \\
Blue Collar & 4 & 3,740 & -.06 & -.13 & .01 & & \\
White Collar & 1 & 1,501 & -.08 & -.20 & .04 & & \\
Nurses/Healthcare & 5 & 1,905 & -.17 & -.24 & -.09 & & \\
Mixed/Other & 14 & 8,207 & -.20 & -.24 & -.15 & &
\end{tabular}


Table 3 (continued)

\begin{tabular}{|c|c|c|c|c|c|c|c|}
\hline \multirow[b]{2}{*}{ Antecedent/Outcome } & \multirow[b]{2}{*}{$k$} & \multicolumn{6}{|c|}{$95 \% \mathrm{CI}$} \\
\hline & & $n$ & $\bar{r}$ & Lower & Upper & $Q$ & $p$ \\
\hline Justice Perceptions & 14 & 11,963 & -.29 & -.38 & -.20 & 4.66 & .097 \\
\hline White Collar & 1 & 1,501 & -.37 & -.57 & -.13 & & \\
\hline Nurses/Healthcare & 4 & 3,760 & -.19 & -.30 & -.07 & & \\
\hline Mixed/Other & 9 & 6,702 & -.34 & -.42 & -.25 & & \\
\hline Quantitative Job & 26 & 18,639 & -.15 & -.20 & -.10 & 4.43 & .22 \\
\hline \multicolumn{8}{|l|}{ Demands } \\
\hline Blue Collar & 3 & 1,090 & -.12 & -.29 & .06 & & \\
\hline White Collar & 2 & 1,853 & .04 & -.16 & .23 & & \\
\hline Nurses/Healthcare & 5 & 2,288 & -.21 & -.34 & -.08 & & \\
\hline Mixed/Other & 15 & 13,408 & -.21 & -.34 & -.08 & & \\
\hline Mental/Emotional & 8 & 5,060 & -.20 & -.30 & -.09 & .98 & .61 \\
\hline \multicolumn{8}{|l|}{ Demands } \\
\hline Blue Collar & 1 & 351 & -.13 & -.52 & .30 & & \\
\hline Nurses/Healthcare & 2 & 2,510 & -.11 & -.41 & .21 & & \\
\hline Mixed/Other & 5 & 2,199 & -.29 & -.48 & -.07 & & \\
\hline \multicolumn{8}{|l|}{ Job Resources } \\
\hline Supervisor Support & 20 & 17,244 & .21 & .17 & .25 & 5.16 & .16 \\
\hline Blue Collar & 1 & 1,285 & .09 & -.07 & .25 & & \\
\hline White Collar & 3 & 2,666 & .28 & .19 & .37 & & \\
\hline Nurses/Healthcare & 1 & 1,225 & .15 & -.01 & .31 & & \\
\hline Mixed/Other & 14 & 12,068 & .21 & .16 & .25 & & \\
\hline Coworker Support & 12 & 9,432 & .25 & .20 & .30 & 1.02 & .60 \\
\hline White Collar & 1 & 352 & .30 & .11 & .47 & & \\
\hline Nurses/Healthcare & 1 & 509 & .32 & .14 & .48 & & \\
\hline Mixed/Other & 10 & 8,571 & .24 & .18 & .30 & & \\
\hline Job Control & 29 & 25,592 & .19 & .15 & .23 & 22.27 & $<.01$ \\
\hline Blue Collar & 4 & 1,994 & .04 & -.04 & .11 & & \\
\hline White Collar & 3 & 2,886 & .28 & .20 & .35 & & \\
\hline Nurses/Healthcare & 7 & 2,938 & .19 & .12 & .25 & & \\
\hline Mixed/Other & 15 & 17,774 & .21 & .17 & .24 & & \\
\hline \multicolumn{8}{|l|}{ Personal Resources } \\
\hline Core Self-Evaluations & 12 & 4,682 & .34 & .27 & 41 & 4.39 & .11 \\
\hline White Collar & 1 & 352 & .51 & .34 & .65 & & \\
\hline Nurses/Healthcare & 3 & 260 & .31 & .15 & .45 & & \\
\hline Mixed/Other & 8 & 4,070 & .32 & .24 & .39 & & \\
\hline
\end{tabular}


Table 3 (continued)

\begin{tabular}{|c|c|c|c|c|c|c|c|}
\hline \multirow[b]{2}{*}{ Antecedent/Outcome } & \multirow[b]{2}{*}{$k$} & \multicolumn{6}{|c|}{$95 \%$ CI } \\
\hline & & $n$ & $\bar{r}$ & Lower & Upper & $Q$ & $p$ \\
\hline \multicolumn{8}{|l|}{ Health } \\
\hline General Health & 32 & 33,456 & .44 & .37 & .50 & 6.28 & .10 \\
\hline Blue Collar & 1 & 196 & .58 & .26 & .79 & & \\
\hline White Collar & 2 & 2,697 & .37 & .12 & .58 & & \\
\hline Nurses/Healthcare & 4 & 4,900 & .58 & .45 & .70 & & \\
\hline Mixed/Other & 25 & 25,663 & .41 & .34 & .47 & & \\
\hline Physical Health & 15 & 10,187 & .45 & .29 & .59 & .14 & .99 \\
\hline Blue Collar & 1 & 1,036 & .53 & -.15 & .87 & & \\
\hline White Collar & 2 & 2,262 & .43 & -.06 & .75 & & \\
\hline Nurses/Healthcare & 3 & 2,088 & .48 & .09 & .74 & & \\
\hline Mixed/Other & 9 & 4,801 & .43 & .21 & .61 & & \\
\hline Mental Health & 35 & 29,360 & .42 & .34 & .49 & 2.44 & .49 \\
\hline Blue Collar & 3 & 490 & .51 & .27 & .69 & & \\
\hline White Collar & 3 & 2,529 & .54 & .32 & .70 & & \\
\hline Nurses/Healthcare & 8 & 5,170 & .38 & .22 & .52 & & \\
\hline Mixed/Other & 21 & 21,171 & .40 & .30 & .48 & & \\
\hline BMI & 26 & 16,595 & -.14 & -.17 & -.10 & .46 & .93 \\
\hline Blue Collar & 7 & 3,932 & -.12 & -.19 & -.06 & & \\
\hline White Collar & 3 & 1,185 & -.13 & -.22 & -.03 & & \\
\hline Nurses/Healthcare & 2 & 618 & -.14 & -.27 & -.02 & & \\
\hline Mixed/Other & 14 & 5,252 & -.15 & -.21 & -.10 & & \\
\hline Pain & 26 & 12,906 & -.40 & -.45 & -.34 & .98 & .81 \\
\hline Blue Collar & 4 & 778 & -.41 & -.54 & -.27 & & \\
\hline Mixed/Other & 14 & 8,959 & -.39 & -.46 & -.31 & & \\
\hline Nurses/Healthcare & 4 & 1,220 & -.35 & -.49 & -.18 & & \\
\hline White Collar & 4 & 1,949 & -.44 & -.56 & -.31 & & \\
\hline Musculoskeletal Disease & 9 & 7,487 & -.23 & -.30 & -.16 & 16.27 & .01 \\
\hline Blue Collar & 2 & 2,363 & -.09 & -.18 & .00 & & \\
\hline Mixed & 4 & 3,134 & -.31 & -.37 & -.24 & & \\
\hline Nurses/Healthcare & 1 & 515 & -.29 & -.41 & -.16 & & \\
\hline White Collar & 2 & 1,475 & -.23 & -.32 & -.13 & & \\
\hline \multicolumn{8}{|l|}{ Health Behaviors } \\
\hline Smoking (Tobacco) & 22 & 16,890 & -.09 & -.12 & -.05 & 2.69 & .44 \\
\hline Blue Collar & 8 & 4,455 & -.09 & -.15 & -.04 & & \\
\hline White Collar & 3 & 6,729 & -.09 & -.18 & -.02 & & \\
\hline
\end{tabular}


Table 3 (continued)

\begin{tabular}{|c|c|c|c|c|c|c|c|}
\hline \multirow{2}{*}{ Antecedent/Outcome } & \multirow[b]{2}{*}{$k$} & \multicolumn{6}{|c|}{$95 \% \mathrm{CI}$} \\
\hline & & $n$ & $\bar{r}$ & Lower & Upper & $Q$ & $p$ \\
\hline Nurses/Healthcare & 2 & 1,090 & .00 & -.11 & .10 & & \\
\hline Mixed/Other & 9 & 4,616 & -.09 & -.14 & -.04 & & \\
\hline Alcohol Consumption & 13 & 13,268 & -.01 & -.05 & .03 & .63 & .89 \\
\hline Blue Collar & 5 & 3,446 & -.03 & -.10 & .06 & & \\
\hline White Collar & 3 & 6,595 & .02 & -.07 & .11 & & \\
\hline Nurses/Healthcare & 1 & 654 & .00 & -.17 & .17 & & \\
\hline Mixed/Other & 4 & 2,573 & -.02 & -.10 & .06 & & \\
\hline Physical activity & 25 & 9,630 & .15 & .11 & .18 & 3.59 & .31 \\
\hline Blue Collar & 8 & 4,498 & .12 & .06 & .18 & & \\
\hline White Collar & 2 & 739 & .18 & .05 & .30 & & \\
\hline Nurses/Healthcare & 3 & 1,157 & .11 & .00 & .21 & & \\
\hline Mixed/Other & 12 & 3,236 & .18 & .05 & .30 & & \\
\hline \multicolumn{8}{|l|}{ Demographics } \\
\hline Age & 94 & 81,201 & -.13 & -.15 & -.11 & 2.42 & .49 \\
\hline Blue Collar & 21 & 7,342 & -.11 & -.17 & -.05 & & \\
\hline White Collar & 6 & 3,889 & -.17 & -.27 & -.07 & & \\
\hline Nurses/Healthcare & 20 & 22,064 & -.10 & -.16 & -.05 & & \\
\hline Mixed/Other & 47 & 47,906 & -.14 & -.18 & -.11 & & \\
\hline \multicolumn{8}{|l|}{ Job Outcomes } \\
\hline Job Satisfaction & 10 & 14,155 & .23 & .20 & .26 & 7.45 & .02 \\
\hline White Collar & 1 & 224 & .25 & .12 & .37 & & \\
\hline Nurses/Healthcare & 1 & 7,136 & .20 & .17 & .22 & & \\
\hline Mixed/Other & 8 & 6,795 & .24 & .22 & .26 & & \\
\hline Self-Rated Job & 4 & 11,291 & .23 & .21 & .25 & .09 & .76 \\
\hline \multicolumn{8}{|l|}{ Performance } \\
\hline Blue Collar & 1 & 309 & .24 & .13 & .35 & & \\
\hline Mixed/Other & 3 & 10,982 & .22 & .20 & .25 & & \\
\hline Burnout & 7 & 6,864 & .47 & .55 & .40 & .01 & .94 \\
\hline Mixed/Other & 4 & 3,814 & -.47 & -.57 & -.36 & & \\
\hline Teachers & 3 & 3,050 & -.48 & -.57 & -.37 & & \\
\hline Absenteeism & 9 & 11,682 & -.19 & -.25 & -.14 & 1.59 & .45 \\
\hline Blue Collar & 1 & 119 & -.34 & -.55 & -.10 & & \\
\hline White Collar & 1 & 1,036 & -.18 & -.35 & -.01 & & \\
\hline Mixed/Other & 7 & 10,527 & -.18 & -.25 & -.12 & & \\
\hline
\end{tabular}


Table 3 (continued)

\begin{tabular}{lccccccc}
\hline & & \multicolumn{7}{c}{$95 \%$ CI } \\
Antecedent/Outcome & $k$ & $n$ & $\bar{r}$ & Lower & Upper & $Q$ & $p$ \\
\hline Disability & 7 & 4,006 & -.28 & -.37 & -.18 & 1.10 & .58 \\
Blue Collar & 3 & 1,370 & -.32 & -.45 & -.19 & & \\
White Collar & 2 & 702 & -.27 & -.43 & -.10 & & \\
Mixed/Other & 2 & 1,934 & -.21 & -.37 & -.04 & & \\
& & & & & & & \\
Retirement Intentions & 5 & 7,082 & -.36 & -.55 & -.12 & 29.44 & $<.01$ \\
White Collar & 1 & 1,036 & -.71 & -.80 & -.59 & & \\
Nurses/Healthcare & 2 & 1,580 & -.21 & -.36 & -.05 & & \\
Mixed/Other & 2 & 4,466 & -.26 & -.39 & -.12 & & \\
Retirement & & & & & & & \\
Blue Collar & 4 & 5,598 & -.19 & -.25 & -.11 & 5.78 & .056 \\
White Collar & 1 & 126 & -.37 & -.53 & -.18 & & \\
Mixed/Other & 1 & 120 & -.26 & -.44 & -.06 & & \\
\hline Not Mixed & 2 & 5,352 & -.14 & -.22 & -.06 & & \\
\hline
\end{tabular}

Note. Mixed effect models were used in all analyses. The average effect size is reported for all occupation groups, even in cases where $k<$ less than 3. $Q$ statistics are also provided for omnibus comparison of heterogeneity among the effect size estimates across occupations. $Q$ statistics are provided for reference in all cases, including those where there was an insufficient number of studies to properly assess occupation as a moderator. Only comparisons where at least two occupation groups had 3 or more effect size estimates were assessed and discussed in the results of this paper.

Table 4 Meta-Regression Estimates-Moderated by Age Mixed methods Meta-Regression Analyses on Work Ability Moderated by Age

\begin{tabular}{lcccccc}
\hline Antecedent/Outcome & $b$ & $\mathrm{SE}$ & $\mathrm{Z}$ & $p$ & $Q$ & $R^{2}$ \\
\hline Job Demands & & & & & & \\
Physical Job Demands & -.01 & .003 & -2.02 & .04 & 138.64 & .37 \\
Justice Perceptions & .02 & .02 & 1.03 & .30 & 121.00 & .13 \\
Quantitative Job Demands & -.001 & .01 & -.10 & .92 & 231.17 & .00 \\
Mental/Emotional Demands & -.003 & .006 & -.44 & .66 & 72.23 & .00 \\
Job Resources & & & & & & \\
Supervisor Support & -.002 & .004 & -.41 & .68 & 55.39 & .00 \\
Coworker Support & -.004 & .004 & -.98 & .33 & 36.15 & .00 \\
Job Control & .01 & .002 & 2.22 & .03 & 100.91 & .42 \\
Personal Resources & & & & & & \\
Core Self-Evaluations & -.001 & .01 & -.01 & .98 & 32.54 & .00 \\
Health & & & & & & \\
General Health & -.01 & .01 & -1.74 & .08 & 2281.85 & .00 \\
Physical Health & .00 & .01 & .03 & .98 & 759.55 & .22
\end{tabular}


Table 4 (continued)

\begin{tabular}{|c|c|c|c|c|c|c|}
\hline Antecedent/Outcome & $b$ & SE & $\mathrm{Z}$ & $p$ & $Q$ & $R^{2}$ \\
\hline Mental Health & .005 & .01 & .72 & .47 & 1631.86 & .17 \\
\hline BMI & .002 & .003 & .77 & .44 & 101.13 & .00 \\
\hline Pain & .003 & .01 & .48 & .63 & 118.74 & .00 \\
\hline $\begin{array}{l}\text { Musculoskeletal Disease } \\
\text { (MSD) }\end{array}$ & .02 & .01 & 2.14 & .03 & 82.69 & .35 \\
\hline \multicolumn{7}{|l|}{ Health Behaviors } \\
\hline Smoking (Tobacco) & .002 & .002 & .93 & .35 & 51.81 & .01 \\
\hline Alcohol Consumption & -.004 & .003 & -1.09 & .28 & 25.31 & .27 \\
\hline Physical activity & .001 & .004 & .33 & .74 & 55.00 & .00 \\
\hline \multicolumn{7}{|l|}{ Demographics } \\
\hline Age & .00 & .002 & -.03 & .98 & 1082.62 & .00 \\
\hline \multicolumn{7}{|l|}{ Job Outcomes } \\
\hline Job Satisfaction & -.001 & .003 & -.23 & .81 & 7.32 & .00 \\
\hline Self-Rated Job Performance & -.003 & .003 & -1.02 & .31 & 2.29 & .00 \\
\hline \multicolumn{6}{|l|}{ Strain Indicators } & 65 \\
\hline \multicolumn{7}{|l|}{ Exit Behaviors } \\
\hline Absenteeism & .01 & .004 & 1.38 & .17 & 23.11 & .00 \\
\hline Disability & .02 & .06 & 3.10 & $<.01$ & 8.64 & .81 \\
\hline Retirement Intentions & .15 & .11 & 1.39 & .16 & 47.30 & .69 \\
\hline Retirement & -.01 & .01 & -.48 & .63 & 14.05 & .00 \\
\hline
\end{tabular}

Note. This table shows the results for mixed-effect meta-regression analyses with age as the moderator on the relationships between WA and its correlates. This table shows the moderating effect of the mean age of the sample on the relationships between WA and its correlates. See Appendices D and E for scatterplot diagrams of these results. $b=$ unstandardized beta-coefficient, with age centered at 0 . 


\section{References}

*Abdolalizadeh, M., Arastoo, A. A., Ghsemzadeh, R., Montazeri, A., Ahmadi, K., \& Azizi, A. (2012). The psychometric properties of an Iranian translation of the Work Ability Index (WAI) questionnaire. Journal of Occupational Rehabilitation, 22, 401-408.

Abma, F. I., Amick III, B. C., Brouwer, S., van der Klink, J. J., \& Bültmann, U. (2012). The cross-cultural adaptation of the Work Role Functioning Questionnaire to Dutch. Work, 43, 203-210. Doi: DOI 10.3233/WOR-2012-1362.

*Agnew, L., Johnston, V., Ludvigsson, M. L., Peterson, G., Overmeer, T., Johansson, G., \& Peolsson, A. (2015). Factors associated with work ability in patients with chronic whiplash-associated disorder grade II-III: A cross-sectional analysis. Journal of Rehabilitation Medicine, 47, 546-551.

*Ahlstrom, L., Grimby-Ekman, A., Hagberg, M., \& Dellve, L. (2010). The work ability index and single-item question: Associations with sick leave, symptoms, and health-a prospective study of women on long-term sick leave. Scandinavian Journal of Work, Environment \& Health, 36, 404-412.

Airila, A., Hakanen, J., Punakallio, A., Lusa, S., \& Luukkonen, R. (2012). Is work engagement related to work ability beyond working conditions and lifestyle factors?. International Archives of Occupational and Environmental Health, 85, 915-925.

*Airila, A., Hakanen, J. J., Luukkonen, R., Lusa, S., \& Punakallio, A. (2013). Positive and negative mood trajectories and their relationship with work ability, self-rated 
health, and life satisfaction: A 13-year follow-up study. Journal of Occupational and Environmental Medicine, 55, 779-785.

*Airila, A., Hakanen, J. J., Schaufeli, W. B., Luukkonen, R., Punakallio, A., \& Lusa, S. (2014). Are job and personal resources associated with work ability 10 years later? The mediating role of work engagement. Work \& Stress, 28, 87-105.

*Alavinia, S. M., De Boer, A. G. E. M., Van Duivenbooden, J. C., Frings-Dresen, M. H. W., \& Burdorf, A. (2009). Determinants of work ability and its predictive value for disability. Occupational Medicine, 59, 32-37. Doi: 10.1093/occmed/kqn148.

Alavinia, S. M., van Duivenbooden, C., \& Burdorf, A. (2007). Influence of work-related factors and individual characteristics on work ability among Dutch construction workers. Scandinavian Journal of Work, Environment \& Health, 33, 351-357.

*Assunção, A. A., Sampaio, R. F., \& Nascimento, L. (2010). Actions in small companies to promote occupational health: the case of the food and beverage sector. Brazilian Journal of Physical Therapy, 14, 52-59.

*Attarchi, M., Ghaffari, M., Abdi, A., Mirzamohammadi, E., Seyedmehdi, S. M., Rahimpour, F., Fazlalizadeh, M., \& Mohammadi, S. (2014). Assessment of the Relationship between Physical Working Conditions and Different Levels of Work Ability. Global Journal of Health Science, 6, 213-220-.

Bakker, A. B., \& Demerouti, E. (2007). The job demands-resources model: State of the art. Journal of Managerial Psychology, 22, 309-328. 
Bakker, A. B., Demerouti, E., \& Euwema, M. C. (2005). Job resources buffer the impact of job demands on burnout. Journal of Occupational Health Psychology, 10, 170180.

*Bennett, A. I., Hanley, J., Buckle, P., \& Bridger, R. S. (2011). Work demands during firefighting training: does age matter?. Ergonomics, 54, 555-564.

*Bertilsson, M., Vaez, M., Waern, M., Ahlborg Jr, G., \& Hensing, G. (2014). A prospective study on self-assessed mental well-being and work capacity as determinants of all-cause sickness absence. Journal of Occupational Rehabilitation, 25, 52-64.

*Bethge, M., \& Radoschewski, F. M. (2010). Physical and psychosocial work stressors, health-related control beliefs and work ability: cross-sectional findings from the German Sociomedical Panel of Employees. International Archives of Occupational and Environmental Health, 83, 241-250.

*Bethge, M., Radoschewski, F. M., \& Gutenbrunner, C. (2012a). Effort-reward imbalance and work ability: cross-sectional and longitudinal findings from the Second German Sociomedical Panel of Employees. BioMed Central Public Health, 12, 1-9.

*Bethge, M., Radoschewski, F. M., \& Gutenbrunner, C. (2012b). The Work Ability Index as a screening tool to identify the need for rehabilitation: longitudinal findings from the second German Sociomedical Panel of Employees. Journal of Rehabilitation Medicine, 44, 980-987. 
Borenstein M., Hedges L., Higgins J., Rothstein H (2009). Multiple outcomes or timepoints within a study. In: Borenstein M, Hedges LV, Higgins JPT, Rothstein HR, editors. Introduction to Meta-Analysis. Chichester, England: John Wiley; pp. $225-238$.

*Bordin, G., Padalino, M. A., Perentaler, S., Castaldi, B., Maschietto, N., Michieli, P., \& Milanesi, O. (2015). Clinical profile and quality of life of adult patients after the fontan procedure. Pediatric Cardiology, 36, 1-9.

Borenstein, M., Hedges, L., Higgins, J. \& Rothstein, H. (2014) Comprehensive MetaAnalysis Version 2. Biostat, Englewood, New Jersey.

Bridger, R. S., Dobson, K., \& Davison, H. (2015). Using the HSE stress indicator tool in a military context. Ergonomics, 59 1-12.

*Bugajska, J., \& Sagan, A. (2014). Chronic musculoskeletal disorders as risk factors for reduced work ability in younger and ageing workers. International Journal of Occupational Safety and Ergonomics, 20, 607-615.

Burmeister, A., \& Deller, J. (2016). Knowledge retention from older and retiring workers: what do we know, and where do we go from here?. Work, Aging and Retirement, waw002, 1-18. DOI: http://dx.doi.org/10.1093/workar/waw002.

Butrica, B. (2011). Making a case for working longer at older ages. Public Policy \& Aging Report, 21, 20-24.

Camerino, D., Conway, P. M., Van der Heijden, B. I. J., Estryn-Behar, M., Consonni, D., Gould, D., \& Hasselhorn, H. M. (2006). Low-perceived work ability, ageing and 
intention to leave nursing: a comparison among 10 European countries. Journal of Advanced Nursing, 56, 542-552.

*Camerino, D., Conway, P. M., Sartori, S., Campanini, P., Estryn., Béhar, M., van der Heijden, B. I. J. M., \& Costa, G. (2008). Factors affecting work ability in day and shift working nurses. Chronobiology International, 25, 425-442.

*Carel, R. S., Zusman, M., \& Karakis, I. (2013). Work ability index in Israeli hospital nurses: applicability of the adapted questionnaire. Experimental Aging Research, 39, 579-590.

*Chang, Y., ChenSea, M., Jang, Y., Wang, J. D. (2000). A simple self-rating assessment method of residual work capability for occupational permanent disabilities. American Journal of Industrial Medicine, 38, 539-547.

*Chiu, M. C., Wang, M. J. J., Lu, C. W., Pan, S. M., Kumashiro, M., \& Ilmarinen, J. (2007). Evaluating work ability and quality of life for clinical nurses in Taiwan. Nursing Outlook, 55, 318-326.

*Claudi, J. A. (2012). Towards a parsimonious program theory of return to work intervention. Work, 44, 155-164.

Cohen, S., \& Wills, T. A. (1985). Stress, social support, and the buffering hypothesis. Psychological Bulletin, 98, 310-357.

Collins, J. J., Baase, C. M., Sharda, C. E., Ozminkowski, R. J., Nicholson, S., Billotti, G. M., \& Berger, M. L. (2005). The assessment of chronic health conditions on work performance, absence, and total economic impact for employers. Journal of Occupational and Environmental Medicine, 47, 547-557. 
*Conway, P. M., Campanini, P., Sartori, S., Dotti, R., \& Costa, G. (2008). Main and interactive effects of shiftwork, age and work stress on health in an Italian sample of healthcare workers. Applied Ergonomics, 39, 630-639.

Darr, W., \& Johns, G. (2008). Work strain, health, and absenteeism: a meta-analysis. Journal of Occupational Health Psychology, 13, 293-318.

*De Croon, E. M., Sluiter, J. K., Nijssen, T. F., Kammeijer, M., Dijkmans, B. A. C., Lankhorst, G. J., \& Frings-Dresen, M. H. W. (2005). Work ability of Dutch employees with rheumatoid arthritis. Scandinavian Journal of Rheumatology, 34 , 277-283.

*de Souza Magnago, T. S. B., de Lima, A. C. S., Prochnow, A., da Silva Ceron, M. D., Tavares, J. P., \& de Souza Urbanetto, J. (2012). Intensity of musculoskeletal pain and (in) ability to work in nursing. Rev. Latino-Am. Enfermagem, 20, 1125-33.

*de Vries, H. J., Reneman, M. F., Groothoff, J. W., Geertzen, J. H., \& Brouwer, S. (2013). Self-reported work ability and work performance in workers with chronic nonspecific musculoskeletal pain. Journal of Occupational Rehabilitation, 23, 110.

Demerouti, E., \& Bakker, A. B. (2011). The job demands-resources model: Challenges for future research. Journal of Industrial Psychology, 37, 1-9.

Demerouti, E., Bakker, A. B., Nachreiner, F., \& Schaufeli, W. B. (2001). The job demands-resources model of burnout. Journal of Applied Psychology, 86, 499512. 
Duval, S., \& Tweedie, R. (2000). Trim and fill: a simple funnel-plot-based method of testing and adjusting for publication bias in meta-analysis. Biometrics, 56, 455463.

*Edlund, M., Gerhardsson, L., \& Hagberg, M. (2012). Physical capacity and psychological mood in association with self-reported work ability in vibrationexposed patients with hand symptoms. Journal of Occupational Medicine and Toxicology, 7, 1-7.

Edwards, J. A., Webster, S., Van Laar, D., \& Easton, S. (2008). Psychometric analysis of the UK Health and Safety Executive's Management Standards work-related stress Indicator Tool. Work \& Stress, 22, 96-107.

Egger, M., Smith, G. D., Schneider, M., \& Minder, C. (1997). Bias in meta-analysis detected by a simple, graphical test. British Medical Journal, 315, 629-634.

*El Fassi, M., Bocquet, V., Majery, N., Lair, M. L., Couffignal, S., \& Mairiaux, P. (2013). Work ability assessment in a worker population: comparison and determinants of Work Ability Index and work ability score. BMC Public Health, $13,305-315$.

*Elo, A. L., Ervasti, J., Kuosma, E., \& Mattila, P. (2008). Evaluation of an organizational stress management program in a municipal public works organization. Journal of Occupational Health Psychology, 13, 10-23.

*Elovainio, M., Kuusio, H., Aalto, A. M., Sinervo, T., \& Heponiemi, T. (2010). Insecurity and shiftwork as characteristics of negative work environment: 
psychosocial and behavioural mediators. Journal of Advanced Nursing, 66, 10801091.

Ekberg, K., Wåhlin, C., Persson, J., Bernfort, L., \& Öberg, B. (2015). Early and late return to work after sick leave: predictors in a cohort of sick-listed individuals with common mental disorders. Journal of Occupational Rehabilitation, 25, 627637.

Faragher, E. B., Cass, M., \& Cooper, C. L. (2005). The relationship between job satisfaction and health: a meta-analysis. Occupational and Environmental Medicine, 62, 105-112.

*Feldt, T., Hyvönen, K., Mäkikangas, A., Kinnunen, U., \& Kokko, K. (2009). Development trajectories of Finnish managers' work ability over a 10-year follow-up period. Scandinavian Journal of Work, Environment \& Health, 35, 3747.

*Feldt, T., Hyvönen, K., Oja-Lipasti, T., Kinnunen, U., \& Salmela-Aro, K. (2012). Do work ability and job involvement channel later personal goals in retirement? An 11-year follow-up study. International Archives of Occupational and Environmental Health, 85, 547-558.

*Fischer, F. M., Borges, F. D. S., Rotenberg, L., Latorre, M. R. D. O., Soares, N. S., Rosa, P. F. L. S., \& Landsbergis, P. (2006). Work ability of health care shift workers: what matters?. Chronobiology International, 23, 1,165-1,179. 
*Fischer, F. M., \& Martinez, M. C. (2011). Work ability among hospital food service professionals: multiple associated variables require comprehensive intervention. Work, 41, 3,746-3,752.

*Fischer, F. M., \& Martinez, M. C. (2012). Individual features, working conditions and work injuries are associated with work ability among nursing professionals. Work, 45, 509-517.

Gallagher, D., Visser, M., De Meersman, R. E., Sepúlveda, D., Baumgartner, R. N., Pierson, R. N., Harris, T., \& Heymsfield, S. B. (1997). Appendicular skeletal muscle mass: Effects of age, gender, and ethnicity. Journal of Applied Physiology, 83, 229-239.

*Geukes, M., van Aalst, M. P., Nauta, M. C., \& Oosterhof, H. (2012). The impact of menopausal symptoms on work ability. Menopause, 19, 278-282.

Gjesdal, S., Ringdal, P. R., Haug, K., \& Maeland, J. G. (2004). Predictors of disability pension in long-term sickness absence. The European Journal of Public Health, $14,398-405$.

*Golubic, R., Milosevic, M., Knezevic, B., \& Mustajbegovic, J. (2009). Work related stress, education and work ability among hospital nurses. Journal of Advanced Nursing, 65, 2056-2066.

Goodpaster, B. H., Park, S. W., Harris, T. B., Kritchevsky, S. B., Nevitt, M., Schwartz, A. V., Simonsick, E. M., Tylavsky, F. A., Visser, M., \& Newman, A. B. (2006). The loss of skeletal muscle strength, mass, and quality in older adults: the health, 
aging and body composition study. The Journals of Gerontology Series A: Biological Sciences and Medical Sciences, 61, 1059-1064.

*Graafmans, J. (1998). Age, absenteeism and physical fitness in relation to work ability. Gerontechnology: A Sustainable Investment in the Future, 48, 254-265.

*Guidi, S., Bagnara, S., \& Fichera, G. P. (2012). The HSE indicator tool, psychological distress and work ability. Occupational Medicine, 62, 203-209.

*Gupta, N., Jensen, B. S., Søgaard, K., Carneiro, I. G., Christiansen, C. S., Hanisch, C., \& Holtermann, A. (2014). Face validity of the single work ability item: comparison with objectively measured heart rate reserve over several days. International Journal of Environmental Research and Public Health, 11, 5,3335,348 .

*Gustafsson, K., \& Marklund, S. (2011). Consequences of sickness presence and sickness absence on health and work ability: a Swedish prospective cohort study. International Journal of Occupational Medicine and Environmental Health, 24, 153-165.

*Hakanen, J. J., Bakker, A. B., \& Schaufeli, W. B. (2006). Burnout and work engagement among teachers. Journal of School Psychology, 43, 495-513.

*Han, L., Shi, L., Lu, L., \& Ling, L. (2014). Work ability of Chinese migrant workers: the influence of migration characteristics. BMC Public Health, 14, 1-8.

*Hansen, K. E., Kesmodel, U. S., Baldursson, E. B., Schultz, R., \& Forman, A. (2013). The influence of endometriosis-related symptoms on work life and work ability: a 
study of Danish endometriosis patients in employment. European Journal of Obstetrics \& Gynecology and Reproductive Biology, 169, 331-339.

Hedges, L. V., \& Olkin, I. (1985). Statistical methods for meta-analysis. Orlando, FL: Academic Press.

*Heponiemi, T., Kouvonen, A., Vänskä, J., Halila, H., Sinervo, T., Kivimäki, M., \& Elovainio, M. (2008). Health, psychosocial factors and retirement intentions among Finnish physicians. Occupational Medicine, 58, 406-412.

Herzog, A., House, J. S., \& Morgan, J. N. (1991). Relation of work and retirement to health and well-being in older age. Psychology and Aging, 6, 202.

*Holtermann, A., Hansen, J. V., Burr, H., \& Søgaard, K. (2010). Prognostic factors for long-term sickness absence among employees with neck-shoulder and low-back pain. Scandinavian Journal of Work, Environment \& Health, 36, 34-41.

Huedo-Medina, T. B., Sánchez-Meca, J., Marín-Martínez, F., \& Botella, J. (2006). Assessing heterogeneity in meta-analysis: Q statistic or $\mathrm{I}^{2}$ index?.Psychological methods, 11, 193-206.

Ilmarinen, J. (2007). The work ability index (WAI). Occupational Medicine, 57, 160. Ilmarinen, J. (2009). Work ability — a comprehensive concept for occupational health research and prevention. Scandinavian Journal of Work, Environment \& Health, $35,1-5$.

*Ilmarinen, V., Ilmarinen, J., Huuhtanen, P., Louhevaara, V., \& Näsman, O. (2015). Examining the factorial structure, measurement invariance and convergent and 
discriminant validity of a novel self-report measure of work ability: work abilitypersonal radar. Ergonomics, 58, 1445-1460.

Ilmarinen, J., Tuomi, K., Eskelinen, L., Nygård, C. H., Huuhtanen, P., \& Klockars, M. (1991a). Background and objectives of the Finnish research project on aging workers in municipal occupations. Scandinavian Journal of Work, Environment \& Health, 17, 7-11.

*Ilmarinen, J., Tuomi, K., Eskelinen, L., Nygård, C. H., Huuhtanen, P., \& Klockars, M. (1991b). Summary and recommendations of a project involving cross-sectional and follow-up studies on the aging worker in Finnish municipal occupations (1981-1985). Scandinavian Journal of Work, Environment \& Health, 17, 135141.

Ilmarinen, J., Tuomi, K., \& Klockars, M. (1997). Changes in the work ability of active employees over an 11-year period. Scandinavian Journal of Work, Environment \& Health, 23, 49-57.

*Ję dryka-Góral, A., Bugajska, J., Łastowiecka, E., Najmiec, A., Rell-Bakalarska, M., Bownik, I., \& Kochmański, M. (2006). Work ability in ageing workers suffering from chronic diseases. International Journal of Occupational Safety and Ergonomics, 12, 17-30.

Jia, H., \& Lubetkin, E. I. (2005). The impact of obesity on health-related quality-of-life in the general adult US population. Journal of Public Health, 27, 156-164. 
Johnson, J. V., \& Hall, E. M. (1988). Job strain, work place social support, and cardiovascular disease: a cross-sectional study of a random sample of the Swedish working population. American Journal of Public Health, 78, 1336-1342.

Judge, T. A., \& Bono, J. E. (2001). Relationship of core self-evaluations traits-selfesteem, generalized self-efficacy, locus of control, and emotional stability-with job satisfaction and job performance: A meta-analysis. Journal of Applied Psychology, 86, 80-92.

*Kaewboonchoo, O., \& Ratanasiripong, P. (2015). Psychometric properties of the Thai version of the work ability index (Thai WAI). Journal of Occupational Health, 57, 371-377.

*Kaleta, D., Makowiec-Dąbrowska, T., \& Jegier, A. (2006). Lifestyle index and work ability. International Journal of Occupational Medicine and Environmental Health, 19, 170-177.

Karasek, R.A. (1979). Job demands, job decision latitude, and mental strain: Implications for job redesign. Administrative Science Quarterly, 24, 285-308. doi: $10.2307 / 2392498$.

Karasek, R., Brisson, C., Kawakami, N., Houtman, I., Bongers, P., \& Amick, B. (1998). The Job Content Questionnaire (JCQ): An instrument for internationally comparative assessment of psychosocial job characteristics. Journal of Occupational Health Psychology, 3, 322-355. doi: 10.1037/1076-8998.3.4.322. 
*Karttunen, J. P., \& Rautiainen, R. H. (2011). Risk factors and prevalence of declined work ability among dairy farmers. Journal of Agricultural Safety and Health, 17, 243-257.

*Karvala, K., Nordman, H., Luukkonen, R., \& Uitti, J. (2014). Asthma related to workplace dampness and impaired work ability. International Archives of Occupational and Environmental Health, 87, 1-11.

Kenworthy, J., Fay, C., Frame, M., \& Petree, R. (2014). A meta-analytic review of the relationship between emotional dissonance and emotional exhaustion. Journal of Applied Social Psychology, 44, 94-105.

Kepes, S., McDaniel, M. A., Brannick, M. T., \& Banks, G. C. (2013). Meta-analytic reviews in the organizational sciences: Two meta-analytic schools on the way to MARS (the Meta-Analytic Reporting Standards). Journal of Business and Psychology, 28, 123-143.

*Kinnunen, U., Parkatti, T., \& Rasku, A. (1994). Occupational well-being among aging teachers in Finland. Scandinavian Journal of Educational Research, 38, 315-332.

*Klasan, A., Madzarac, G., Milosevic, M., Mustajbegovic, J., \& Keleuva, S. (2012). Predictors of lower work ability among emergency medicine employees: the Croatian experience. Emergency Medicine Journal, (online), 3-5.

*Koolhaas, W., van der Klink, J. J., Groothoff, J. W., \& Brouwer, S. (2011). Towards a sustainable healthy working life: associations between chronological age, functional age and work outcomes. The European Journal of Public Health, 22, 424-429. 
Kulik, C. T., Ryan, S., Harper, S., \& George, G. (2014). Aging populations and management. Academy of Management Journal, 57, 929-935.

*Kuusio, H., Heponiemi, T., Aalto, A. M., Sinervo, T., \& Elovainio, M. (2012). Differences in well-being between GPs, medical specialists, and private physicians: The role of psychosocial factors. Health Services Research, 47, 68-85.

*Labbafinejad, Y., Ghaffari, M., Bahadori, B., Mohammadi, S., Abdi, A., Namvar, M., \& Attarchi, M. (2014). The effect of sleep disorder on the work ability of workers in a car accessories manufacturing plant. Medical journal of the Islamic Republic of Iran, 28, 111-119.

*Laitinen, J., Näyhä, S., \& Kujala, V. (2005). Body mass index and weight change from adolescence into adulthood, waist-to-hip ratio and perceived work ability among young adults. International Journal of Obesity, 29, 697-702.

*Larsson, A., Karlqvist, L., Westerberg, M., \& Gard, G. (2012). Identifying work ability promoting factors for home care aides and assistant nurses. BMC musculoskeletal disorders, 13, 1-11.

*Lin, S., Wang, Z., \& Wang, M. (2006). Work ability of workers in western China: reference data. Occupational Medicine, 56, 89-93.

Locke, E. A. (1969). What is job satisfaction?. Organizational Behavior and Human Performance, 4, 309-336.

*Mache, S., Danzer, G., Klapp, B. F., \& Groneberg, D. A. (2013). Surgeons' work ability and performance in surgical care: relations between organisational predictors, 
work engagement and work ability. Langenbeck's Archives of Surgery, 398, 317325.

*Madeleine, P., Vangsgaard, S., Andersen, J. H., Ge, H. Y., \& Arendt-Nielsen, L. (2013). Computer work and self-reported variables on anthropometrics, computer usage, work ability, productivity, pain, and physical activity. BMC musculoskeletal disorders, 14, 1-12.

*Magnago, T. S. B. D. S., Lima, A. C. S. D., Prochnow, A., Ceron, M. D. D. S., Tavares, J. P., \& Urbanetto, J. D. S. (2012). Intensity of musculoskeletal pain and (in) ability to work in nursing. Revista latino-americana de enfermagem, 20, 11251133.

Mäkitalo, J., \& Palonen, J. (1994). What is the capacity for work: A medical balance model and integrated understanding of type. People and Work, 8, 155-162.

Manchikanti, L., Singh, V., Datta, S., Cohen, S. P., \& Hirsch, J. A. (2008). Comprehensive review of epidemiology, scope, and impact of spinal pain. Pain Physician, 12, 35-70.

*Marqueze, E. C., Voltz, G. P., Borges, F. N., \& Moreno, C. R. (2008). A 2-year followup study of work ability among college educators. Applied Ergonomics, 39, 640645.

*Martinez, M. C., \& Fischer, F. M. (2015). A cohort study of psychosocial work stressors on work ability among Brazilian hospital workers. American Journal of Industrial Medicine, 58, 795-806. 
*Martinez, M. C., \& Latorre, M. D. R. D. D. (2006). Health and work ability among office workers. Revista de Saúde Pública, 40, 851-858.

*Martinez, M. C., Latorre, M. D. R. D. D., \& Fischer, F. M. (2009). Validity and reliability of the Brazilian version of the Work Ability Index questionnaire. Revista de Saude Publica, 43, 525-532.

*Martinez, M. C., Paraguay, A. I. B. B., \& Latorre, R. D. D. (2004). Relationship between psychosocial job satisfaction and health in white collar workers. Revista de Saúde Pública, 38, 55-61.

*McGonagle, A. K., \& Barnes-Farrell, J. L. (2014). Chronic illness in the workplace: Stigma, identity threat and strain. Stress and Health, 30, 310-321.

*McGonagle, A.K., Barnes-Farrell, J.L., Di Milia, L., Fischer, F.M., Hobbs, B., IskraGolec, I., Kaliterna, L., \& Smith, L. (2014). Demands, resources, and work ability: A cross-national examination of health care workers. European Journal of Work and Organizational Psychology, 23, 830-846.

*McGonagle, A.K., Fisher, G.G., Barnes-Farrell, J.L., and Grosch, J.W. (2015). Individual and work factors related to perceived work ability and labor force outcomes. Journal of Applied Psychology, 100, 376-398.

McHorney, C. A., Ware Jr, J. E., \& Raczek, A. E. (1993). The MOS 36-Item Short-Form Health Survey (SF-36): II. Psychometric and clinical tests of validity in measuring physical and mental health constructs. Medical Care, 31, 247-263.

*Milani, D., \& Monteiro, M. S. (2012). Musculoskeletal symptoms and work ability among agricultural machinery operators. Work, 41, 5,721-5,724. 
Millanvoye, M. (1998). Ageing of the organism before sixty years of age. In: J.C., Marquie, D. Paumes Cau-Bareille, \& S. Volkoff, (Eds.) Working with age (pp. 133-161). London: Taylor \& Francis Inc.

*Milosevic, M., Golubic, R., Knezevic, B., Golubic, K., Bubas, M., \& Mustajbegovic, J. (2011). Work ability as a major determinant of clinical nurses' quality of life. Journal of Clinical Nursing, 20, 2931-2938.

*Mohammadi, S., Ghaffari, M., Abdi, A., Bahadori, B., Mirzamohammadi, E., \& Attarchi, M. (2015). Interaction of Lifestyle and Work Ability Index in Blue Collar Workers. Global journal of health science, 7, 90-97.

*Monteiro, M. S., \& Alexandre, N. M. C. (2009). Work ability and low back pain among workers from a public health institution. Revista Gaúcha de Enfermagem, 30, 297-302.

Morschhäuser, M., \& Sochert, R. (2006). Healthy work in an ageing Europe. Federal Association of Company Health Insurance Funds, Essen, Germany, 1-76.

*Müller, A., Heiden, B., Herbig, B., Poppe, F., \& Angerer, P. (2016). Improving wellbeing at work: A randomized controlled intervention based on selection, optimization, and compensation. Journal of Occupational Health Psychology, 21, 169-181.

*Müller, A., Weigl, M., Heiden, B., Glaser, J., \& Angerer, P. (2012). Promoting work ability and well-being in hospital nursing: The interplay of age, job control, and successful ageing strategies. Work, 41, 5137-5144. 
*Müller, A., Weigl, M., Heiden, B., Herbig, B., Glaser, J., \& Angerer, P. (2013).

Selection, optimization, and compensation in nursing: exploration of job-specific strategies, scale development, and age-specific associations to work ability. Journal of Advanced Nursing, 69, 1630-1642.

Must, A., Spadano, J., Coakley, E. H., Field, A. E., Colditz, G., \& Dietz, W. H. (1999). The disease burden associated with overweight and obesity. The Journal of the American Medical Association, 282, 1523-1529.

National Institutes of Health, (2011). Living longer. Global Health and Aging. Retrieved from http://www.nia.nih.gov/research/publication/global-health-and-aging/livinglonger.

*Neri, L., Rocca, R. L., Gallieni, M., Brancaccio, D., Cozzolino, M., Colombi, A., \& Burroughs, T. E. (2009). Occupational stress is associated with impaired work ability and reduced quality of life in patients with chronic kidney failure. The International Journal of Artificial Organs, 32, 291-298.

Neovius, M., Kark, M., \& Rasmussen, F. (2008). Association between obesity status in young adulthood and disability pension. International Journal of Obesity, 32, 1319-1326.

*Neupane, S., Virtanen, P., Leino-Arjas, P., Miranda, H., Siukola, A., \& Nygård, C. H. (2013). Multi-site pain and working conditions as predictors of work ability in a 4-year follow-up among food industry employees. European Journal of Pain, 17, 444-451. 
*Niessen, M. A., Laan, E. L., Robroek, S. J., Essink-Bot, M. L., Peek, N., Kraaijenhagen, R. A., \& Burdorf, A. (2013). Determinants of participation in a web-based health risk assessment and consequences for health promotion programs. Journal of Medical Internet research, 15, e151.

*Nilsson, S., \& Ekberg, K. (2013). Employability and work ability: Returning to the labour market after long-term absence. Work: A Journal of Prevention, Assesment and Rehabilitation, 44, 449-457.

Ng, T. W., \& Feldman, D. C. (2008). The relationship of age to ten dimensions of job performance. Journal of Applied Psychology, 93, 392.

*Ohta, M., Eguchi, Y., Inoue, T., Honda, T., Morita, Y., Konno, Y., \& Kumashiro, M. (2015). Effects of bench step exercise intervention on work ability in terms of cardiovascular risk factors and oxidative stress: a randomized controlled study. International Journal of Occupational Safety and Ergonomics, 21, 141-149.

*Padula, R. S., Comper, M. L., Moraes, S. A., Sabbagh, C., Pagliato Junior, W., \& Perracini, M. R. (2013). The work ability index and functional capacity among older workers. Brazilian Journal of Physical Therapy, 17, 382-391.

*Palermo, J., Fuller-Tyszkiewicz, M., Walker, A., \& Appannah, A. (2013). Primary-and secondary-level organizational predictors of work ability. Journal of Occupational Health Psychology, 18, 220-229.

Pedersen, B. K., \& Saltin, B. (2006). Evidence for prescribing exercise as therapy in chronic disease. Scandinavian Journal of Medicine \& Science in Sports, 16, 3-63. 
Penedo, F. J., \& Dahn, J. R. (2005). Exercise and well-being: a review of mental and physical health benefits associated with physical activity. Current Opinion in Psychiatry, 18, 189-193.

*Phongamwong C, Deema $\mathrm{H}$. The impact of multi-site musculoskeletal pain on work ability among health care providers. (2015). Journal of Occupational Medicine and Toxicology, 1, 1-10.

*Pilger, A., Haslacher, H., Ponocny-Seliger, E., Perkmann, T., Böhm, K., Budinsky, A., \& Winker, R. (2014). Affective and inflammatory responses among orchestra musicians in performance situation. Brain, Behavior, and Immunity, 37, 23-29.

*Pit, S. W., \& Hansen, V. (2014). Factors influencing early retirement intentions in Australian rural general practitioners. Occupational Medicine, 64, 297-304

*Plat, M. C. J., Frings-Dresen, M. H., \& Sluiter, J. K. (2012). Impact of chronic diseases on work ability in ageing firefighters. Journal of Occupational Health, 54, 158163.

*Pohjonen, T. (2001). Perceived work ability of home care workers in relation to individual and work-related factors in different age groups. Occupational Medicine, 51, 209-217.

Radkiewicz, P., Widerszal-Bazyl, M., \& NEXT-Study Group. (2005). Psychometric properties of Work Ability Index in the light of comparative survey study. International Congress Series, 1280, 304-309.

*Riedel, N., Müller, A., \& Ebener, M. (2015). Applying strategies of selection, optimization, and compensation to maintain work ability - a psychosocial 
resource complementing the Job Demand-Control Model? Results from the representative lid: A cohort study on work, age, and health in Germany. Journal of Occupational and Environmental Medicine, 57, 552-561.

Rimm, E. B., Klatsky, A., Grobbee, D., \& Stampfer, M. J. (1996). Review of moderate alcohol consumption and reduced risk of coronary heart disease: is the effect due to beer, wine, or spirits?. British Medical Journal, 312, 731-736.

*Roelen, C. A., Heymans, M. W., Twisk, J. W., van der Klink, J. J., Groothoff, J. W., \& van Rhenen, W. (2014). Work Ability Index as tool to identify workers at risk of premature work exit. Journal of Occupational Rehabilitation, 24, 747-754.

Rohwedder, S., \& Willis, R. J. (2010). Mental Retirement. The Journal of Economic Perspectives, 24, 119-138. doi:10.1257/jep.24.1.119.

*Rolander, B., Jonker, D., Winkel, J., Sandsjö, L., Balogh, I., Svensson, E., \& Ekberg, K. (2013). Working conditions, health and productivity among dentists in Swedish public dental care-a prospective study during a 5-year period of rationalisation. Ergonomics, 56, 1376-1386

*Rongen, A., Robroek, S. J., Schaufeli, W., \& Burdorf, A. (2014). The contribution of work engagement to self-perceived health, work ability, and sickness absence beyond health behaviors and work-related factors. Journal of Occupational and Environmental Medicine, 56, 892-897.

Room, R., Babor, T., \& Rehm, J. (2005). Alcohol and public health. The Lancet, 365, 519-530. 
*Rostamabadi, A., Mazloumi, A., \& Rahimi Foroushani, A. (2014). Work Ability Index (WAI) and Its Health-related Determinants among Iranian Farmers Working in Small Farm Enterprises. Journal of Occupational Health, 56, 478-484.

*Ruitenburg, M. M., Frings-Dresen, M. H., \& Sluiter, J. K. (2012). The prevalence of common mental disorders among hospital physicians and their association with self-reported work ability: a cross-sectional study. BMC Health Services Research, 12, 292-298.

*Sahlin, E., Ahlborg, G., Matuszczyk, J. V., \& Grahn, P. (2014). Nature-based stress management course for individuals at risk of adverse health effects from workrelated stress — effects on stress related symptoms, workability and sick leave. International Journal of Environmental Research and Public Health, 11, 6,586-6,611.

*Salonen, P., Arola, H., Nygård, C. H., Huhtala, H., \& Koivisto, A. M. (2003). Factors associated with premature departure from working life among ageing food industry employees. Occupational Medicine, 53, 65-68.

*Saltychev, M., Laimi, K., Pentti, J., Kivimäki, M., \& Vahtera, J. (2014). Short-and longterm changes in perceived work ability after interdisciplinary rehabilitation of chronic musculoskeletal disorders: prospective cohort study among 854 rehabilitants. Clinical Rehabilitation, 28, 592-603.

*Sampaio, R. F., Coelho, C. M., Barbosa, F. B., Mancini, M. C., \& Parreira, V. F. (2009). Work ability and stress in a bus transportation company in Belo Horizonte, Brazil. Ciência \& Saúde Coletiva, 14, 287-296. 
Scammacca, N., Roberts, G., \& Stuebing, K. K. (2014). Meta-analysis with complex research designs dealing with dependence from multiple measures and multiple group comparisons. Review of Educational Research, 84, 328-364.

Schaie, K. W., \& Willis, S. L. (1993). Age difference patterns of psychometric intelligence in adulthood: Generalizability within and across ability domains. Psychology and Aging, 8, 44-55.

Schane, R. E., Ling, P. M., \& Glantz, S. A. (2010). Health effects of light and intermittent smoking a review. Circulation, 121, 1518-1522.

Schaufeli, W. B., Bakker, A. B., \& Van Rhenen, W. (2009). How changes in job demands and resources predict burnout, work engagement, and sickness absenteeism. Journal of Organizational Behavior, 30, 893-917.

*Seibt, R., Spitzer, S., Blank, M., \& Scheuch, K. (2009). Predictors of work ability in occupations with psychological stress. Journal of Public Health, 17, 9-18.

*Sell, L., Lund, H. L., Holtermann, A., \& Søgaard, K. (2014). The interactions between pain, pain-related fear of movement and productivity. Occupational Medicine, 64, 376-381.

*Shiri, R., Kaila-Kangas, L., Ahola, K., Kivekäs, T., Viikari-Juntura, E., Heliövaara, M., \& Leino-Arjas, P. (2013). The relation of co-occurring musculoskeletal pain and depressive symptoms with work ability. Journal of Occupational and Environmental Medicine, 55, 1,281-1,285. 
Shultz, K. S., Morton, K. R., \& Weckerle, J. R. (1998). The influence of push and pull factors on voluntary and involuntary early retirees' retirement decision and adjustment. Journal of Vocational Behavior, 53, 45-57.

Shultz, K. S., \& Wang, M. (2007). The influence of specific physical health conditions on retirement decisions. The International Journal of Aging and Human Development, 65, 149-161.

*Silvia Monteiro, M., Maria Costa Alexandre, N., Ilmarinen, J., \& Mendes Rodrigues, C. (2009). Work ability and musculoskeletal disorders among workers from a public health institution. International Journal of Occupational Safety and Ergonomics, 15, 319-324.

*Sluiter, J. K., \& Frings-Dresen, M. H. (2008). Quality of life and illness perception in working and sick-listed chronic RSI patients. International Archives of Occupational and Environmental Health, 81, 495-501.

Social Security Administration (2015, May). Disability Benefits, Social Security Administration. Retrieved from https://www.ssa.gov/pubs/EN-05-10029.pdf.

*Sörensen, L., Honkalehto, S., Kallinen, M., Pekkonen, M., Louhevaara, V., Smolander, J., \& Alén, M. (2007). Are cardiorespiratory fitness and walking performance associated with self-reported quality of life and work ability?. International Journal of Occupational Medicine and Environmental Health, 20, 257-264.

*Sörensen, L. E., Pekkonen, M. M., Männikkö, K. H., Louhevaara, V. A., Smolander, J., \& Alén, M. J. (2008). Associations between work ability, health-related quality of 
life, physical activity and fitness among middle-aged men. Applied Ergonomics, 39, 786-791.

*Sormunen, E., Remes, J., Hassi, J., Pienimaki, T., \& Rintamaki, H., (2009). Factors associated with self-estimated work ability and musculoskeletal symptoms among male and female workers in cooled food-processing facilities. Industrial Health, 47, 271-282.

Spector, P. E. (1986). Perceived control by employees: A meta-analysis of studies concerning autonomy and participation at work. Human Relations, 39, 10051016.

*Sugimura, H., \& Thériault, G. (2010). Impact of supervisor support on work ability in an IT company. Occupational Medicine, 60, 451-457.

*Sun, J., Buys, N., \& Wang, X. (2013). Depression in employees in privately owned enterprises in China: is it related to work environment and work ability?. International Journal of Environmental Research and Public Health, 10, 1152-1167.

*Szlachta, E., Gawlik-Chmiel, B., \& Kallus, K. W. (2012). Do the long-term unemployed regard themselves as able to work?. Journal of Public Health, 20, 505-511.

Toossi, M. (2005). Labor force projections to 2014: Retiring boomers. Monthly Labor Review, 128, 25-44.

Toossi, M. (2015). Labor force projections to 2024: The labor force is growing, but slowly. Monthly Labor Review, 1-36. Retrieved from 
http://www.bls.gov/opub/mlr/2015/article/pdf/labor-force-projections-to2024.pdf.

*Torp, S., Nielsen, R. A., Gudbergsson, S. B., \& Dahl, A. A. (2012). Worksite adjustments and work ability among employed cancer survivors. Supportive Care in Cancer, 20, 2,149-2,156.

*Tuomi, K., Huuhtanen, P., Nykyri, E., \& Ilmarinen, J. (2001). Promotion of work ability, the quality of work and retirement. Occupational Medicine-Oxford, 51, 318-324.

Tuomi, K., Ilmarinen, J., Eskelinen, L., Järvinen, E., Toikkanen, J., \& Klockars, M. (1991). Prevalence and incidence rates of diseases and work ability in different work categories of municipal occupations. Scandinavian Journal of Work, Environment \& Health, 1, 67-74.

Tuomi, K., Ilmarinen, J., Seitsamo, J., Huuhtanen, P., Martikainen, R., Nygard, C.H., \& Klockars, M. (1997). Summary of the Finnish research project (1981-1992) to promote the health and work ability of aging workers. Scandinavian Journal of Work, Environment and Health, 23, 66-71.

*Tuomi, K., Vanhala, S., Nykyri, E., \& Janhonen, M. (2004). Organizational practices, work demands and the well-being of employees: a follow-up study in the metal industry and retail trade. Occupational Medicine, 54, 115-121. Doi:

10.1093/occmed/kqh005 
Van der Doef, M., \& Maes, S. (1999). The job demand-control (-support) model and psychological well-being: a review of 20 years of empirical research. Work \& Stress, 13, 87-114.

Vartanian, L. R., \& Shaprow, J. G. (2008). Effects of weight stigma on exercise motivation and behavior a preliminary investigation among college-aged females. Journal of Health Psychology, 13, 131-138.

*van den Berg, T. I., Alavinia, S. M., Bredt, F. J., Lindeboom, D., Elders, L. A., \& Burdorf, A. (2008). The influence of psychosocial factors at work and life style on health and work ability among professional workers. International Archives of Occupational and Environmental Health, 81, 1,029-1,036.

van den Berg, T., Elders, L., de Zwart, B., \& Burdorf, A. (2009). The effects of workrelated and individual factors on the Work Ability Index: a systematic review. Occupational and Environmental Medicine, 66, 211-220.

*van den Heuvel PhD, S. G., \& van der Beek PhD, A. J. (2014). The influence of chronic health problems on work ability and productivity at work: a longitudinal study among older employees. Scandinavian Journal of Work, Environment \& Health, 40, 473-487.

*van Holland, B. J., Soer, R., de Boer, M. R., Reneman, M. F., \& Brouwer, S. (2015). Workers' health surveillance in the meat processing industry: work and health indicators associated with work ability. Journal of Occupational Rehabilitation, 25, 618-626. 
*Vasconcelos, S. P., Fischer, F. M., Reis, A. O. A., \& Moreno, C. R. D. C. (2011). Factors associated with work ability and perception of fatigue among nursing personnel from Amazonia. Revista Brasileira de Epidemiologia, 14, 688-697.

*Vastamäki, J., Wolff, H. G., Paul, K. I., \& Moser, K. (2014). Sense of Coherence Mediates the Effects of Low Work Ability on Mental Distress During Unemployment. Journal of Workplace Behavioral Health, 29, 317-332.

*Vastamäki, J., Moser, K., \& Paul, K. I. (2009). How stable is sense of coherence? Changes following an intervention for unemployed individuals. Scandinavian Journal of Psychology, 50, 161-171.

*von Bonsdorff, M. E., Huuhtanen, P., Tuomi, K., \& Seitsamo, J. (2009). Predictors of employees' early retirement intentions: an 11-year longitudinal study. Occupational Medicine, 60, 94-100.

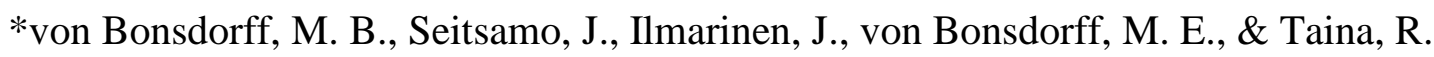
(2012). Work ability as a determinant of old age disability severity: Evidence from the 28-year Finnish Longitudinal Study on Municipal Employees. Aging Clinical and Experimental Research, 24, 354-360. Doi:10.1093/occmed/kqh005.

*von Bonsdorff, M. B., Seitsamo, J., Ilmarinen, J., Nygård, C. H., von Bonsdorff, M. E., \& Rantanen, T. (2011). Work ability in midlife as a predictor of mortality and disability in later life: a 28-year prospective follow-up study. Canadian Medical Association Journal, 183, E235-E242.

*Wagenaar, A. F., Kompier, M. A., Houtman, I. L., van den Bossche, S. N., \& Taris, T. W. (2015). Who gets fired, who gets re-hired: the role of workers' contract, age, 
health, work ability, performance, work satisfaction and employee investments. International Archives of Occupational and Environmental Health, 88, 321-334.

*Walker, E. J., Jackson, C. A., Egan, H. H., \& Tonkin, M. (2015). Workability and mental wellbeing among therapeutic prison officers. Occupational Medicine, 65, 549-551.

*Walsh, I. A., Oishi, J., \& Coury, H. J. (2008). Clinical and functional aspects of workrelated musculoskeletal disorders among active workers. Revista de Saude Publica, 42, 108-116.

Warburton, D. E., Nicol, C. W., \& Bredin, S. S. (2006). Health benefits of physical activity: The evidence. Canadian Medical Association Journal, 174, 801-809.

*Weigl, M., Müller, A., Hornung, S., Zacher, H., \& Angerer, P. (2013). The moderating effects of job control and selection, optimization, and compensation strategies on the age-work ability relationship. Journal of Organizational Behavior, 34, 607628.

*Weng, L. C., Huang, H. L., Wang, Y. W., Lee, W. C., Chen, K. H., \& Yang, T. Y. (2014). The effect of self-efficacy, depression and symptom distress on employment status and leisure activities of liver transplant recipients. Journal of Advanced Nursing, 70, 1573-1583.

Wott, C. B., \& Carels, R. A. (2010). Overt weight stigma, psychological distress and weight loss treatment outcomes. Journal of Health Psychology, 15, 608-614. 
World Health Organization. (2015, December). Disability and health, World Health Organization. Retrieved from http://www.who.int/mediacentre/factsheets/fs352/en/.

Xanthopoulou, D., Bakker, A. B., Demerouti, E., \& Schaufeli, W. B. (2007). The role of personal resources in the job demands-resources model. International Journal of Stress Management, 14, 121-141.

*Yong, M., Nasterlack, M., Pluto, R. P., Elmerich, K., Karl, D., \& Knauth, P. (2010). Is health, measured by work ability index, affected by 12-hour rotating shift schedules?. Chronobiology International, 27, 1,135-1,148.

Zhan, Y., Wang, M., Liu, S., \& Shultz, K. S. (2009). Bridge employment and retirees’ health: A longitudinal investigation. Journal of Occupational Health Psychology, 14, 374-389. 


\section{Appendix A}

Full Work Ability Index

Dimension 1: Current work ability compared with lifetime best.

1. Assume that your work ability at its best has a value of 10 points. How many points would you give your current work ability?

( 0 means that you cannot currently work at all -10 work ability at its best)

Dimension 1 scoring: The score for this dimension is out of 10 possible points and is simply the number the individual selects $(0-10)$ in response to the question asked.

\section{Dimension 2: Work ability in relation to the demands of the job}

2. How do you rate your current work ability with respect to the physical demands of your work?

Very good............5
Rather good........
Moderate.............
Rather poor.........2
Very poor...........

3. How do you rate your current work ability with respect to the mental demands of your work?

Very good............5
Rather good........4
Moderate.............
Rather poor.........2
Very poor...........1

Dimension 2 scoring: Responses for each item correspond to the value listed. The scores for each dimension are weighted in proportion to the demands of the respondent's job such that in physically demanding jobs the physical demands score is multiplied by 1.5 , and the mental demands score is multiplied by .5 . On the other hand, in mentally demanding positions the mental demands are multiplied by 1.5 and physical demands by .5. This scaling produces possible values between 2-10. This computed value is the WA score for this dimension.

\section{Dimension 3: Number of current diseases}

In the following list, mark your diseases or injuries. Also indicate whether a physician has diagnosed or treated these diseases.

Injury from accidents

4. back

5. Arm/hand

6. leg/foot

7. other part of body, where and what kind of injury?

Musculoskeletal disease 
8. disorder of the upper back or cervical spine, repeated instances of pain

9. disorder of the lower back, repeated instances of pain

10. (sciatica) pain radiating from the back into the leg

11. Musculoskeletal disorder affecting the limbs (hands, feet), repeated

instances of pain

12. rheumatoid arthritis

13. other musculoskeletal disorder, what?

Cardiovascular Diseases

14. hypertension (high blood pressure)

15. Coronary heart disease, chest pains during exercise (angina pectoris)

16. coronary thrombosis, myocardial infarction

17. cardiac insufficiency

18. other cardiovascular disease, what?

Respiratory disease

19. repeated infections of the respiratory tract (also tonsillitis, acute sinusitis, acute bronchitis)

20. chronic bronchitis

21 chronic sinusitis

22 bronchial asthma

23 emphysema

24 pulmonary tuberculosis

25 other respiratory disease, what?

Mental disorder

26 mental disease or severe mental health problem (for example, severe depression, mental disturbance)

27 slight mental disorder or problem (for example, slight depression, tension, anxiety, insomnia)

Neurological and sensory disease

28 problems or injury to hearing

29 visual disease or injury (other than refractive error)

30 neurological disease (for example stroke, neuralgia, migraine, epilepsy)

31 other neurological or sensory disease, what?

Digestive disease

32 gall stones or disease

33 liver or pancreatic disease

34 gastric or duodenal ulcer

35 gastritis or duodenal irritation

36 colonic irritation, colitis

37 other digestive disease, what?

Genitourinary disease

38 urinary tract infection

39 kidney disease

40 genitals disease (for example fallopian tube infection in women

or prostatic infection in men) 
41 Other genitourinary disease, what?

Skin diseases

42 allergic rash, eczema

43 other rash, what?

44 other skin disease, what?

Tumor

45 benign tumor

46 malignant tumor (cancer), where?

Endocrine and metabolic diseases

47 obesity

48 diabetes

49 goiter or others thyroid disease

50 other endocrine or metabolic disease, what?

Blood diseases

51 anemia

52 other blood disorder, what?

Birth defects

53 birth defect, what?

Other disorder or disease

54 What?

Dimension 3 Scoring: The number of ailments an individual has are summed and assigned a score based on the following scoring standards:

5 or more ailments....... 1

4 ailments ....................2

3 ailments..................... 3

2 ailments.................... 4

1 ailment........................5

no ailments................... 7

\section{Dimension 4: Estimated work impairment due to diseases}

55. Is your illness or injury a hindrance to your current job?

There is no hindrance/I have no diseases...................................................6

I am able to do my job, but it causes some symptoms................................5

I must sometimes slow down my work pace or change my work methods.....4

I must often slow down my work pace or change my work methods.............. 3

Because of my disease, I feel I am able to do only part-time work.................2

In my opinion, I am entirely unable to work............................................

Dimension 4 scoring: The score for this dimension is the number listed that corresponds to the selected response option.

Dimension 5: Sick leave during the past year (12 months) 
56. How many whole days have you been off work because of a health problem (disease or health care or for examination) during the past year (12 months)?

None at all.................................5

At the most 9 days......................4

10 - 24 days................................ 3

25 - 99 days...............................2

100 - 365 days............................1

Dimension 5 scoring: The score is the number listed that corresponds to the selected range of number of sick days taken in the past year.

\section{Dimension 6: Own prognosis of work ability two years from now}

57. Do you believe that - from the standpoint of your health - you will be able to do your current job two years from now?

Unlikely 1

Not certain....................4

Relatively certain......... 7

Dimension 6 scoring: The score is the number listed that corresponds to the selected response option.

\section{Dimension 7: Mental resources}

58. Have you recently been able to enjoy your regular daily activities?

Often...........................4

Rather often...............3

Sometime...................2

Rather seldom.............1

Never.........................0

59. Have you recently been active and alert?

Often..........................4

Rather often............... 3

Sometime...................2

Rather seldom............1

Never.........................0

60. Have you recently felt yourself to be full of hope for the future?

Continuously............. 4

Rather often................ 3

Sometime....................2

Rather seldom............1

Never..........................

Dimension 7 scoring: The response scores are summed to create a 0-12 possible score range, then scores from 0-3 are assigned a value of 1, scores from 4-6 are assigned to 
value of 2, scores from 7-9 are assigned a value of 3, and scores between 10-12 are assigned a value of 4 .

Work Ability Index scale scoring: The sum for each dimension are added up to create a score ranging from 7-49. Poor work ability $=7-27$, Moderate work ability $=28-36$, Good work ability = 37-43, and Excellent work ability $=44-49$. 


\section{Appendix B}

Work Ability Index Short Form

\section{Dimension 1: Current work ability compared with lifetime best.}

1. Assume that your work ability at its best has a value of 10 points. How many points would you give your current work ability?

( 0 means that you cannot currently work at all -10 work ability at its best)

Dimension 1 scoring: The score for this dimension is out of 10 possible points and is the number the individual selects $(0-10)$ in response to the question asked.

\section{Dimension 2: Work ability in relation to the demands of the job}

2. How do you rate your current work ability with respect to the demands of your work?

$$
(\text { Very poor }=2, \text { Very good }=10)
$$

Dimension 2 scoring: The score for this dimension is the number listed that corresponds to the selected response option.

\section{Dimension 3: Number of current diseases}

3. Please indicate the number of diagnosed diseases, illnesses or injuries you currently have.

Dimension 3 Scoring: The number of ailments an individual has is assigned a score based on the following scoring standards:

5 or more ailments........ 1
4 ailments ...................
3 ailments...................
2 ailments..................
1 ailment....................
no ailments................

\section{Dimension 4: Estimated work impairment due to diseases}

4. Is your illness or injury a hindrance to your current job?

There is no hindrance/I have no diseases.........................................................

I am able to do my job, but it causes some symptoms.....................................

I must sometimes slow down my work pace or change my work methods.....4

I must often slow down my work pace or change my work methods................ 3

Because of my disease, I feel I am able to do only part-time work...................2

In my opinion, I am entirely unable to work....................................................

Dimension 4 scoring: The score for this dimension is the number listed that corresponds to the selected response option. 


\section{Dimension 5: Sick leave during the past year (12 months)}

5. How many whole days have you been off work because of a health problem (disease or health care or for examination) during the past year (12 months)?

None at all ..............................
At the most 9 days....................
$10-24$ days............................
25 - 99 days.............................
100 - 365 days.........................

Dimension 5 scoring: The score is the number listed that corresponds to the selected range of number of sick days taken in the past year.

\section{Dimension 6: Own prognosis of work ability two years from now}

6. Do you believe that - from the standpoint of your health - you will be able to do your current job two years from now?

Unlikely.......................1

Not certain....................4

Relatively certain.........7

Dimension 6 scoring: The score for this dimension is the number listed that corresponds to the selected response option.

\section{Dimension 7: Mental resources}

7. Have you recently been able to enjoy your regular daily activities, been active and alert, and felt full of hope for the future?

Often ...................... 4
Rather often..............
Sometime..................
Rather seldom.............
Never.......................

Dimension 7 scoring: The score for this dimension is the number listed that corresponds to the selected response option.

Work Ability Index scale scoring: The sum for each dimension are added up to create a score ranging from 7-49. Poor work ability = 7-27, Moderate work ability = 28-36, Good work ability = 37-43, and Excellent work ability $=44-49$. 


\section{Appendix C}

Theoretical Model of the Antecedents and Outcomes of Work Ability

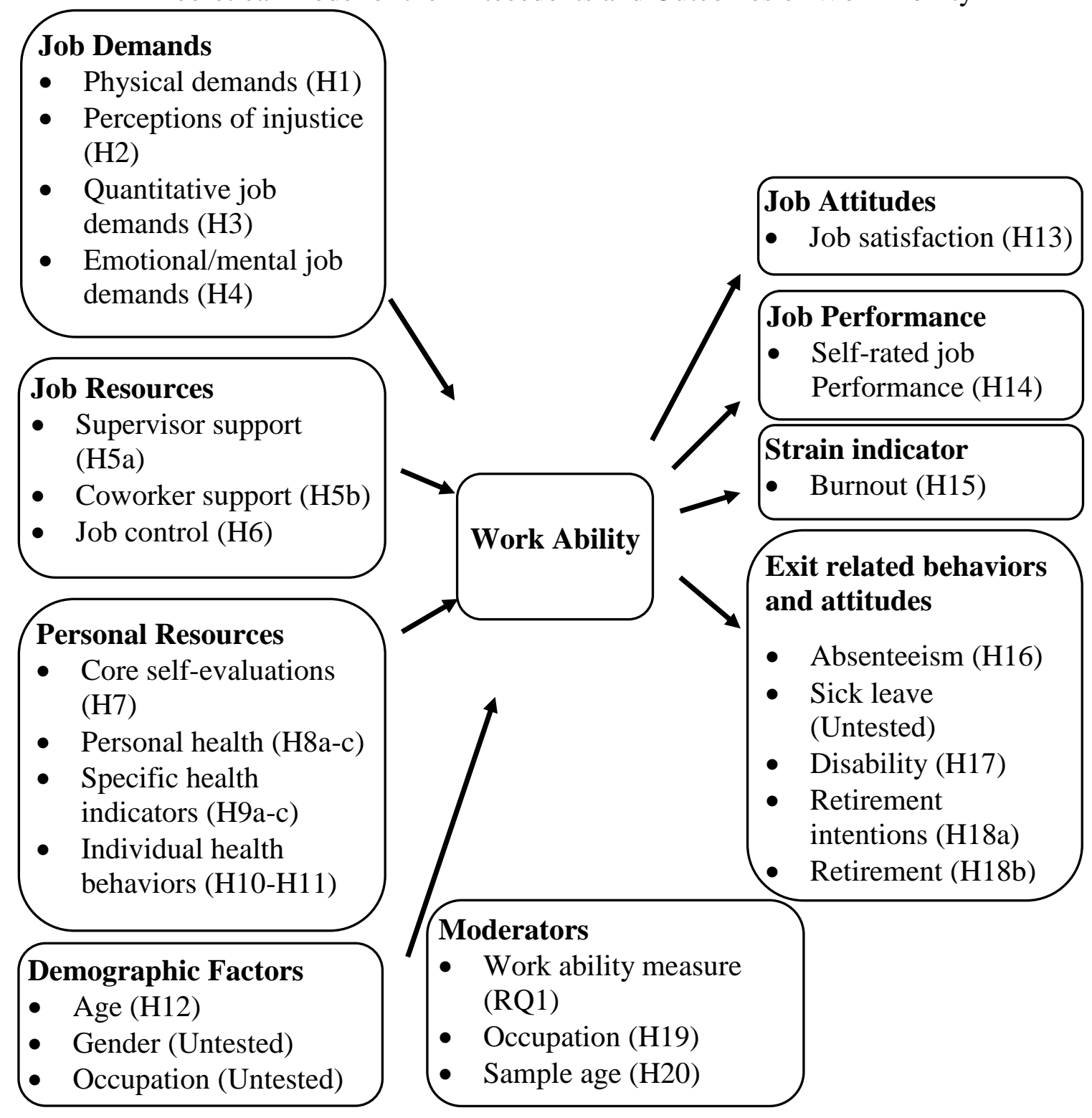

Note. This model depicts the anticipated antecedents and outcomes of work ability. 


\section{Appendix D}

\section{Meta-Regression of Physical Demands on Age}

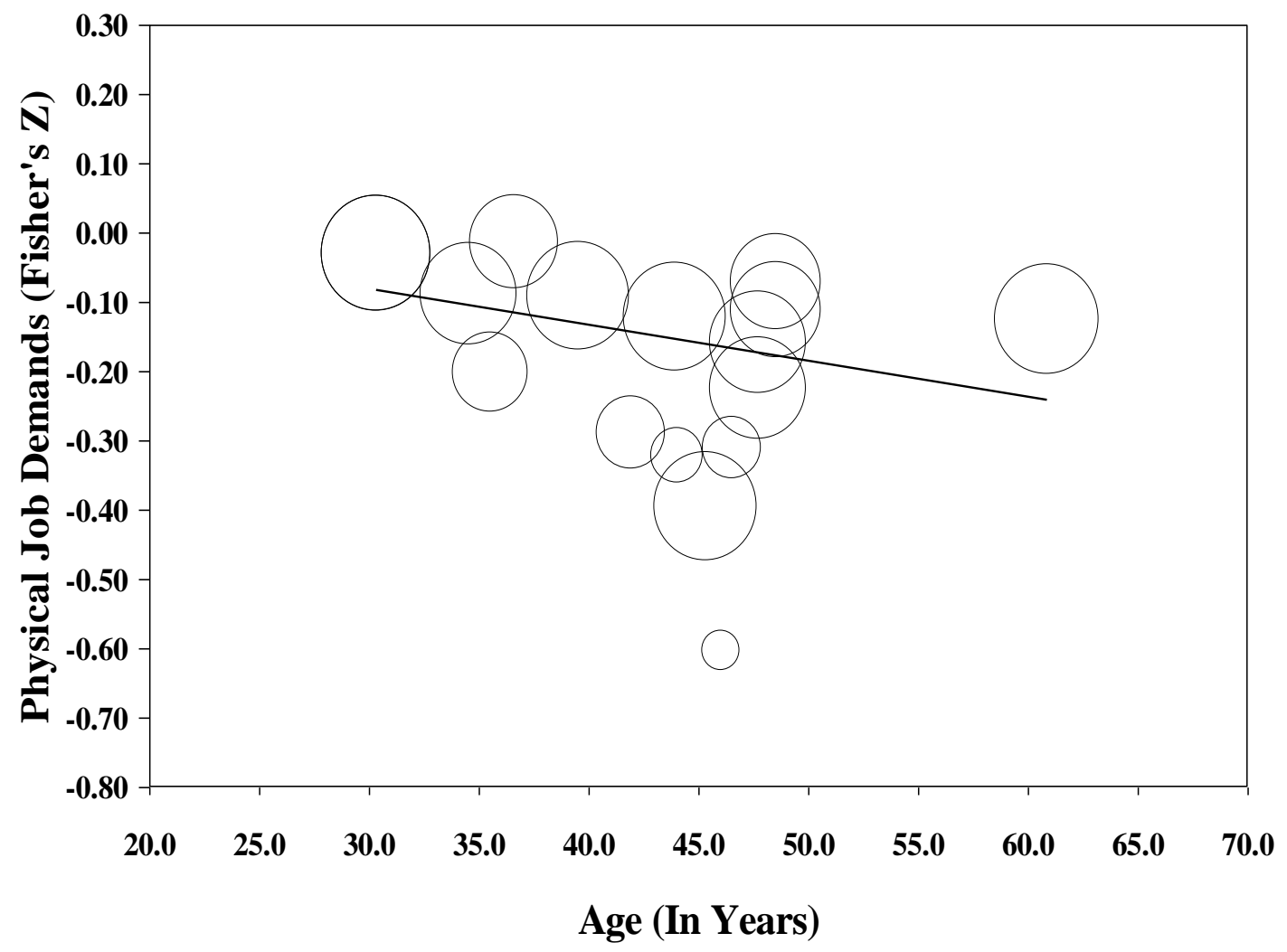

Note. This scatterplot shows the moderating effect of the mean age of the sample on the relationship between job control and work ability. 
Appendix E

Meta-Regression of Job Control on Age

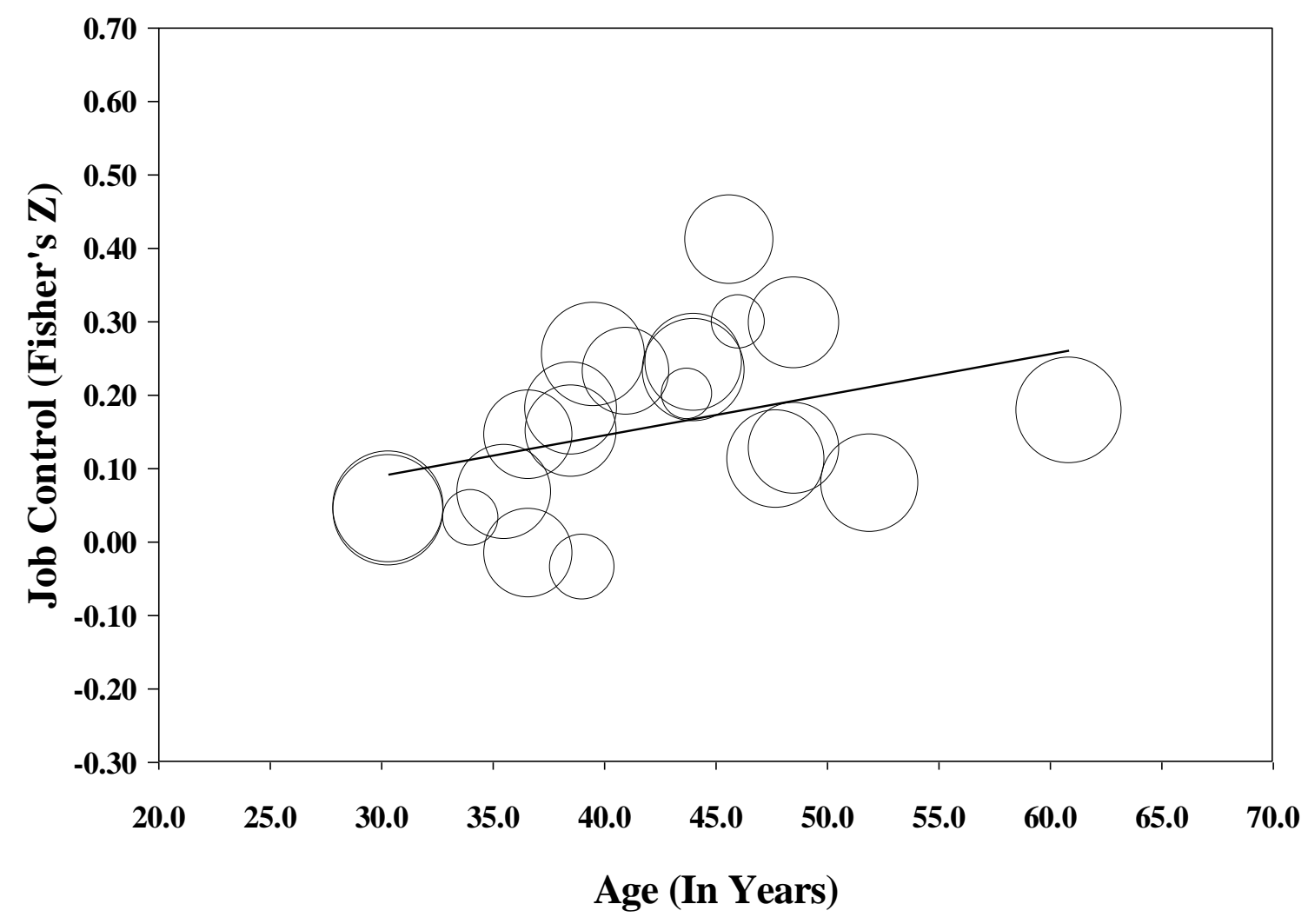

Note. This scatterplot shows the moderating effect of the mean age of the sample on the relationship between job control and work ability. 